\title{
WestVirginiaUniversity
}

THE RESEARCH REPOSITORY @ WVU

Graduate Theses, Dissertations, and Problem Reports

2004

\section{Compatible taper and volume equations for yellow-poplar in West Virginia}

Lichun Jiang

West Virginia University

Follow this and additional works at: https://researchrepository.wvu.edu/etd

\section{Recommended Citation}

Jiang, Lichun, "Compatible taper and volume equations for yellow-poplar in West Virginia" (2004).

Graduate Theses, Dissertations, and Problem Reports. 1493.

https://researchrepository.wvu.edu/etd/1493

This Thesis is protected by copyright and/or related rights. It has been brought to you by the The Research Repository @ WVU with permission from the rights-holder(s). You are free to use this Thesis in any way that is permitted by the copyright and related rights legislation that applies to your use. For other uses you must obtain permission from the rights-holder(s) directly, unless additional rights are indicated by a Creative Commons license in the record and/ or on the work itself. This Thesis has been accepted for inclusion in WVU Graduate Theses, Dissertations, and Problem Reports collection by an authorized administrator of The Research Repository @ WVU. For more information, please contact researchrepository@mail.wvu.edu. 
COMPATIBLE TAPER AND VOLUME EQUATIONS FOR YELLOW-POPLAR IN WEST VIRGINIA

\author{
Lichun Jiang
}

Thesis submitted to the Davis College of Agriculture, Forestry, and Consumer Sciences at West Virginia University in partial fulfillment of the requirements

for the degree of

Master of Science

in

Forestry

John R. Brooks, Ph.D., Chair

Jingxin Wang, Ph.D.

Gerald R. Hobbs, Ph.D.

Division of Forestry

Morgantown, West Virginia

2004

Keywords: Yellow-poplar, Taper, Compatible Volume Equations, Simultaneous Equations. 


\begin{abstract}
COMPATIBLE TAPER AND VOLUME EQUATIONS FOR YELLOW-POPLAR

IN WEST VIRGINIA
\end{abstract}

Lichun Jiang

Yellow-poplar (Liriodendron tulipifera L.) is an important source of raw material for the forest products industry in West Virginia. Accurate taper and volume functions are an important component of most inventory systems for use in estimating upper stem diameter, form, and tree volume. Compatible taper and volume functions can be derived through the mathematical integration of taper functions. Non-linear regression techniques were employed to estimate the parameters in both the taper and volume functions while accounting for correlated error structures. This technique was used to simultaneously minimize the error in both the taper and volume functions. The data included 44 sample trees equally distributed in both the Central Appalachian Broadleaf Forest and Eastern Broadleaf Forest provinces. Six systems were evaluated to determine the best equation forms for predicting upper stem diameter and stem volume: Kozak et al. (1969), Demaerschalk (1972), Max and Burkhart (1976), Clark et al. (1991), and two alternate forms of Clark's equation. The alternate forms of the original Clark et al. (1991) provided the lowest mean squared error for both volume and taper. 


\section{ACKNOWLEDGEMENTS}

First, I would like to express my gratitude to Division of Forestry at West Virginia for the financial support. Many people help me make this thesis a reality. I also wish to thank the members of my committee: Dr. John Brooks, Dr. Jingxin Wang, and Dr. Gerald R. Hobbs for their invaluable advice. I am especially grateful to Dr. John Brooks, my major advisor, for his advice, assistance, encouragement, and friendship throughout this project. I was very fortunate to have the opportunity to work for such a supportive, patient, and dedicated person. Special thanks go to Dr. Ben Dawson-Andoh and Paul Ludrosky for laboratory assistance, support and advice. In addition, thanks also go to Mike Smith for the data entry.

Finally, I am very grateful to my family who gave me true love and support. Especially, to my wife, without her encouragement, understanding and patience, this degree would not have been possible. And my daughter, Trina, she brings lots of fun to me. 


\section{TABLE OF CONTENTS}

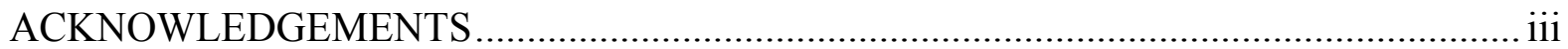

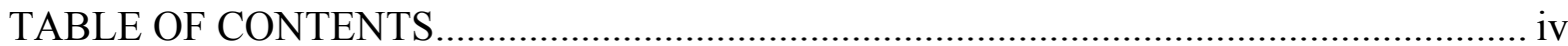

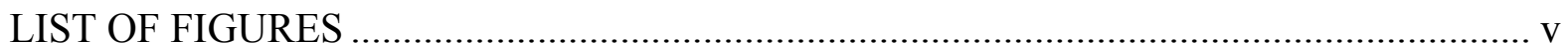

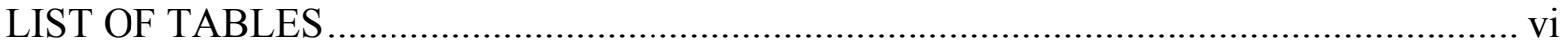

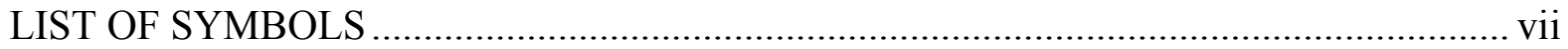

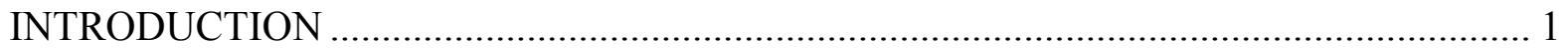

CHAPTER 1 : LITERATURE REVIEW ................................................................... 3

1.1 History of Taper Systems ................................................................................ 3

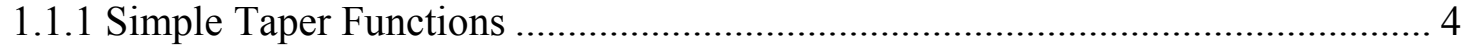

1.1.2 Variable Form Taper Functions ……............................................................. 10

1.1.3 Segmented Polynomial Taper Functions....................................................... 12

1.2 History of Taper Systems in Hardwoods and Appalachian Hardwoods ..................... 19

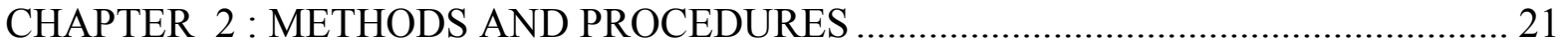

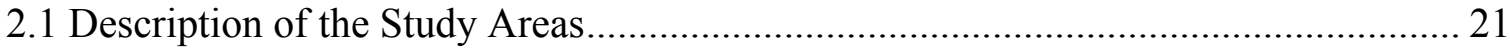

2.1.1 Central Appalachian Broadleaf Forest ...................................................... 22

2.1.2 Eastern Broadleaf Forest Province .................................................................. 22

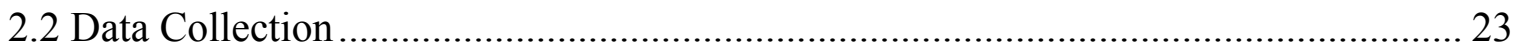

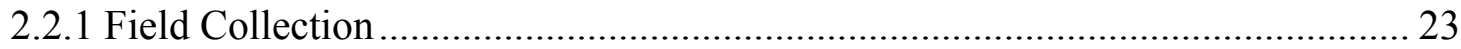

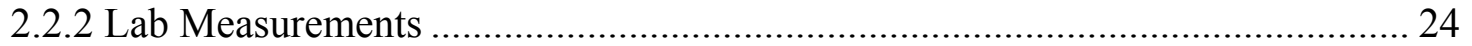

2.3 Actual Volume Calculation ................................................................................ 25

2.4 Selection of Model Forms ................................................................................... 28

2.5 Criteria for Model Evaluation........................................................................... 32

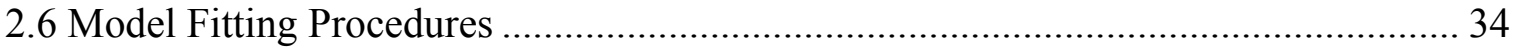

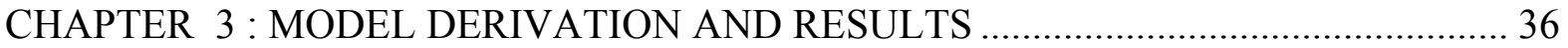

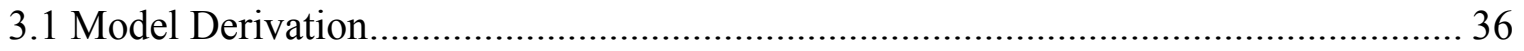

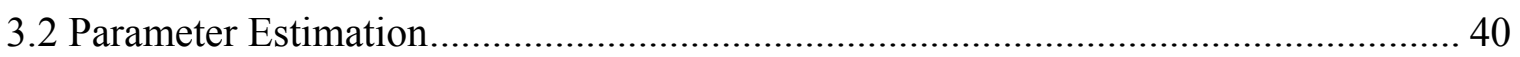

3.3 Model Evaluation by Overall Fit Statistics......................................................... 42

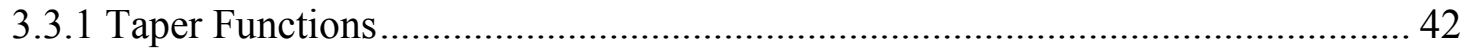

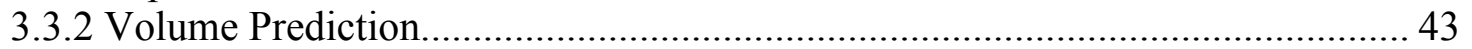

3.4 Model Evaluation by dbh Classes ......................................................................... 44

3.5 Model Evaluation by Relative Height Classes ...................................................... 49

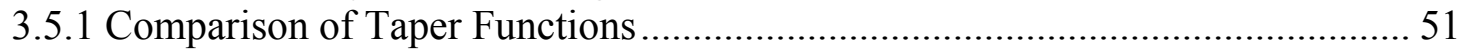

3.5.2 Comparison of Volume Prediction.................................................................. 54

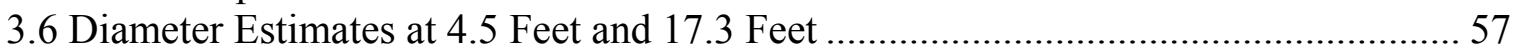

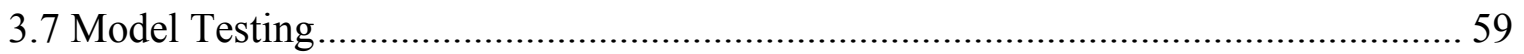

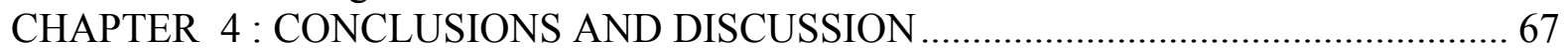

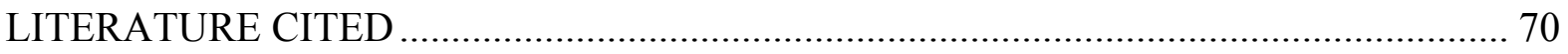

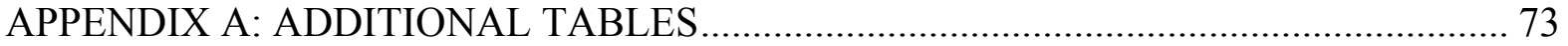




\section{LIST OF FIGURES}

Figure 2.1. Location of study areas........................................................................ 21

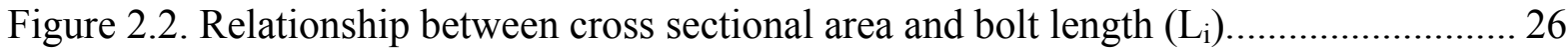

Figure 2.3. Volume of overlapping bolts ..................................................................... 28

Figure 3.1. Average bias and standard errors of estimate (SEE) for predicting diameter outside bark along the stem by relative height classes.................................... 52

Figure 3.2. Average bias and standard errors of estimate (SEE) for predicting diameter inside bark along the stem by relative height classes. ............................................. 53

Figure 3.3. Average bias and standard errors of the estimate (SEE) for predicting volume outside bark along the stem by relative height classes...................................... 55

Figure 3.4. Average bias and standard errors of the estimate (SEE) for predicting volume inside bark along the stem by relative height classes........................................ 56

Figure 3.5. The relationship between diameter inside bark and DBH for all sample data ..... 57

Figure 3.6. Relative diameter over relative height for all yellow-poplar trees.................... 60

Figure 3.7. A set of taper curves generated from model 4 with the same value of total height (90 feet) and different values of $\mathrm{dbh}(10,14,18$, and 22 inches). ......................6 62

Figure 3.8. A set of taper curves generated from model 5 with the same value of total height (90 feet) and different values of dbh (10, 14, 18, and 22 inches).

Figure 3.9. A set of taper curves generated from model 6 with the same value of total height (90 feet) and different values of dbh (10, 14, 18, and 22 inches).

Figure 3.10. A set of taper curves generated from model 4 with the same value of dbh (13 inches) and different values of total height (70, 80, 90, and 100 feet).

Figure 3.11. A set of taper curves generated from model 5 with the same value of dbh (13

inches) and different values of total height $(70,80,90$, and 100 feet $) \ldots \ldots \ldots \ldots . . . . .$.

inches) and different values of total height $(70,80,90$, and 100 feet).............. 65

Figure 3.13. A set of taper curves generated from model 4 with the groups by the different values of dbh $(10,14,18$, and 22 inches) and different values of total height (70, 80,90 , and 100 feet).

Figure 3.14. A set of taper curves generated from model 5 with the groups by the different values of dbh $(10,14,18$, and 22 inches) and different values of total height (70, 80,90 , and 100 feet). 66

Figure 3.15. A set of taper curves generated from model 6 with the groups by the different values of dbh $(10,14,18$, and 22 inches) and different values of total height $(70$, 80,90 , and 100 feet). 


\section{LIST OF TABLES}

Table 3.1. Parameter estimates (standard errors in parentheses) for outside bark and inside bark taper and volume equations................................................................. 41

Table 3.2. Overall fit statistics for yellow-poplar taper models. ....................................... 43

Table 3.3. Overall fit statistics for yellow-poplar volume prediction models. ..................... 44

Table 3.4. Bias and standard error of estimates by dbh classes for diameter and volume. .... 47

Table 3.5. Rankings of the five models by dbh classes for diameter and volume prediction. 48

Table 3.6. Bias and standard error of estimates by relative height $(\mathrm{RH})$ for diameter and

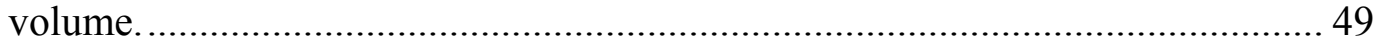

Table 3.7. Estimate of parameters for diameter at 4.5 and 17.3 feet. ................................ 58

Table 3.8. Fit statistics for taper models using diameter predicted at 17.3 feet................... 59

Table 3.9. Fit statistics for taper models for volume prediction using diameter predicted at

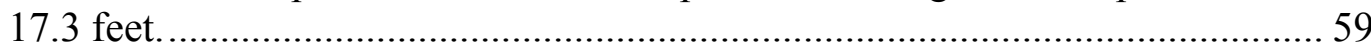

Table A.1. Parameter estimates of location 1 for outside and inside bark taper and volume

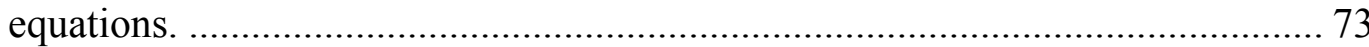

Table A.2. Fit statistics of location 1 for outside and inside bark taper and volume equations.

Table A.3. Parameter estimates of location 2 for outside and inside bark taper and volume

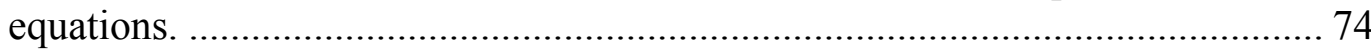

Table A.4. Fit statistics of location 2 for outside and inside bark taper and volume equations.

Table A.5. Parameter estimates of location 1 for diameter at 4.5 and 17.3 feet.................. 75

Table A.6. Parameter estimates of location 2 for diameter at 4.5 and 17.3 feet................... 75

Table A.7. Bias and standard error of estimates for outside bark diameter for the validation

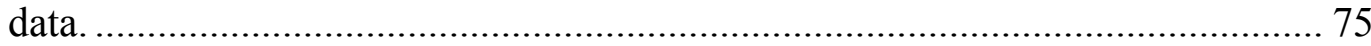




\section{LIST OF SYMBOLS}

The following commonly used symbols are frequently used throughout this document.

All diameters are in inches, heights are in feet, and volume is in cubic feet.

$h=$ height above the ground to the measurement point.

$H=$ total tree height.

$D_{i}=$ diameter inside bark at breast height (4.5 feet above ground).

$d_{i}=$ diameter inside bark to measurement point.

$D=$ diameter outside bark at breast height (4.5 feet above ground).

$d=$ diameter outside bark to measurement point.

$V=$ total tree volume in cubic feet.

$a_{i}$ and $a(i=1,2)$ : join points of the segmented polynomial equations.

$I_{i}, I$ and $J_{i}(i=1,2)$ : indicator variables of the segmented polynomial equations.

$b_{i}(i=0,1,2 \ldots \ldots .8)$ : regression coefficients.

$k=0.005454154$ 


\section{INTRODUCTION}

Yellow-poplar is an important commercial species for the forest products industry of West Virginia. This species is utilized for plywood, lumber, OSB and pulpwood products. Existing available volume tables and equations with fixed merchantability limits are no longer sufficient for estimating product volume to currently changing market conditions. One of the most accurate approaches to estimating stem volume to any top diameter is obtained through the integration of taper equations.

Numerous taper functions of various forms have been developed over the past 100 years from simple taper functions (Behre 1923, Kozak et al. 1969, Demaerschalk 1972, Ormerod 1973, Hilt 1980) to more complex segmented forms (Max and Burkhart 1976, Demaerschalk and Kozak 1977, Cao et al. 1980, Clark et al. 1991, Fang et al. 2000). Most of these equations are applied on an individual species or species group basis. For example, the Max and Burkhart model (1976) was developed for loblolly pine (Pinus taeda); Cao et al. (1980) also fitted their model for loblolly pine; McTague and Baily (1987) fitted their model for loblolly pine; Hilt's model was constructed for upland oaks (Quercus spp.); Fang et al. (2000) fitted their models for loblolly and slash pine (Pinus elliottii).

At least two major forms of taper functions have been used with success. The first is a variable form taper function which describes the tree stem shape using an exponent or variable that varies from the ground to the top in order to compensate for the neiloid, paraboloid, and conic forms within a tree bole (Newnham 1988,1992, Kozak 1988, Perez et al. 1990 and Muhairwe 1999). However, variable form models have some disadvantages: 
(1) they can not be integrated directly to calculate volume.

(2) volume must be calculated by numerical integration from an estimated diameter.

(3) merchantable height for a given top diameter can not be calculated directly, it must be obtained through iteration.

The second major form includes segmented polynomial taper functions that describe the taper of different tree sections using different equation forms. For example, the Max and Burkhart model (1976) divides the tree stem into three sections that are described by three submodels. The three submodels are splined at two join points to form a single segmented polynomial taper equation. Segmented taper functions can be integrated directly to calculate volume and can be rearranged algebraically to directly estimate merchantable height for a given top diameter.

The major objectives of this study were to:

1. Compare existing taper functions and determine which taper system is the best for simultaneously predicting upper stem diameter and volume for yellowpoplar in West Virginia.

2. Develop compatible taper and volume equations for yellow-poplar in West Virginia.

3. Test the accuracy and precision of the compatible taper and volume equations. 


\section{CHAPTER 1 : LITERATURE REVIEW}

\subsection{History of Taper Systems}

The form and taper of tree stems have been studied for more than 100 years. Taper is the rate of change in diameter in relation to the increase in height along the tree stem (Gray 1956). Differences in tree form and taper are a result of changes in diameter with changes in height along the stem. Factors that affect the relative relationship between height and diameter, such as climatic fluctuations, site quality (water and nutrients), tree species, stand age, density and the effect of defoliation with respect to crown size and canopy position can affect changes of tree form and taper (Muhairwe 1994). Taper functions are the mathematical expression of stem changes based on these factors. In most cases, taper functions utilize the measurements of total height, diameter at breast height and height above the ground as independent variables, since these variables are easily measured during common forest inventory activities.

According to Newnham (1988), there are two reasons for the continuous study in this area: first, no single theory has been developed that adequately explains the variation in stem form for all kind of trees. Second, as a method of estimating volume, a single taper equation can estimate both total and merchantable tree stem volume. If tree form can be accurately described, then volume for any merchantability limit can be accurately predicted.

During the past 100 years, numerous taper functions have been published with various forms and complexities. These functions can be classified as follows: 
1. Simple taper functions.

2. Variable form taper functions.

3. Segmented polynomial taper functions.

\subsubsection{Simple Taper Functions}

According to Behre (1923), Höjer is one of the earliest researchers to describe form-class taper using measurements from Norway spruce (Picea abies). Höjer developed the following empirical function:

$$
\frac{d}{D}=b_{0} \log \frac{b_{1}+z}{b_{1}}
$$

Where:

$$
\begin{aligned}
& z=(H-h) /(H-4.5) \\
& \log =\text { base } 10 \text { logarithm. }
\end{aligned}
$$

Other variables as previously defined.

This function expresses the diameter of a tree at any point on the stem as a percentage of diameter at breast height.

Behre tested the conformity of Höjer's function based on detailed measurement of about 200 western yellow pines, and found that Höjer's function overestimated upper stem diameters. To solve this problem, Behre made an analytic study of the western pine data to determine whether Hojer's equation could be modified or a new equation could be found. As a result of this study, Behre introduced a new taper function with a hyperbolic form, which gave a more consistent expression of form than Höjer's original formula: 


$$
\frac{d}{D}=\frac{z}{b_{0}+b_{1} z}
$$

Although equation (1.2) was found to work well for yellow pines, large errors occurred at the butt swell for some other species.

Noticing that none of the previous equations could account for the butt swell which often extends above breast height. Matte (1949) introduced a quadratic paraboloid taper function for loblolly pine with an inflection point accounting for butt swell. The equation was of the form:

$$
\frac{d}{D}=z\left(b_{0} z^{2}+b_{1} z+b_{2}\right)^{1 / 2}
$$

To condition $d=D$ when $h=4.5$, the constraint $b_{0}+b_{1}+b_{2}=1$ was imposed. However, Matte (1949) found that the form factor alone could not provide adequate description of tree taper and form and did not provide accurate volume estimates. Even though trees have the same form quotient, they often express considerably different stem forms.

In the early days, computational difficulties led to oversimplified equations, which did not satisfactorily describe the butt swell or taper at the top. With the advent of powerful computers, more complex polynomial taper equations became possible. Bruce et al. (1968) presented a rather lengthy polynomial taper equation for red alder (Alnus rubra) based on an extension of the methods used by Matte. The resulting equation was of the form: 


$$
\begin{aligned}
\frac{d^{2}}{D^{2}} & =\alpha_{0}\left(z^{3 / 2}\right)\left(10^{-1}\right)+b_{1}\left(z^{3 / 2}-z^{3}\right)(D)\left(10^{-2}\right)+b_{2}\left(z^{3 / 2}-z^{3}\right)(H)\left(10^{-3}\right) \\
& +b_{3}\left(z^{3 / 2}-z^{32}\right)(D)(H)\left(10^{-5}\right)+b_{4}\left(z^{3 / 2}-z^{32}\right)\left(H^{0.5}\right)\left(10^{-3}\right) \\
& +b_{5}\left(z^{3 / 2}-z^{40}\right)\left(H^{2}\right)\left(10^{-6}\right)
\end{aligned}
$$

The ratio of relative diameter squared was expressed as a function of dbh, total height, and relative height. The $a_{0}$ parameter in equation (1.4) represents the squared bark ratio at breast height. The $3 / 2$ and $3^{\text {rd }}$ powers were used to describe the upper four-fifths of the bole, while higher powers $\left(32^{\text {nd }}\right.$ and $\left.40^{\text {th }}\right)$ were used to describe the butt swell.

This equation, which is conditioned so that $d=0$ when $h=H$, can be integrated to obtain cubic foot volume. However, merchantable height for a given top diameter cannot be calculated directly and must be obtained through iteration. Martin (1981) compared five taper equations fit to 18 Appalachian hardwood species (Ormerod 1973, Bruce et el. 1968, Demaerschalk 1972, Kozak et el. 1969, and Max and Burkhart 1976) and found that the function by Bruce et al.(1968) was better for predicting volume outside bark for all stem sections.

Forest inventory requires detailed volume information to any desired standard of utilization. To meet the requirement, Kozak et al. (1969) presented a simple quadratic taper function based on the assumption that the tree stem is a quadratic paraboloid. The function was developed based on dbh, total height, and bolt height. Their basic function was:

$$
\frac{d^{2}}{D^{2}}=b_{0}+b_{1}\left(\frac{h}{H}\right)+b_{2}\left(\frac{h^{2}}{H^{2}}\right)
$$


In most instances, upper stem diameters were overestimated. To overcome this bias for upper stem diameters, Kozak et al. (1969) conditioned the equation so that $d=0$ when $h=H$, and the condition $b_{0}+b_{1}+b_{2}=0$ was imposed. Substitution of this condition into basic function yielded the following final taper function:

$$
\frac{d^{2}}{D^{2}}=b_{1}\left(\frac{h}{H}-1\right)+b_{2}\left(\frac{h^{2}}{H^{2}}-1\right)
$$

The conditioned equation resulted in better estimates for most species from British Columbia. For several species, however, the single condition imposed was not sufficient and negative diameters occurred near the top of the tree. In order to overcome this bias, an additional constraint $b_{0}=b_{2}$ was imposed so that the equation has a unique solution:

$$
\frac{d^{2}}{D^{2}}=b_{2}\left(1-2 \frac{h}{H}+\frac{h^{2}}{H^{2}}\right)
$$

This equation was only appropriate for those species that had provided negative estimates of upper stem diameter that occurred close to the top of tree. The final equation was the most commonly applied.

A tree bole consists of various geometric solids. The form of a tree stem is generally modeled as a frustum of a neiloid near the butt, as a frustum of a paraboloid in the middle sections and as a cone at the top (Avery and Burkhart 2002). 
Noticing that most of the previous volume and taper equations were of an empirical form, Ormerod (1973) developed a simple and flexible bole model using a geometric approach. The model is of the form:

$$
d=d_{j}\left(\frac{H-h}{H-h_{j}}\right)^{b_{0}} \quad\left(b_{0}>0\right)
$$

Where $d_{j}$ is the measured diameter at height $h_{j}$, and $b_{0}$ is the fitted exponent. The form of tree stem is parabolic if $b_{0}$ is less than one, otherwise the form of tree stem will be neiloidal when $b_{0}$ is greater than one. The model is conditioned so that $d=0$ when $h=H$ and $d=d_{j}$ when $h=h_{j}$. However, this simple model could not provide an adequate description of the tree stem, due to the complex changes that occur along the tree stem. Therefore, Ormerod (1973) obtained a two-section model by modifying equation (1.8) as a step function:

$$
d=\left(d_{j}-C_{i}\right)\left(\frac{H_{i}-h}{H_{i}-h_{j}}\right)^{b_{0}}+C_{i} \quad b_{0}>0
$$

Where $H_{i}$ is the height to top of section $i, d_{j}$ is the measured diameter at height $h_{j}$, and $C_{i}$ is the diameter at the $H_{i}$. The model assumes that all boles have a single taper inflection point at 30 percent of total height $\left(H_{i}=0.3 H\right)$. Ormerod compared the twosection model with the model by Kozak et al. (1969) based on the standard errors of inside-bark diameter estimates and found that the two-section model gave more accurate estimates in the upper portion of the bole. 
Ormerod's equation has only one fitted exponent which describes the shape of stem to be parabolic or neiloidal. Using loblolly pine data, Cao et al. (1980) found that Ormerod's model was good for predicting diameters, however, it did not provide good estimates of merchantable volume.

A new approach that existing volume equations can be readily converted into compatible taper equations was presented by Demaerschalk (1972). A taper equation was obtained from an existing logarithmic volume equation.

Any logarithmic volume equation of the form:

$$
\log (V)=b_{1}+b_{2} \log (D)+b_{3} \log (H)
$$

can be converted into a logarithmic taper equation:

$$
\log (d)=b_{1}+b_{2} \log (D)+b_{4} \log (H-h)+b_{3} \log (H)
$$

Using the ratio of relative diameter squared as dependent variables, Equation (1.11) can be expressed as this following form:

$$
\frac{d^{2}}{D^{2}}=10^{2 b_{1}} D^{2 b_{2}-2}(H-h)^{2 b_{3}} H^{2 b_{4}}
$$

By generalizing Demaerschalk's compatibility, compatible taper equations have also been derived from existing volume equations (Goulding and Murry 1976). Using the same methods, Clutter (1980) also derived compatible taper functions from variable-top merchantable volume equations. A similar mathematical relationship was demonstrated between taper equations and volume ratio equations where all parameter estimates are derived from the merchantable volume equation. 
A new method to simultaneously estimate the coefficients of a total and merchantable volume equation was presented by McTague and Bailey (1987) for loblolly pine. Using Clutter's (1980) technique, a compatible taper equation was derived by imposing a constraint on the parameters of total and merchantable volume equation so that the taper equation can predict diameter at breast height when merchantable height equal to $1.3 \mathrm{~m}$. The compatible taper and volume equations proved superior to Clutter's (1980) taper and volume models.

Bailey (1994) also presented a compatible volume-taper model based on the Schumacher and Hall (1933) generalized constant form factor volume equation by carefully defining the "form factor" function for the tip of the tree. He compared diameter and volume predicted using the new model with those predicted using the McTague and Bailey (1987) taper and volume model for slash pine. Both models had a smaller bias. However, the new model was superior to the McTague and Bailey model when predicting upper-stem volume and diameter for slash pine.

\subsubsection{Variable Form Taper Functions}

Kozak (1988) introduced an approach that described the form of tree stems using an exponent that changed from the ground to the top to compensate for the inherent neiloid, paraboloid, and conic form of tree boles.

$$
d=b_{0} D^{b_{1}} b_{2}{ }^{D} S^{C}
$$


Where:

$$
\begin{aligned}
& C=b_{3} x^{2}+b_{4} \ln (x+0.001)+b_{5} \sqrt{x}+b_{6} e^{x}+b_{7}(D / H) \\
& S=\left(\frac{1-\sqrt{x}}{1-\sqrt{p}}\right) \\
& p=H I / H \\
& x=h / H \\
& \ln =\text { natural logarithm } \\
& H I=\text { stem height of inflection point }
\end{aligned}
$$

Other variables as previously defined.

This taper function was found to provide good estimates of diameter inside bark, but it could not be integrated to calculate volume. Volume must be estimated from calculated inside bark diameter and length. A second limitation was that merchantable height for a given top diameter could not be calculated directly and must be obtained through iteration.

Variation in tree form makes it difficult to formulate general rules for a single species or for all the stems in a single stand (Larson 1963). Using Kozak's (1988) model, Perez et al. (1990) developed an accurate taper function for trees of Schiede (Pinus oocarpa) in central Honduras. Through the use of logarithmic transformations, Kozak's model became:

$$
\begin{aligned}
\ln (d)= & \ln \left(b_{0}\right)+b_{1} \ln (D)+\ln \left(b_{2}\right) D+b_{3} \ln (S) x^{2}+b_{4} \ln (S) \ln (x+0.001) \\
& +b_{5} \ln (S) \sqrt{x}+b_{6} \ln (S) e^{z}+b_{7} \ln (S)(D / H)
\end{aligned}
$$


This full model has three independent variables $(D, H$, and $h)$ and eight coefficients. In order to reduce variables, the model was fitted based on the following criteria:

1) Mean square error (MSE).

2) Coefficient of determination $\left(R^{2}\right)$.

3) Prediction sum of squares ( PRESS ).

The best model was defined as having either the highest $R^{2}$ or the lowest value for one or more of the other criteria. The selected reduced model was:

$\ln (d)=\ln \left(b_{0}\right)+b_{1} \ln (D)+b_{3} \ln (S) x^{2}+b_{4} \ln (S) \ln (x+0.001)+b_{7} \ln (S)(D / H)$

Equation (1.14) and (1.15) were fitted for predicting diameter inside bark. They found that both models had almost the same prediction and low mean bias along the stem.

\subsubsection{Segmented Polynomial Taper Functions}

Relatively simple taper functions effectively describe the general taper of trees. However, they fail to describe the entire stem profile well. Some equations are better for describing the profile along the mid stem portion of the tree, but these equations are inadequate for describing the area near the butt and at the very top sections of the tree. With the advent of computers, relatively complex models were developed to derive taper functions so that more accurate estimates could be obtained.

Using the techniques of segmented polynomial regression, Max and Burkhart (1976) developed three segmented polynomial taper models (quadratic-quadratic model, quadratic-linear-quadratic model, and quadratic-quadratic-quadratic model) based on the 
assumption that segments of a tree bole approximate various geometric solids. All three models and a previously proposed single quadratic model by Kozak et al. (1969) were fitted to both planted and natural loblolly pine data. They found that the three segmented polynomial taper models provided a better description of tree taper than a single quadratic model. The quadratic-linear-quadratic model was found to be sufficient to describe the data from plantation grown loblolly pine, while the quadratic-quadraticquadratic model was found to be superior for natural loblolly pine. This segmented model has the following form:

$$
\frac{d^{2}}{D^{2}}=b_{1}(x-1)+b_{2}\left(x^{2}-1\right)+b_{3}\left(a_{1}-x\right)^{2} I_{1}+b_{4}\left(a_{2}-x\right)^{2} I_{2}
$$

Where:

$$
I_{i}=\left\{\begin{array}{ll}
1 & x \leq a_{i} \\
0 & x>a_{i}
\end{array} \quad i=1,2\right.
$$

This model consists of three models that describe the neiloid frustum of the lower bole, the paraboloid frustum of the middle bole, and the conical shape of the upper bole. The three models are defined using two join points to form a single segmented polynomial taper equation. The condition was imposed so that $d=0$ when $h=H$. Four parameters and the two join points are estimated from the data using nonlinear regression techniques.

Demaerschalk and Kozak (1977) pointed out that several reasons led to the problem of bias for existing taper functions: 
(1) Taper functions are very simple.

(2) The taper system cannot be properly conditioned to make them smooth and continuous at the inflection point when several models were combined.

(3) Many taper systems were based on a fixed diameter that is commonly affected by butt swell.

To overcome all these shortcomings, Demaerschalk and Kozak (1977) developed a new taper function, which was properly conditioned and used relative height instead of fixed height. Two equations were used to describe the upper and lower stem taper before conditioning. The upper stem equation was developed to describe the tree profile from the inflection point to the tip:

$$
\frac{d_{i}}{D I}=b_{0} z_{i}^{b_{1}} b_{2}{ }^{\left(1-z_{i}\right)}
$$

The lower stem equation was used to describe the tree profile below the inflection point:

$$
\frac{d_{i}}{D I}=b_{3}+b_{4}\left(1-z_{i}\right)^{b_{5}}
$$

Where:

$$
\begin{aligned}
& z_{i}=\frac{H-h}{H} \\
& D I=\text { diameter at the inflection point. } \\
& \text { Other variables as previously defined. }
\end{aligned}
$$


This study showed that the inflection point should occur at some specific relative height above the ground. Therefore, the diameter at the inflection point was selected as the base diameter for the profile model. The two equations were linked at the inflection point. The conditions $d_{i}=0$ when $h=H$ and $d_{i}=D_{i}$ when $h=4.5 \mathrm{ft}$. were imposed on the equations to ensure the profile model to be continuous and smooth at the inflection point. The precision and accuracy of tree diameter prediction were greatly improved except that there was a slight underestimation below breast height in very large trees.

By evaluating two methods for predicting merchantable volume of loblolly pine, Cao et al. (1980) developed a segmented polynomial taper model similar to the Max and Burkhart (1976) taper model. This model consists of three submodels with two join points. Each submodel has the form of a modified Goulding and Murray (1976) model:

$$
\frac{d^{2} K H}{V}-2 z_{i}=b_{1}\left(3 z_{i}^{2}-2 z_{i}\right)+b_{2}\left(z_{i}-a_{1}\right)^{2} I_{1}+b_{3}\left(z_{i}-a_{2}\right)^{2} I_{2}
$$

Where:

$$
I_{i}=\left\{\begin{array}{ll}
1 & z_{i} \geq a_{i} \\
0 & z_{i}<a_{i}
\end{array} \quad i=1,2\right.
$$

This model was compared to several existing models using loblolly pine data, and it was found that the model was the most accurate for predicting merchantable volumes to multiple top diameter limits and provided consistently good estimates of both diameters and volumes. When only diameter prediction was considered, the Max-Burkhart model 
was found to be superior. However, the use of the Cao et al. (1980) function requires an estimate of total tree volume $(V)$.

Bald cypress (Taxodium distichum) commonly shows considerable variation in the butt section of a tree. Most existing taper systems did not fit well for this species. A segmented taper equation was developed by Parresol et al. (1987) for bald cypress using sample tree data collected in Louisiana:

$$
\frac{d^{2}}{D^{2}}=z_{i}\left(b_{1}+b_{2} z_{i}\right)+\left(z_{i}-a\right)^{2}\left[b_{3}+b_{4}\left(z_{i}+2 a\right)\right] I
$$

Where:

$$
I= \begin{cases}1 & z_{i} \geq a \\ 0 & z_{i}<a\end{cases}
$$

This model joins two cubic subfunctions at a join point and is referred to as a cubic-cubic segmented-polynomial function. They compared the cubic-cubic model with five other models (Max and Burkhart 1976, Demaerschalk 1972, Ormerod 1973, Cao et al. 1980, Bennett et al. 1978) and found that cubic-cubic function ranked best for estimating taper in this species.

A form class taper model was developed by Schlaegel (1983) for willow oak (Quercus phellos) from 10 natural bottomland hardwood stands in the Mississippi Delta. The final equation was of the form: 


$$
\left\{\begin{array}{cc}
\frac{d^{2}}{D^{2}}=1-\frac{\left(D^{2}-F^{2}\right)\left(x_{i}^{b_{1}}-z_{i}^{2}\right)}{D^{2}\left(x_{i}^{b_{1}}-x_{j}{ }^{b_{1}}\right)} & x_{j} \leq z_{i} \leq 1 \\
\frac{d^{2}}{F^{2}}=\frac{z_{i}}{x_{j}}+b_{2} z_{i}\left(z_{i}-x_{j}\right)+b_{3} z_{i}\left(z_{i}^{2}-x_{j}{ }^{2}\right)+b_{4} z_{i}\left(z_{i}^{3}-x_{j}{ }^{3}\right) \\
+b_{5} z_{i}\left(z_{i}{ }^{4}-x_{j}{ }^{4}\right) & 0 \leq z_{i} \leq x_{j}
\end{array}\right.
$$

Where:

$$
\begin{aligned}
& F=\text { diameter outside bark at } 17.3 \text { feet. } \\
& x_{i}=(\mathrm{H}-4.5) / \mathrm{H} \\
& x_{j}=(\mathrm{H}-17.3) / \mathrm{H}
\end{aligned}
$$

Other variables as previously defined.

This model consists of two separate equations joined at 17.3 feet for the buttsection and upper-section of tree stem. The dependent variables are $d^{2} / D^{2}$ and $d^{2} / F^{2}$ for the butt-section and upper-section models, respectively. The model was conditioned so that $d=D$ when $h=4.5, d=F$ when $h=17.3$ and $d=0$ when $h=H$.

A complex segmented-profile model combining the better attributes of Schlaegel's and Max and Burkhart's models was developed by Clark et al. (1991) for 13,469 trees of 58 species in the south. The model divides the stem into four segments:

(1) Butt section from stump to 4.5 feet.

(2) Lower stem from 4.5 to 17.3 feet.

(3) Middle stem from 17.3 feet to $40-70$ percent of total height.

(4) Upper stem from 40-70 percent of total height to the tip of the tree. 
This model, when used to estimate diameter, accounted for over $90 \%$ variation in stem diameter with heights below 4.5 feet for most species, $97 \%$ to $99 \%$ variation in stem diameter with heights from 4.5 to 17.3 feet and $93 \%$ to $99 \%$ variation in stem diameter with heights above 17.3 feet. The Clark et al.(1991) taper function has the following form:

$$
d=\left\{\begin{array}{l}
I_{S}\left[\begin{array}{l}
D^{2}\left(\begin{array}{l}
1+\left(b_{2}+b_{3} / D^{3}\right)\left((1-h / H)^{b_{1}}-\right. \\
\left.(1-4.5 / H)^{b_{1}}\right) /\left(1-(1-4.5 / H)^{b_{1}}\right)
\end{array}\right)
\end{array}\right] \\
+I_{B}\left[\begin{array}{l}
D^{2}-\left(D^{2}-F^{2}\right)\left((1-4.5 / H)^{b_{4}}-\right. \\
\left.(1-h / H)^{b_{4}}\right) /\left((1-4.5 / H)^{b_{4}}-(1-17.3 / H)^{b_{4}}\right)
\end{array}\right] \\
+I_{T}\left[\begin{array}{l}
F^{2}\left(b_{6}(((h-17.3) /(H-17.3))-1)^{2}+\right. \\
\left.I_{M}\left((1-b) / b_{5}{ }^{2}\right)\left(b_{5}-(h-17.3) /(H-17.3)\right)^{2}\right)
\end{array}\right]
\end{array}\right\}^{0.5}
$$

Where:

$F=$ diameter at 17.3 feet.

$b_{1}, b_{2}, b_{3}=$ regression coefficients for stem height below 4.5 feet.

$b_{4}=$ regression coefficient for stem height between 4.5 and 17.3 feet.

$b_{5}, b_{6}=$ regression coefficients for stem height above 17.3 feet.

Four indicator variables for taper function were defined as follows:

$$
\begin{aligned}
I_{S} & = \begin{cases}1 & h<4.5 \\
0 & \text { otherwise }\end{cases} \\
I_{T}= \begin{cases}1 & h>17.3 \\
0 & \text { otherwise }\end{cases} & I_{B}= \begin{cases}1 & 4.5 \leq h \leq 17.3 \\
0 & \text { otherwise }\end{cases} \\
& I_{M}= \begin{cases}1 & h<\left(17.3+b_{5}(H-17.3)\right) \\
0 & \text { otherwise }\end{cases}
\end{aligned}
$$

All other variables as previously defined. 


\subsection{History of Taper Systems in Hardwoods and Appalachian Hardwoods}

Most of the taper systems described were developed for softwoods. However, fewer taper systems have been constructed for hardwoods, especially for Appalachian hardwoods. Hilt (1980) proposed a taper-based system by using a modification of the equation by Bruce et al. (1968) using 418 upland oaks located in Ohio, Kentucky, Missouri, Indiana, and Illinois. The taper equation is as the following form:

$$
\frac{d_{i}{ }^{2}}{D_{i}{ }^{2}}=z^{3 / 2}+\sum_{i=1}^{n} \sum_{j=0}^{1} \sum_{k=0}^{1} b_{i j k}\left(z^{3 / 2}-z^{\gamma_{i}}\right) D_{i}{ }^{j} H^{k}
$$

By using $\gamma_{1}=3$ and $\gamma_{2}=30$ as suggested by Bruce, stepwise regression

procedures were used to estimate the $b$ 's parameters. A form factor $(\hat{F})$ that can be computed by integrating equation (1.24) was introduced to describe the ratio of cubic volume inside bark from the tip to a given height to a cylinder of diameter $D_{i}$ with height $(H-4.5)$. The predicted cubic volume inside bark $\left(\hat{V}_{i}\right)$ from the tip to height $\mathrm{h}$ can be calculated based on this form factor:

$$
\begin{gathered}
\hat{F}=\int_{0}^{z \wedge} y d x \\
\hat{V}_{i}=k D_{i}^{2}(H-4.5) \hat{F}
\end{gathered}
$$

Martin (1981) compared five taper equations fit to 18 commercial Appalachian hardwood species (Ormerod 1973, Bruce et al. 1968, Demaerschalk 1972, Kozak et al. 1969, and Max and Burkhart 1976). Each model is a function of $D, H, h$, and $d$. The dependent variable in each model was $d^{2} / D^{2}$. Stem measurements were collected from 1,162 trees located in West Virginia and southwestern Virginia. Eighteen species were 
sampled and data were obtained from 39 different stands from poor to excellent sites. All model forms were fitted to the sample data using nonlinear regression. Results of the regression analyses indicated that Max-Burkhart model was better than other four models for most species.

Martin also tested the five equations to evaluate if any of the models were significantly better than the others. The tests compared diameter prediction, height prediction, and the prediction of volume for different stem sections. First, all comparisons were made by using the appropriate coefficients for individual species in each model. Biases, mean absolute biases, and standard deviations were employed for these comparisons. The results indicated that the Kozak et al. (1969) model was the best predictor of diameter, for predicting height, the Max and Burkhart (1976) model was better than other models, and the Bruce et al. (1968) model was better for predicting volume. Although the Max and Burkhart model did not rank highest in all cases, it showed the most consistent performance.

As mentioned previously, Clark et al. (1991) developed form-class segmented profile equations for a large number of southern Appalachian hardwoods and conifers. They found that their segmented polynomial model with three inflection points more accurately described stem profile. 
CHAPTER 2 : METHODS AND PROCEDURES

\subsection{Description of the Study Areas}

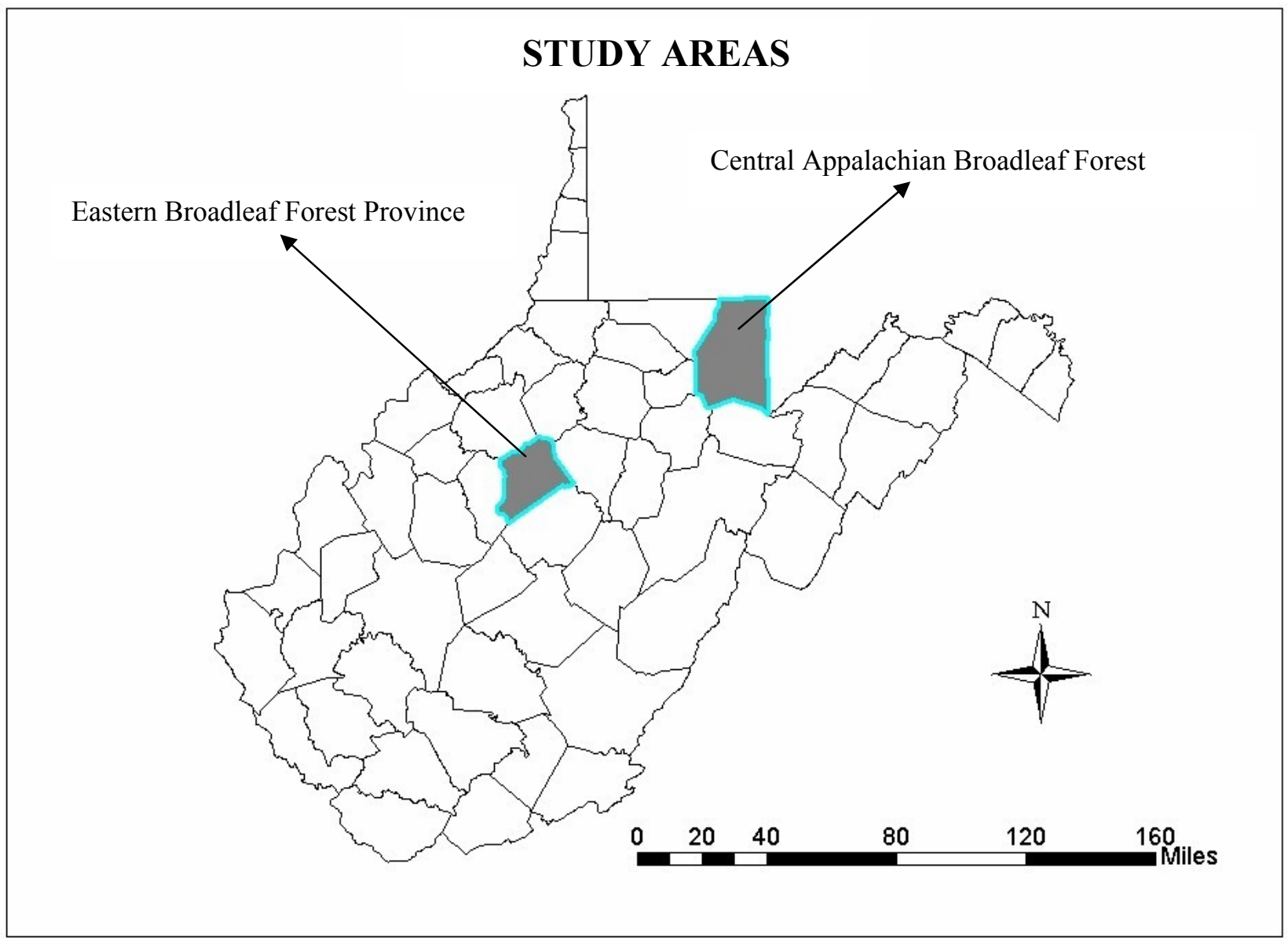

Figure 2.1. Location of study areas.

Study areas were selected from two forest provinces in West Virginia. The first was from the Central Appalachian Broadleaf Forest which contains a mixture of oaks, black cherry (Prunus serotina Ehrh.), yellow-poplar, maple (Acer spp.), and other associated hardwoods. The second was from the Eastern Broadleaf Forest Province consisting of white oak (Quercus alba L.), red oak (Quercus rubra L.), black oak 
(Quercus velutina Lam.), hickory (Carya spp.), yellow-poplar, red maple (Acer rubrum L.), and other hardwoods.

\subsubsection{Central Appalachian Broadleaf Forest}

The study area selected from the Central Appalachian Broadleaf Forest is part of the West Virginia University Research Forest and Coopers Rock State Forest located east of Morgantown, WV. Elevation ranges from 1000 feet in the lowest valley to 2600 feet. Mean annual precipitation is approximate 60 inches and mean annual temperature is between 39 and $54{ }^{\circ} \mathrm{F}$. The soils in this area have been classified as inceptisols and ultisols. This area supports mixed hardwood forest vegetation. Oak, black cherry, yellowpoplar, maple, and other associated hardwoods are the principle species at lower elevations (Henry and Bailey, 1994).

\subsubsection{Eastern Broadleaf Forest Province}

The central study area is located approximately six miles southwest of GilmerLewis County near Sand Fork, WV. Elevation ranges from 660 feet in the lowest valley to 1350 feet. Mean annual precipitation ranges from 35 to 45 inches and mean annual temperature is between 39 and $55^{\circ} \mathrm{F}$. Inceptisols and ultisols are the major soil types for this region. The major species in this region includes white oak, red oak, black oak, hickory, and associated upland hardwoods. yellow-poplar, red maple, and other species requiring moist sites grow in sheltered coves, on foot slopes, and on north - facing slopes. This particular site was located on the lower slope adjacent to a major tributary. 


\subsection{Data Collection}

\subsubsection{Field Collection}

Data were collected during the summer of 2002 and 2003. Sample trees were selected from both the dominant and codominant crown class. Trees possessing multiple stems, broken tops, obvious cankers or crooked boles were not included in the sample. A total of forty-four sample trees were selected for study. Twenty-six trees were sampled from the Central Appalachian Broadleaf Forest province, and another eighteen trees were obtained from the Eastern Broadleaf Forest Province on lands owned by Columbia Forest Products Company.

Each sample tree selected for stem analysis was felled at ground level. A tape was stretched along the stem from base to tree tip for measuring the total height of the individual tree, which was recorded to the neatest 0.1 foot. Diameter outside bark (dob) at breast height was measured and recorded to the nearest 0.1 inch with a diameter tape.

Each tree was bucked into sections. One-inch thick sample disks were taken at different heights from the tree base. Disks were extracted at 1.0 foot, 2.0 feet, 4.5 feet, 6.0 feet and the remaining disks were taken at 4-foot intervals to a two-inch top diameter outside bark. One additional disk was extracted at 17.3 feet to permit form class analysis. Each disk was labeled and sealed in plastic bag to preserve moisture and prevent shrinkage. All samples were obtained during the growing season between July 1 and Aug. $15^{\text {th }}$ of each year. 


\subsubsection{Lab Measurements}

In laboratory, two procedures were carried out. If a steel diameter tape (d-tape) is level and pulled taut, it is the most consistent method for measuring diameter. However, if the tree cross sections are not circular, taped reading of irregular trees are likely to be positively biased. Wooden and steel calipers provide a quick measure of diameter. Bias can be minimized by obtaining the average diameter of the major and minor axis diameter. If diameter outside bark of the disk was less than 13 inches, the diameter was measured with a steel diameter tape. Otherwise, the diameter was measured with wooden calipers. Two diameter readings were recorded for each disk with the caliper for the major axis $\left(d_{1}\right)$ and minor axis $\left(d_{2}\right)$. The average diameter $\left(d_{\text {avg }}\right)$ of each disk was then computed as the geometric mean of the major and minor axis,

$$
d_{a v g}=\sqrt{d_{1} * d_{2}}
$$

After the bark was removed, the same procedure was applied for diameter inside bark. All data were saved to a relational database (MS ACCESS) for later data analysis.

Table 2.1. Summary statistics for yellow-poplar tree data.

\begin{tabular}{lccccc}
\hline Variable & Range & Mean & SD & $\begin{array}{l}\text { Number } \\
\text { of trees }\end{array}$ & $\begin{array}{c}\text { Number } \\
\text { of disks }\end{array}$ \\
\hline DBH (in.) & $6.8-22.1$ & 13.02 & 3.73 & & \\
Total height (ft.) & $61.8-126.2$ & 92.21 & 11.95 & & \\
$\begin{array}{l}\text { Disk diameter } \\
\text { inside bark (in.) }\end{array}$ & $2.30-13.36$ & 8.91 & 3.71 & 44 & 913 \\
$\begin{array}{l}\text { Disk diameter } \\
\text { outside bark (in.) }\end{array}$ & $2.60-25.30$ & 9.95 & 4.06 & & \\
\begin{tabular}{l} 
Disk height (ft.) \\
\hline \hline
\end{tabular} & $1-114$ & 35.37 & 25.03 & \\
\hline
\end{tabular}




\subsection{Actual Volume Calculation}

Actual cubic foot volume for each bolt was calculated by applying an overlapping bolts method described by Bailey (1995). The overlapping bolts method has been shown to improve the volume estimates over the usual single-bolt estimation (Bailey 1995).

Volume of the top bolt was assumed to be a conic section and obtained using the following equation:

$$
V=\frac{1}{3} A * L
$$

Where: $A=$ cross section area of the base $\left(\mathrm{ft}^{2}\right.$.)

$$
L=\text { length of the bolt (ft.) }
$$

Volumes of the other bolts were obtained using the following method. It was assumed that basal area increases along a bolt in the form of a quadratic equation:

$$
y=\beta_{0}+\beta_{1} x+\beta_{2} x^{2}
$$

Where: $y=\log$ basal area $\left(\mathrm{ft}^{2}\right.$.)

$$
x=\text { distance from end of } \log (\mathrm{ft} .)
$$

This relationship is graphically depicted in Figure 2.2. 


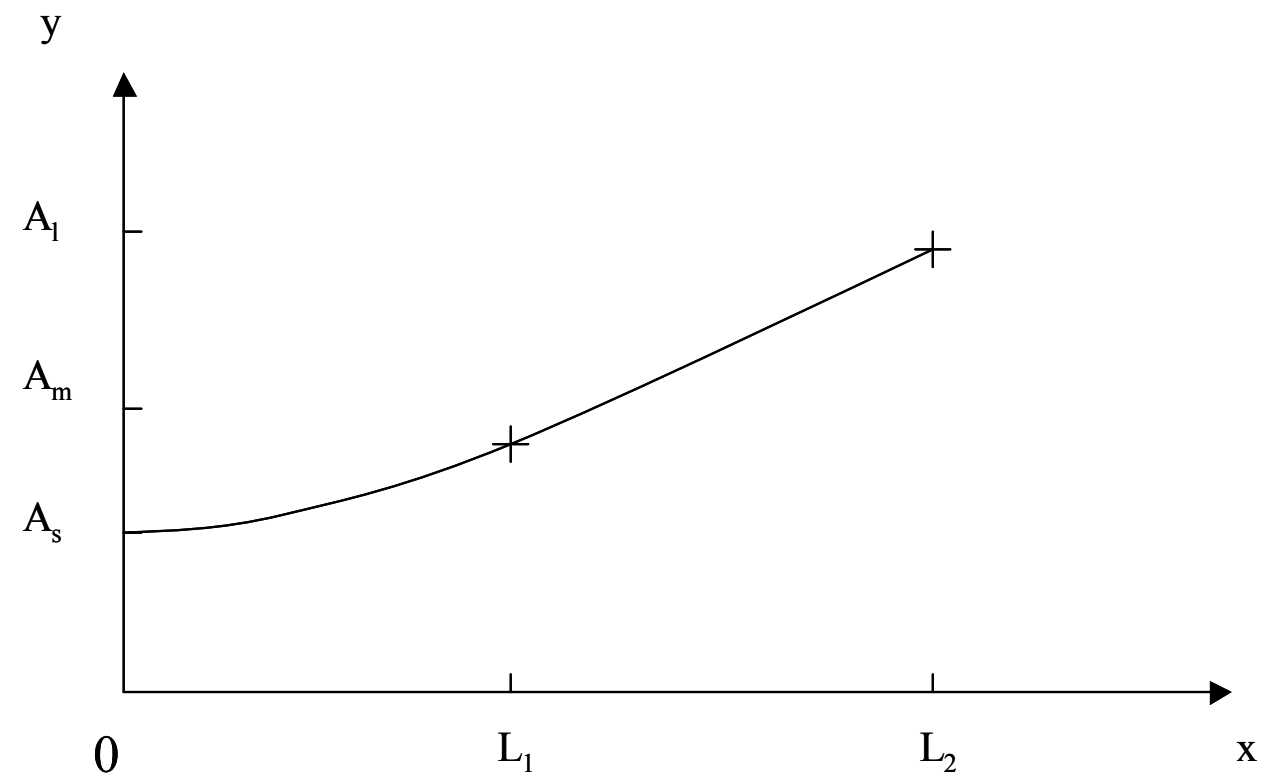

Figure 2.2. Relationship between cross sectional area and bolt length $\left(\mathrm{L}_{\mathrm{i}}\right)$.

Solving equation (2.2) for the cross sectional area of the small end $\left(A_{s}\right)$, mid point $\left(A_{m}\right)$ and large end $\left(A_{l}\right)$ provides the following set of equations:

$$
\left\{\begin{array}{l}
A_{s}=\beta_{0}+\beta_{1}(0)+\beta_{2}(0)^{2} \\
A_{m}=\beta_{0}+\beta_{1}\left(L_{1}\right)+\beta_{2}\left(L_{1}\right)^{2} \\
A_{l}=\beta_{0}+\beta_{1}\left(L_{2}\right)+\beta_{2}\left(L_{2}\right)^{2}
\end{array}\right.
$$

Solving for $\beta_{0}, \beta_{1}, \beta_{2}$ yields:

$$
\left\{\begin{array}{l}
\beta_{0}=A_{s} \\
\beta_{1}=\frac{\left(A_{l}-A_{s}-\beta_{2} L_{2}^{2}\right)}{L_{2}} \\
\beta_{2}=\frac{\left(A_{l}-A_{m}\left(\frac{L_{2}}{L_{1}}\right)-A_{s}\left(1-\frac{L_{2}}{L_{1}}\right)\right)}{L_{2}{ }^{2}-L_{1} L_{2}}
\end{array}\right.
$$


Where:

$$
\begin{aligned}
& A_{s}=\text { basal area of small cross section of the bolt }\left(\mathrm{ft}^{2} .\right) \\
& A_{m}=\text { basal area of central cross section of the bolt }\left(\mathrm{ft}^{2} .\right) \\
& A_{l}=\text { basal area of large cross section of the bolt }\left(\mathrm{ft}^{2} .\right)
\end{aligned}
$$

Bolt volume can be obtained by integrating equation (2.2) and substituting parameter estimates for $\beta_{0}, \beta_{1}$ and $\beta_{2}$ as indicated by equation (2.4).

$$
\begin{aligned}
V & =\int_{0}^{x} y d x \\
& =\int_{0}^{x}\left(\beta_{0}+\beta_{1} x+\beta_{2} x^{2}\right) d x \\
& =\beta_{0} x+\frac{\beta_{1}}{2} x^{2}+\frac{\beta_{2}}{3} x^{3}
\end{aligned}
$$

Starting with the second bolt from the top of the stem (first bolt $\left(v_{l}\right)$ assumed to be a cone), equation (2.6) was used to calculate the total cubic foot volume $\left(V_{23}\right)$ of the next bolt (Figure 2.3). Volumes of each segment $\left(v_{2}\right.$ and $\left.v_{3}\right)$ can be estimated during this process. Moving down the stem by one segment, this process can be repeated, thus providing the volume for the next bolt $\left(V_{34}\right)$ and volumes for both sections $\left(v_{3}\right.$ and $\left.v_{4}\right)$. This process provides two estimates for each segment except for the first $\left(v_{2}\right)$ and last $\left(v_{n}\right)$ segments. Total volume to any point can be obtained by summing the average volume of each bolt. 


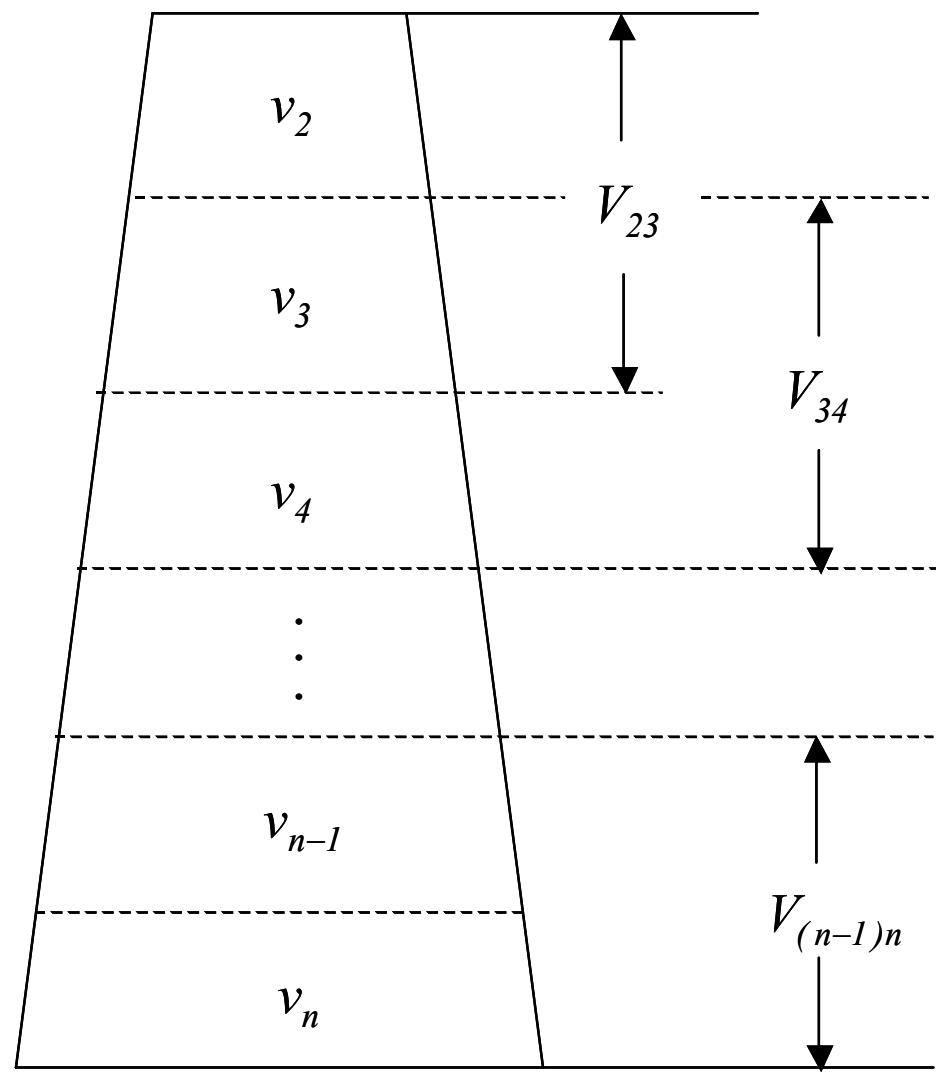

Figure 2.3. Volume of overlapping bolts

\subsection{Selection of Model Forms}

Compatible taper equations as defined by Demaerschalk (1972) and Clutter (1980) can be developed through numerical integration of a taper function. Based on this point, four taper equations were selected from the literature for this study. Two equations (Model 1 and Model 2) are simple polynomial models, the other two (Model 3 and Model 4) are segmented polynomial models. Two additional model forms will be derived from Model 4. The model forms selected include: 
Model 1: Kozak et al. (1969)

$$
\begin{aligned}
& \frac{d^{2}}{D^{2}}=b_{1}\left(\frac{h}{H}-1\right)+b_{2}\left(\frac{h^{2}}{H^{2}}-1\right) \\
& V=k D^{2}\left[\left(b_{1}-b_{2}\right)(h u-h l)+\frac{b_{1}\left(h u^{2}-h l^{2}\right)}{2 H}+\frac{b_{2}\left(h u^{3}-h l^{3}\right)}{3 H}\right]
\end{aligned}
$$

Where:

$$
\begin{aligned}
& d=\text { diameter outside bark to measurement point. } \\
& D=\text { diameter outside bark at breast height ( } 4.5 \text { feet above ground). } \\
& h=\text { height above the ground to the measurement point. } \\
& H=\text { total tree height. } \\
& V=\text { stem volume between two heights, } h l \text { and } h u . \\
& h l=\text { lower height of the bole from ground to top. } \\
& h u=\text { upper height of the bole from ground to top. } \\
& b_{1}, b_{2}=\text { regression coefficients estimated from the sample data. } \\
& k=0.005454154
\end{aligned}
$$

Model 2: Demaerschalk (1972)

$$
\begin{aligned}
& \frac{d^{2}}{D^{2}}=10^{2 b_{1}} D^{2 b_{2}-2}(H-h)^{2 b_{3}} H^{2 b_{4}} \\
& V=\frac{k\left(10^{2 b_{1}}\right)\left(D^{2 b_{2}}\right)\left(H^{2 b_{4}}\right)\left((H-h l)^{2}-(H-h u)^{2}\right)}{2 b_{3}}
\end{aligned}
$$

Where:

$$
b_{1}, \ldots b_{4} \text { are parameters to be estimated from the sample data. }
$$

All other variables as previously defined. 
Model 3: Max and Burkhart (1976)

$$
\begin{aligned}
& \frac{d^{2}}{D^{2}}=b_{1}(x-1)+b_{2}\left(x^{2}-1\right)+b_{3}\left(a_{1}-x\right)^{2} I_{1}+b_{4}\left(a_{2}-x\right)^{2} I_{2} \\
& V=k D^{2} H\left\{\begin{array}{l}
\frac{b_{2}}{3}\left(h u^{3}-h l^{3}\right)+\frac{b_{1}}{2}\left(h u^{3}-h l^{3}\right)-\left(b_{1}+b_{2}\right)(h u-h l) \\
-\frac{b_{3}}{3}\left[\left(a_{1}-h u\right)^{3} I_{1}-\left(a_{1}-h l\right)^{3} J_{2}\right] \\
\frac{b_{4}}{3}\left[\left(a_{2}-h u\right)^{3} I_{1}-\left(a_{2}-h l\right)^{3} J_{2}\right]
\end{array}\right\}
\end{aligned}
$$

Where:

$$
\begin{aligned}
& I_{i}=\left\{\begin{array}{ll}
1 & h u \leq a_{i} \\
0 & h u>a_{i}
\end{array} \quad\right. \text { i=1,2 } \\
& J_{i}=\left\{\begin{array}{ll}
1 & h l \leq a_{i} \\
0 & h l>a_{i}
\end{array} \quad i=1,2\right.
\end{aligned}
$$

Model 4: Clark et al. (1991)

$$
d=\left\{\begin{array}{l}
I_{S}\left[\begin{array}{l}
D^{2}\left(\begin{array}{l}
1+\left(b_{2}+b_{3} / D^{3}\right)\left((1-h / H)^{b_{1}}-\right. \\
\left.(1-4.5 / H)^{b_{1}}\right) /\left(1-(1-4.5 / H)^{b_{1}}\right)
\end{array}\right)
\end{array}\right] \\
+I_{B}\left[\begin{array}{l}
D^{2}-\left(D^{2}-F^{2}\right)\left((1-4.5 / H)^{b_{4}}-\right. \\
\left.(1-h / H)^{b_{4}}\right) /\left((1-4.5 / H)^{b_{4}}-(1-17.3 / H)^{b_{4}}\right)
\end{array}\right] \\
+I_{T}\left[\begin{array}{l}
F^{2}\left(b_{6}(((h-17.3) /(H-17.3))-1)^{2}+\right. \\
\left.I_{M}\left((1-b) / b_{5}{ }^{2}\right)\left(b_{5}-(h-17.3) /(H-17.3)\right)^{2}\right)
\end{array}\right]
\end{array}\right\}^{0.5}
$$




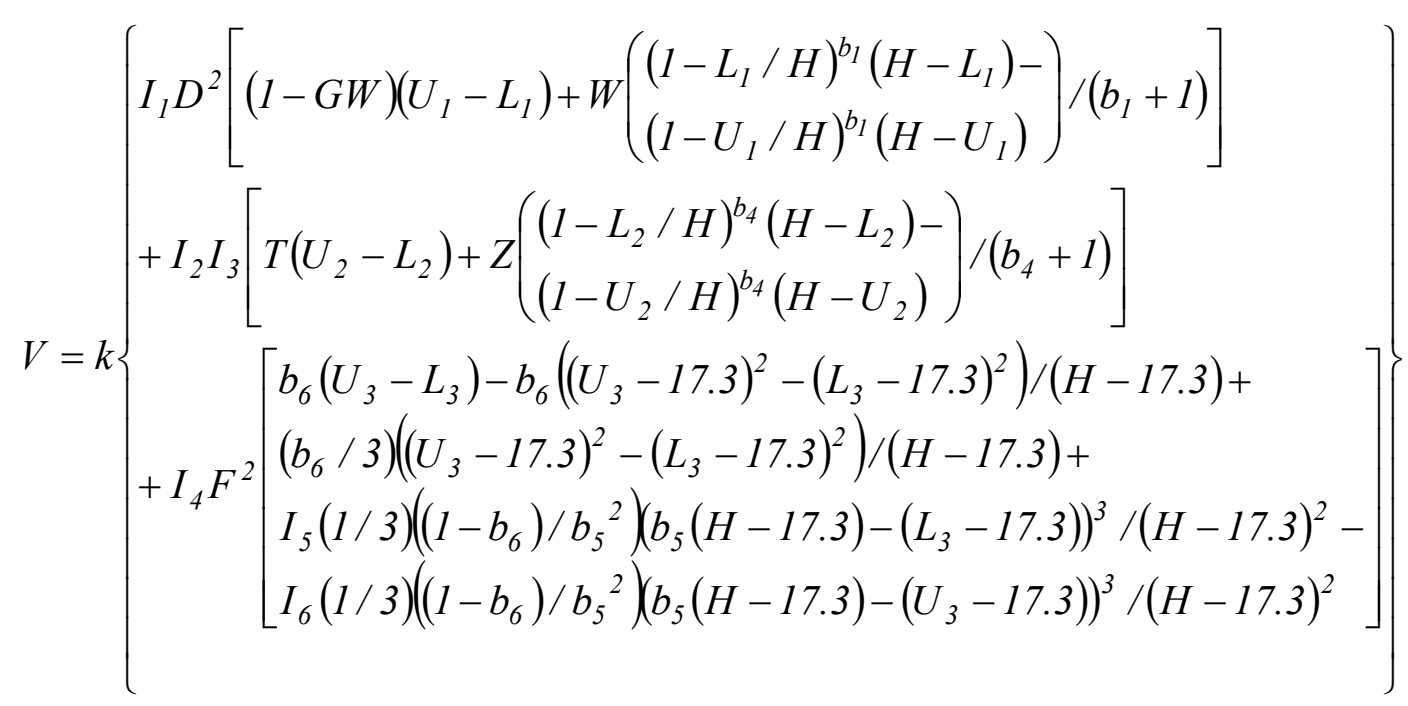

Where:

$$
F=\text { diameter at } 17.3 \text { feet. }
$$

$b_{1}, b_{2}, b_{3}=$ regression coefficients for stem height below 4.5 feet.

$b_{4}=$ regression coefficient for stem height between 4.5 and 17.3 feet.

$b_{5}, b_{6}=$ regression coefficients for stem height above 17.3 feet.

Four indicator variables for the taper function were defined as follows:

$$
\begin{aligned}
& I_{S}= \begin{cases}1 & h<4.5 \\
0 & \text { otherwise }\end{cases} I_{B}= \begin{cases}1 & 4.5 \leq h \leq 17.3 \\
0 & \text { otherwise }\end{cases} \\
& I_{T}=\left\{\begin{array}{ll}
1 & h>17.3 \\
0 & \text { otherwise }
\end{array} I_{M}= \begin{cases}1 & h<\left(17.3+b_{5}(H-17.3)\right) \\
0 & \text { otherwise }\end{cases} \right.
\end{aligned}
$$

The combined variables used in this model are as follows:

$$
\begin{aligned}
& G=(1-4.5 / H)^{b_{1}} \quad W=\left(b_{2}+b_{3} / D^{3}\right) /(1-G) \\
& L_{1}=\max (L, 0) \quad L_{2}=\max (L, 4.5) \quad L_{3}=\max (L, 17.3) \\
& U_{1}=\min (U, 4.5) \quad U_{2}=\min (U, 17.3) \quad U_{3}=\min (U, H)
\end{aligned}
$$


The following indicator variables were used for the volume function:

$$
\begin{gathered}
I_{1}=\left\{\begin{array}{ll}
1 & L<4.5 \\
0 & \text { otherwise }
\end{array} I_{3}=\left\{\begin{array}{ll}
1 & U>4.5 \\
0 & \text { otherwise }
\end{array} \quad I_{2}= \begin{cases}1 & L<17.3 \\
0 & \text { otherwise }\end{cases} \right.\right. \\
I_{5}=\left\{\begin{array}{ll}
1 & \left(L_{3}-17.3\right)<b_{5}(H-17.3) \\
0 & \text { otherwise }
\end{array} \quad\right. \\
I_{6}= \begin{cases}1 & \text { otherwise } \\
0 & \text { otherwise }\end{cases}
\end{gathered}
$$

All other variables as previously defined.

\subsection{Criteria for Model Evaluation}

Since this study involves stem diameter and volume prediction, average bias, SEE and $\mathrm{R}^{2}$ were selected as statistical criteria for model evaluation.

\section{Average bias:}

Average bias is the mean difference between measured value and predicted value.

It is defined as:

$$
\text { Average bias }=\frac{\sum_{i=1}^{n}\left(Y_{i}-\hat{Y}_{i}\right)}{n}
$$

Where:

$$
\begin{aligned}
& Y_{i}=\text { measured value. } \\
& \hat{Y}_{i}=\text { predicted value. } \\
& n=\text { number of observations in the dataset. }
\end{aligned}
$$




\section{Standard error of estimate $(S E E)$ :}

Standard error of estimate $(S E E)$ is defined as:

$$
S E E=\sqrt{\frac{\sum_{i=1}^{n}\left(Y_{i}-\hat{Y}_{i}\right)^{2}}{n-k}}
$$

Where:

$k$ is the number of estimated parameters.

Other variables are as previously defined.

$\mathbf{R}^{2}:$

$\mathrm{R}^{2}$ indicates how much of the variation in the dependant variable is explained by the independent variables. For non-linear models, $\mathrm{R}^{2}$ is not always between 0 and 1 and negative $\mathrm{R}^{2}$ values can occur. It is defined as:

$$
R^{2}=1-\frac{S S E}{C S S}
$$

Where:

$$
\begin{aligned}
& S S E= \sum_{i=1}^{n}\left(Y_{i}-\hat{Y}_{i}\right)^{2} \text { represents sum of square for error. } \\
& C S S=\sum_{i=1}^{n}\left(Y_{i}-\bar{Y}\right)^{2} \text { represents corrected total sum of squares for the } \\
& \text { dependent variable. } \\
& \bar{Y}=\text { mean of the } Y_{i}
\end{aligned}
$$




\subsection{Model Fitting Procedures}

The SYSNLIN procedure in SAS (SAS Institute, 1993) was used for estimation of the nonlinear simultaneous taper and volume equation systems. Seemingly unrelated regression (SUR) method was selected for parameter estimation. Starting values are required for estimation of the model parameters. Starting values were obtained from Martin (1981) for model 1, 2, and 3 and from Clark et al. (1991) for model 4.

Each compatible system is a two-equation system. The first is the taper equation and the second is the volume equation. The two equations are independent regressors. For example, dob that does not show in the volume equation as a independent variable is a dependent, or endogenous variable in the taper equation. SUR can be used to simultaneously estimate equation parameters while minimizing both diameter and volume prediction in the presence of cross correlated error structures. The dependent variable of each taper equation was changed to an expression of dob in order to ensure that the model evaluation criteria (average bias, SEE, and $\mathrm{R}^{2}$ ) were consistent. The endogenous variables include dob and volume. The exogenous variables are dbh (diameter outside bark at breast height), tht (total tree height), hu (upper height of the bole from ground to top), and hl (lower height of the bole from ground to top) etc. To produce consistent parameter estimates, each taper and volume system was simultaneously fitted.

When nonlinear models are fitted, bounds and restrictions were added for the Max and Burkhart model (model 3) and the Clark et al. model (model 4) to ensure optimal estimates by stem segment. Restriction expressions can be composed of parameter names, arithmetic operators, and constants. Using the bounds and restrictions 
for indicator variables, models can be adjusted for different tree sections to obtain segment specific parameters estimates. For example, Max and Burkhart's model consists of three models that describe the neiloid frustum of the lower bole, the paraboloid frustum of the middle bole, and the conical shape of the upper bole. The three models are defined using two join points to form an overall segmented polynomial taper equation. This taper equation can be split into three separate equations by utilizing appropriate indicator variables for different bole segments. 


\section{CHAPTER 3 : MODEL DERIVATION AND RESULTS}

\subsection{Model Derivation}

Model 5 and Model 6 were developed based on the modification of Model 4 (Clark et al. 1991), which used a Schlaegel-type equation for the butt section (below 4.5 feet) as indicated by equation (3.1).

$d_{b}=D\left(1+\left(b_{2}+\frac{b_{3}}{D^{3}}\right)\left(\frac{\left(\left(1-\frac{h}{H}\right)^{b_{1}}-\left(1-\frac{4.5}{H}\right)^{b_{1}}\right)}{\left(1-\left(1-\frac{4.5}{H}\right)^{b_{1}}\right)}\right)\right)^{0.5}$

Where:

$d_{b}=$ diameter below 4.5 feet.

All other variables as previously defined.

The Clark et al. (1991) model (model 4) was fitted to the sample data. All parameters were significant at the 0.0001 significant level with the exception of $b_{3}$ which involves the butt section of the tree boles. Two approaches were used to remove $b_{3}$ from equation 3.1:

First, the $\frac{b_{3}}{D^{3}}$ component was removed from equation 3.1 and the following equation was obtained: 


$$
d_{b}=D\left(1+\left(b_{2}\right)\left(\frac{\left(\left(1-\frac{h}{H}\right)^{b_{1}}-\left(1-\frac{4.5}{H}\right)^{b_{I}}\right)}{\left(1-\left(1-\frac{4.5}{H}\right)^{b_{I}}\right)}\right)\right)^{0.5}
$$

Stem volume equation can be readily obtained by integrating taper function as described by equation 3.3 :

$$
V_{b}=\int_{h l}^{h u} k d_{b}^{2} d h
$$

Where:

$$
\begin{aligned}
& V_{b}=\text { stem volume between two heights (hl and hu). } \\
& \mathrm{hl}=\text { lower height of interest below } 4.5 \text { feet. } \\
& \mathrm{hu}=\text { upper height of interest below } 4.5 \text { feet. }
\end{aligned}
$$

Using equation 3.3, the following equation can be derived by integrating equation 3.2:

$$
V_{b}=k D^{2}\left(\left(1-b_{2} G W_{1}\right)\left(U_{1}-L_{1}\right)+b_{2} W_{1} \frac{\left(\left(1-\frac{L_{1}}{H}\right)^{b_{1}}\left(H-L_{1}\right)-\left(1-\frac{U_{1}}{H}\right)^{b_{1}}\left(H-U_{1}\right)\right)}{b_{1}+1}\right)
$$

Where:

$$
W_{l}=\frac{1}{1-G}
$$

All other variables as previously defined. 
Substituting equation 3.2 and 3.4 for the original butt section in model 4 resulted in new taper and volume equations for model 5:

Model 5:

$d=\left\{\begin{array}{l}I_{S}\left[D^{2}\left(1+\left(b_{2}\right)\left((1-h / H)^{b_{1}}-(1-4.5 / H)^{b_{1}}\right) /\left(1-(1-4.5 / H)^{b_{1}}\right)\right)\right. \\ +I_{B}\left[\begin{array}{l}D^{2}-\left(D^{2}-F^{2}\right)\left((1-4.5 / H)^{b_{4}}-\right. \\ \left.(1-h / H)^{b_{4}}\right) /\left((1-4.5 / H)^{b_{4}}-(1-17.3 / H)^{b_{4}}\right)\end{array}\right] \\ +I_{T}\left[\begin{array}{l}F^{2}\left(b_{6}(((h-17.3) /(H-17.3))-1)^{2}+\right. \\ \left.I_{M}\left(\left(1-b_{6}\right) / b_{5}{ }^{2}\right)\left(b_{5}-(h-17.3) /(H-17.3)\right)^{2}\right)\end{array}\right]\end{array}\right\}$

$V=k\left\{\begin{array}{c}I_{1} D^{2}\left[\begin{array}{c}\left.\left(1-b_{2} G W_{1}\right)\left(U_{1}-L_{1}\right)+b_{2} W_{1}\left(\begin{array}{l}\left(1-L_{1} / H\right)^{b_{1}}\left(H-L_{1}\right)- \\ \left(1-U_{1} / H\right)^{b_{1}}\left(H-U_{1}\right)\end{array}\right) /\left(b_{1}+1\right)\right] \\ +I_{2} I_{3}\left[\begin{array}{l}T\left(U_{2}-L_{2}\right)+Z\left(\begin{array}{l}\left(1-L_{2} / H\right)^{b_{4}}\left(H-L_{2}\right)- \\ \left(1-U_{2} / H\right)^{b_{4}}\left(H-U_{2}\right)\end{array}\right) /\left(b_{4}+1\right)\end{array}\right] \\ +I_{4} F^{2}\left[\begin{array}{l}\left(b_{6} / 3\right)\left(\left(U_{3}-L_{3}\right)-b_{6}\left(\left(U_{3}-17.3\right)^{2}-\left(L_{3}-17.3\right)^{2}\right) /(H-17.3)+\right. \\ I_{5}(1 / 3)\left(\left(1-b_{6}\right) / b_{5}{ }^{2}\right)\left(b_{5}(H-17.3)^{2}\right) /(H-17.3)+ \\ I_{6}(1 / 3)\left(\left(1-b_{6}\right) / b_{5}{ }^{2}\right)\left(b_{5}(H-17.3)-\left(U_{3}-17.3\right)\right)^{3} /(H-17.3)^{2}\end{array}\right]\end{array}\right]\end{array}\right\}$

All variables as previously defined.

To further simplify the model, the $\left(b_{2}+\frac{b_{3}}{D^{3}}\right)$ component was eliminated from equation 3.1 resulting equation 3.5 : 


$$
d_{b}=D\left(1+\left(\frac{\left(\left(1-\frac{h}{H}\right)^{b_{1}}-\left(1-\frac{4.5}{H}\right)^{b_{I}}\right)}{\left(1-\left(1-\frac{4.5}{H}\right)^{b_{l}}\right)}\right)\right)^{0.5}
$$

Similarly, volume equation 3.6 can be derived by integrating equation 3.5 :

$$
V_{b}=k D^{2}\left(\left(1-G W_{1}\right)\left(U_{1}-L_{1}\right)+W_{1} \frac{\left(\left(1-\frac{L_{1}}{H}\right)^{b_{1}}\left(H-L_{1}\right)-\left(1-\frac{U_{1}}{H}\right)^{b_{l}}\left(H-U_{1}\right)\right)}{b_{1}+1}\right)
$$

Substituting equation 3.5 and 3.6 for the original butt section in model 4 resulted in new taper and volume equations for model 6:

Model 6:

$$
d=\left\{\begin{array}{l}
I_{S}\left[\begin{array}{l}
D^{2}\left(1+\left((1-h / H)^{b_{1}}-(1-4.5 / H)^{b_{1}}\right) /\left(1-(1-4.5 / H)^{b_{1}}\right)\right) \\
+I_{B}\left[\begin{array}{l}
D^{2}-\left(D^{2}-F^{2}\right)\left((1-4.5 / H)^{b_{4}}-\right. \\
\left.(1-h / H)^{b_{4}}\right) /\left((1-4.5 / H)^{b_{4}}-(1-17.3 / H)^{b_{4}}\right)
\end{array}\right] \\
+I_{T}\left[\begin{array}{l}
F^{2}\left(b_{6}(((h-17.3) /(H-17.3))-1)^{2}+\right. \\
\left.I_{M}\left(\left(1-b_{6}\right) / b_{5}{ }^{2}\right)\left(b_{5}-(h-17.3) /(H-17.3)\right)^{2}\right)
\end{array}\right]
\end{array}\right\}
\end{array}\right.
$$




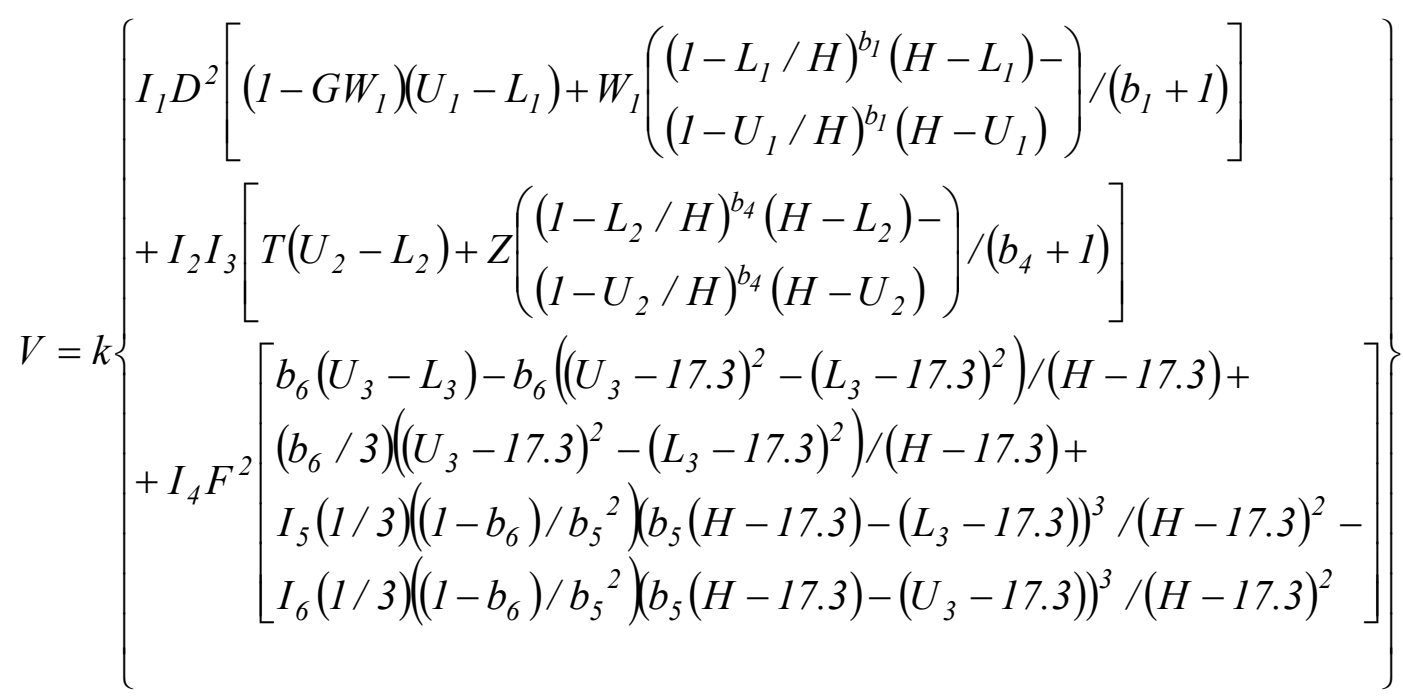

All variables as previously defined.

\subsection{Parameter Estimation}

Model 1, model 2, model 3, model 4, model 5, and model 6 were fitted to the sample data using SYSNLIN procedure in SAS (SAS Institute, 1993). To obtain consistent parameter estimation, taper and volume equations were fitted simultaneously for each model. All parameters were shared by both taper and volume equations. First, the models were fitted to outside bark data. Each model can be easily modified to estimate taper and volume inside bark using diameter inside bark at breast height $\left(D_{i}\right)$ and diameter inside bark to measurement point $\left(d_{i}\right)$ to replace diameter outside bark at breast height $(D)$ and diameter outside bark to measurement point $(d)$, respectively. Similar fitting procedures were used for taper and volume functions inside bark. Parameter estimates for diameter and volume are listed in Table 3.1. All parameters were significant at the 0.0001 significant level except $b_{3}$ for model 4 . All comparisons were conducted based on the parameters estimated in simultaneous approach. In addition, 
significant differences for parameter estimates were found by location (Appendix A,

Table A.1 and Table A.3).

Three methods were used to evaluate the models for various objectives:

(1) Model evaluation by overall fit statistics.

(2) Model evaluation by dbh classes.

(3) Model evaluation by relative height classes.

Table 3.1. Parameter estimates (standard errors in parentheses) for outside bark and inside bark taper and volume equations.

\begin{tabular}{|c|c|c|c|c|c|c|c|}
\hline Model & & $b_{1}$ & $b_{2}$ & $b_{3}$ & $b_{4}$ & $b_{5}$ & $b_{6}$ \\
\hline Model 1 & $\begin{array}{l}\text { Outside bark } \\
\text { Inside bark }\end{array}$ & $\begin{array}{l}-1.68577 \\
(0.0246) \\
-1.78619 \\
(0.0216)\end{array}$ & $\begin{array}{l}0.56232 \\
(0.0185) \\
0.64415 \\
(0.0161)\end{array}$ & & & & \\
\hline Model 2 & $\begin{array}{l}\text { Outside bark } \\
\text { Inside bark }\end{array}$ & $\begin{array}{c}-0.97291 \\
(0.0183) \\
-0.95075 \\
(0.017)\end{array}$ & $\begin{array}{l}0.79793 \\
(0.0123) \\
0.76452 \\
(0.0114)\end{array}$ & $\begin{array}{l}0.59762 \\
(0.0064) \\
0.60049 \\
(0.0062)\end{array}$ & $\begin{array}{l}0.01328 \\
(0.0009) \\
0.01367 \\
(0.0009)\end{array}$ & & \\
\hline Model 3 & $\begin{array}{l}\text { Outside bark } \\
\text { Inside bark }\end{array}$ & $\begin{array}{l}-3.94003 \\
(0.3008) \\
-4.00613 \\
(0.2669)\end{array}$ & $\begin{array}{l}1.88482 \\
(0.1697) \\
1.93203 \\
(0.1489)\end{array}$ & $\begin{array}{l}-2.15472 \\
(0.0552) \\
-1.99947 \\
(0.1376)\end{array}$ & $\begin{array}{c}305.75440 \\
(67.711) \\
551.42780 \\
(79.156)\end{array}$ & $\begin{array}{l}0.70872 \\
(0.0208) \\
0.73225 \\
(0.0178)\end{array}$ & $\begin{array}{l}0.04287 \\
(0.0036) \\
0.03459 \\
(0.0018)\end{array}$ \\
\hline Model 4 & $\begin{array}{l}\text { Outside bark } \\
\text { Inside bark }\end{array}$ & $\begin{array}{c}88.17554 \\
(10.824) \\
95.15853 \\
(7.9298)\end{array}$ & $\begin{array}{c}0.64367 \\
(0.0733) \\
0.82422 \\
(0.063)\end{array}$ & $\begin{array}{c}168.12480 \\
(78.152) \\
37.07814 \\
(41.658)\end{array}$ & $\begin{array}{l}13.74645 \\
(2.2039) \\
9.09707 \\
(1.3767)\end{array}$ & $\begin{array}{l}0.68363 \\
(0.0106) \\
0.67069 \\
(0.0084)\end{array}$ & $\begin{array}{c}2.18744 \\
(0.041) \\
2.02904 \\
(0.0274)\end{array}$ \\
\hline Model 5 & $\begin{array}{l}\text { Outside bark } \\
\text { Inside bark }\end{array}$ & $\begin{array}{c}85.66142 \\
(10.938) \\
94.29937 \\
(7.875)\end{array}$ & $\begin{array}{c}0.70325 \\
(0.0748) \\
0.84282 \\
(0.061)\end{array}$ & & $\begin{array}{l}13.75388 \\
(2.2062) \\
9.09716 \\
(1.3766)\end{array}$ & $\begin{array}{l}0.68349 \\
(0.0106) \\
0.67067 \\
(0.0084)\end{array}$ & $\begin{array}{c}2.18699 \\
(0.041) \\
2.02899 \\
(0.0274)\end{array}$ \\
\hline Model 6 & $\begin{array}{l}\text { Outside bark } \\
\text { Inside bark }\end{array}$ & $\begin{array}{c}120.84160 \\
(4.5035) \\
111.82100 \\
(3.2525)\end{array}$ & & & $\begin{array}{c}13.77969 \\
(2.2099) \\
9.10398 \\
(1.3768)\end{array}$ & $\begin{array}{l}0.68317 \\
(0.0107) \\
0.67041 \\
(0.0084)\end{array}$ & $\begin{array}{l}2.18604 \\
(0.0411) \\
2.02821 \\
(0.0274)\end{array}$ \\
\hline
\end{tabular}




\subsection{Model Evaluation by Overall Fit Statistics}

The performance of each model for describing tree taper was evaluated. In addition, the models were also evaluated in terms of volume prediction. Criteria used for model evaluation included average bias, standard errors of estimate (SEE), and $\mathrm{R}^{2}$. The model with the smallest average bias is considered best for predicting the variable of interest. However, it is possible that large positive and negative biases could cancel each other and result in a low average bias. Therefore, SEE was used to further evaluate the performance

of these models. The models with the lowest SEE were considered best. $\mathrm{R}^{2}$ indicates how much variation in the dependent variable can be explained by the independent variables.

The higher the $\mathrm{R}^{2}$, the better the model. The best model should have the highest $\mathrm{R}^{2}$ and the lowest average bias and SEE.

\subsubsection{Taper Functions}

For each compatible taper and volume equation, statistics of fit (average bias, SEE and $\mathrm{R}^{2}$ ) were calculated and are presented in Table 3.2 for both diameter outside bark and diameter inside bark. The average biases were positive for six models, which indicated that diameter was underestimated. The results indicate that model 4, model 5, and model 6 are superior to model 1, model 2 and model 3 in predicting diameter outside bark. However, no significant differences were noticed for model 4, model 5, and model 6. About $98 \%$ of the variation in outside bark taper was explained by these three models. Average biases were less than 0.2 inches for all six models. Average bias for model 4, model 5 , and model 6 were consistently less than 0.05 inches, which were significantly lower than model 1, model 2, and model 3. Similar results were obtained for diameter 
inside bark. Model 2 had higher SEE of 1.112 and 1.005 for outside bark diameter and inside bark diameter predictions, respectively. These statistics suggest that the segmented models (model 3, model 4, model 5, and model 6) were better than the simple model forms (model 1 and model 2). In addition, model 4, model 5, and model 6 were better than model 3 .

Table 3.2. Overall fit statistics for yellow-poplar taper models.

\begin{tabular}{ccccccccc}
\hline \hline \multirow{2}{*}{ Model } & \multicolumn{3}{c}{ Outside bark } & & \multicolumn{3}{c}{ Inside bark } \\
\cline { 2 - 4 } \cline { 7 - 8 } \cline { 6 - 8 } & Avg. Bias & SEE & $\mathrm{R}^{2}$ & & Avg. Bias & SEE & $\mathrm{R}^{2}$ \\
\hline Model 1 & 0.092 & 0.875 & 0.954 & & 0.157 & 0.763 & 0.958 \\
Model 2 & 0.078 & 1.112 & 0.925 & & 0.067 & 1.005 & 0.927 \\
Model 3 & 0.072 & 0.745 & 0.966 & & 0.143 & 0.641 & 0.970 \\
Model 4 & 0.016 & 0.624 & 0.976 & & 0.045 & 0.506 & 0.981 \\
Model 5 & 0.018 & 0.626 & 0.976 & & 0.045 & 0.506 & 0.981 \\
Model 6 & 0.023 & 0.628 & 0.976 & & 0.048 & 0.506 & 0.981 \\
\hline \hline
\end{tabular}

\subsubsection{Volume Prediction}

Statistics of fit (average bias, SEE and $\mathrm{R}^{2}$ ) are presented in Table 3.3 for volume outside bark and inside bark, respectively. Model 4, model 5, and model 6 explained more than $96 \%$ and $98 \%$ variation about taper models for predicting volumes outside and inside bark, respectively. All six models had average biases less than $0.1 \mathrm{ft}^{3}$ for both volume outside bark and volume inside bark. All models underestimated volume except model 1, which overestimated volume outside bark. Model 1 had the lowest average bias of all models for outside bark volume $(-0.003)$. One possible reason might be that large positive and negative biases cancelled each other resulting in a low average bias. 
Standard errors of estimate (SEE) for model 4 , model 5 , and model 6 were significantly lower than model 1, model 2, and model 3. The results indicate that model 4, model 5, and model 6 had the better overall prediction statistics for volume with lower average biases, SEE and higher $\mathrm{R}^{2}$. Model 4, model 5, and model 6 performed similarly in predicting volumes. The best three models (model 4, model 5, and model 6) for estimating outside and inside bark taper were also best for predicting outside and inside bark volumes. This would indicate that the best taper models provide the best predictive ability for volume.

Table 3.3. Overall fit statistics for yellow-poplar volume prediction models.

\begin{tabular}{ccccccccc}
\hline \multirow{2}{*}{ Model } & \multicolumn{3}{c}{ Outside bark } & & \multicolumn{3}{c}{ Inside bark } \\
\cline { 2 - 5 } \cline { 6 - 8 } & Avg. Bias & SEE & $\mathrm{R}^{2}$ & & Avg. Bias & SEE & $\mathrm{R}^{2}$ \\
\hline Model 1 & -0.003 & 0.468 & 0.927 & & 0.016 & 0.329 & 0.946 \\
Model 2 & 0.093 & 0.775 & 0.799 & & 0.076 & 0.630 & 0.802 \\
Model 3 & 0.019 & 0.393 & 0.949 & & 0.037 & 0.273 & 0.963 \\
Model 4 & 0.006 & 0.332 & 0.963 & & 0.011 & 0.178 & 0.984 \\
Model 5 & 0.006 & 0.332 & 0.963 & & 0.011 & 0.178 & 0.984 \\
Model 6 & 0.008 & 0.332 & 0.963 & & 0.012 & 0.178 & 0.984 \\
\hline \hline
\end{tabular}

In addition, statistics of fit were presented for taper and volume outside and inside bark by location (Appendix A, Table A.2 and Table A.4).

\subsection{Model Evaluation by dbh Classes}

As we know, large trees possess more volume and value. However, it is impossible to determine the predictive abilities for diameter and volume by overall fit statistics for 
different tree sizes. Therefore, to evaluate the models' performance for different tree sizes, models were further evaluated by dbh classes. Four dbh classes were used for the model evaluation.

(1) $6<\mathrm{dbh} \leq 10$ inches.

(2) $10<\mathrm{dbh} \leq 14$ inches.

(3) $14<$ dbh $\leq 18$ inches.

(4) $18<\mathrm{dbh} \leq 23$ inches.

Average bias and standard error of the estimate (SEE) were calculated for diameter and volume prediction (both inside and outside bark) by dbh classes (Table 3.4). The six models were ranked in terms of average bias and SEE for estimating diameter outside bark, diameter inside bark, volume outside bark, and volume inside bark, respectively (Table 3.5). These ranks were also summed for each model. For predicting taper and volume of trees less than 10 inches dbh, model 4 gave the best results with the lowest sum of ranks while model 2 ranked the poorest with the highest sum of ranks. For trees with dbh between 10 and 14 inches, model 6 performed the best and then model 4 and model 5. Model 5 presented the best fitting results for both dbh class 14-18 inches and 18-23 inches. From the ranking results, the predictive ability of each model can be easily evaluated by different dbh classes.

\section{(a) Model 1}

Model 1 ranked fifth for all dbh classes (Table 3.5). It had the lowest bias for predicting diameter outside bark for the 10-14 and 18-23 inch dbh class. However, these results were not obtained for other diameter classes. This model only performed better than model 2 in terms of sum of ranks for all dbh classes. 
(b) Model 2

Model 2 ranked the poorest for all dbh classes (Table 3.5). It had the lowest bias for predicting diameter inside bark for the 10-14 inch dbh class. However, higher standard errors of the estimate were also found for this model.

(c) Model 3

Model 3 ranked fourth for all dbh classes (Table 3.5). It overestimated the inside bark and outside bark diameter and volume of the larger trees $(18<\mathrm{dbh} \leq 23)$ (Table 3.4). This model was superior to model 1 and model 2 in term of sum of ranks.

(d) Model 4

Model 4 performed very well for smaller trees less than 10 inches dbh. It ranked second for the 10-18 inch dbh class and third for the 18-23 inch dbh class. This model was superior to model 1 , model 2 , and model 3 for all dbh classes in terms of sum of ranks.

(e) Model 5 and Model 6

These two models were derived from model 4. Therefore, the general forms of these two models were similar to model 4 . Model 5 performed very well for the larger trees ranging from 14 to 23 inches dbh. However, model 6 performed very well for the 10-14 inch dbh class. 
Table 3.4. Bias and standard error of estimates by dbh classes for diameter and volume.

\begin{tabular}{|c|c|c|c|c|c|c|c|c|c|c|}
\hline \multirow{3}{*}{ Models } & \multirow{3}{*}{$\begin{array}{c}\text { DBH } \\
\text { Classes } \\
\text { (in.) }\end{array}$} & \multirow{3}{*}{$\mathrm{n}$} & \multicolumn{4}{|c|}{ Outside bark } & \multicolumn{4}{|c|}{ Inside bark } \\
\hline & & & \multicolumn{2}{|c|}{ Diameter (in.) } & \multicolumn{2}{|c|}{ Volume $\left(\mathrm{ft}^{3}\right)$} & \multicolumn{2}{|c|}{ Diameter (in.) } & \multicolumn{2}{|c|}{ Volume $\left(\mathrm{ft}^{3}\right)$} \\
\hline & & & Bias & SEE & Bias & SEE & Bias & SEE & Bias & SSE \\
\hline \multirow[t]{5}{*}{ model 1} & $6-10$ & 12 & 0.118 & 0.462 & 0.002 & 0.123 & 0.108 & 0.388 & 0.005 & 0.093 \\
\hline & $10-14$ & 15 & 0.004 & 0.855 & -0.030 & 0.313 & 0.230 & 0.560 & 0.047 & 0.173 \\
\hline & $14-18$ & 13 & 0.194 & 0.982 & 0.050 & 0.626 & 0.219 & 0.909 & 0.056 & 0.372 \\
\hline & $18-23$ & 4 & 0.000 & 1.256 & -0.091 & 0.754 & -0.181 & 1.331 & -0.196 & 0.725 \\
\hline & All & 44 & 0.092 & 0.875 & -0.003 & 0.468 & 0.157 & 0.763 & 0.016 & 0.329 \\
\hline \multirow[t]{5}{*}{ model 2} & $6-10$ & 12 & 0.145 & 0.673 & 0.139 & 0.294 & -0.005 & 0.570 & 0.085 & 0.227 \\
\hline & $10-14$ & 15 & -0.119 & 0.863 & 0.060 & 0.388 & -0.019 & 0.618 & 0.074 & 0.291 \\
\hline & $14-18$ & 13 & 0.158 & 1.417 & 0.079 & 1.115 & 0.151 & 1.320 & 0.070 & 0.888 \\
\hline & $18-23$ & 4 & 0.340 & 1.547 & 0.147 & 1.160 & 0.259 & 1.590 & 0.077 & 1.031 \\
\hline & All & 44 & 0.078 & 1.112 & 0.093 & 0.775 & 0.067 & 1.005 & 0.076 & 0.630 \\
\hline \multirow[t]{5}{*}{ model 3} & $6-10$ & 12 & 0.088 & 0.399 & 0.011 & 0.103 & 0.088 & 0.329 & 0.013 & 0.076 \\
\hline & $10-14$ & 15 & -0.024 & 0.736 & -0.012 & 0.259 & 0.210 & 0.391 & 0.063 & 0.129 \\
\hline & $14-18$ & 13 & 0.194 & 0.846 & 0.077 & 0.557 & 0.219 & 0.796 & 0.082 & 0.331 \\
\hline & $18-23$ & 4 & -0.035 & 1.042 & -0.039 & 0.553 & -0.210 & 1.168 & -0.142 & 0.580 \\
\hline & All & 44 & 0.072 & 0.745 & 0.019 & 0.393 & 0.143 & 0.641 & 0.037 & 0.273 \\
\hline \multirow[t]{5}{*}{ model 4} & $6-10$ & 12 & 0.005 & 0.294 & -0.001 & 0.071 & -0.001 & 0.263 & -0.003 & 0.053 \\
\hline & $10-14$ & 15 & -0.030 & 0.525 & -0.009 & 0.127 & 0.053 & 0.280 & 0.011 & 0.070 \\
\hline & $14-18$ & 13 & 0.070 & 0.726 & 0.019 & 0.499 & 0.087 & 0.642 & 0.023 & 0.223 \\
\hline & $18-23$ & 4 & 0.027 & 1.055 & 0.031 & 0.499 & -0.014 & 0.918 & 0.007 & 0.375 \\
\hline & All & 44 & 0.016 & 0.624 & 0.006 & 0.332 & 0.045 & 0.506 & 0.011 & 0.178 \\
\hline \multirow[t]{5}{*}{ model 5} & $6-10$ & 12 & 0.025 & 0.303 & 0.000 & 0.071 & 0.004 & 0.263 & -0.003 & 0.053 \\
\hline & $10-14$ & 15 & -0.028 & 0.527 & -0.009 & 0.127 & 0.053 & 0.280 & 0.011 & 0.070 \\
\hline & $14-18$ & 13 & 0.064 & 0.726 & 0.018 & 0.499 & 0.085 & 0.641 & 0.023 & 0.223 \\
\hline & $18-23$ & 4 & 0.013 & 1.052 & 0.029 & 0.497 & -0.018 & 0.916 & 0.006 & 0.374 \\
\hline & All & 44 & 0.018 & 0.626 & 0.006 & 0.332 & 0.045 & 0.506 & 0.011 & 0.178 \\
\hline \multirow[t]{5}{*}{ model 6} & $6-10$ & 12 & 0.030 & 0.307 & 0.002 & 0.071 & 0.006 & 0.263 & -0.002 & 0.053 \\
\hline & $10-14$ & 15 & -0.022 & 0.516 & -0.007 & 0.126 & 0.057 & 0.277 & 0.012 & 0.070 \\
\hline & $14-18$ & 13 & 0.068 & 0.735 & 0.021 & 0.498 & 0.088 & 0.644 & 0.024 & 0.222 \\
\hline & $18-23$ & 4 & 0.015 & 1.056 & 0.033 & 0.496 & -0.016 & 0.913 & 0.008 & 0.372 \\
\hline & All & 44 & 0.023 & 0.628 & 0.008 & 0.332 & 0.048 & 0.506 & 0.012 & 0.178 \\
\hline
\end{tabular}

Note: The All for bias and SEE are calculated as overall mean. The dbh intervals are left-side excluded. For example: $10-14$ means $10<\mathrm{dbh} \leq 14$. 
Table 3.5. Rankings of the five models by dbh classes for diameter and volume prediction.

\begin{tabular}{|c|c|c|c|c|c|c|c|c|c|c|}
\hline \multirow{3}{*}{$\begin{array}{c}\text { DBH } \\
\text { (in.) }\end{array}$} & \multirow{3}{*}{ Models } & \multicolumn{4}{|c|}{ Outside bark } & \multicolumn{4}{|c|}{ Inside bark } & \multirow{3}{*}{ Sum } \\
\hline & & \multicolumn{2}{|c|}{$\begin{array}{l}\text { Diameter } \\
\text { (in.) }\end{array}$} & \multicolumn{2}{|c|}{$\begin{array}{c}\text { Volume } \\
\left(\mathrm{ft}^{3}\right)\end{array}$} & \multicolumn{2}{|c|}{$\begin{array}{l}\text { Diameter } \\
\text { (in.) }\end{array}$} & \multicolumn{2}{|c|}{$\begin{array}{c}\text { Volume } \\
\left(\mathrm{ft}^{3}\right)\end{array}$} & \\
\hline & & Bias & SEE & Bias & SEE & Bias & SEE & Bias & SEE & \\
\hline \multirow[t]{6}{*}{$6-10$} & model 1 & 5 & 5 & 3 & 3 & 6 & 3 & 3 & 3 & 31 \\
\hline & model 2 & 6 & 6 & 5 & 4 & 3 & 4 & 5 & 4 & 37 \\
\hline & model 3 & 4 & 4 & 4 & 2 & 5 & 2 & 4 & 2 & 27 \\
\hline & model 4 & 1 & 1 & 2 & 1 & 1 & 1 & 2 & 1 & 10 \\
\hline & model 5 & 2 & 2 & 1 & 1 & 2 & 1 & 2 & 1 & 12 \\
\hline & model 6 & 3 & 3 & 3 & 1 & 4 & 1 & 1 & 1 & 17 \\
\hline \multirow[t]{6}{*}{$10-14$} & model 1 & 1 & 5 & 4 & 4 & 5 & 4 & 3 & 3 & 29 \\
\hline & model 2 & 6 & 6 & 5 & 5 & 1 & 5 & 5 & 4 & 37 \\
\hline & model 3 & 3 & 4 & 3 & 3 & 4 & 3 & 4 & 2 & 26 \\
\hline & model 4 & 5 & 2 & 2 & 2 & 2 & 2 & 1 & 1 & 17 \\
\hline & model 5 & 4 & 3 & 2 & 2 & 2 & 2 & 1 & 1 & 17 \\
\hline & model 6 & 2 & 1 & 1 & 1 & 3 & 1 & 2 & 1 & 12 \\
\hline \multirow[t]{6}{*}{$14-18$} & model 1 & 4 & 4 & 4 & 4 & 5 & 5 & 3 & 4 & 33 \\
\hline & model 2 & 5 & 5 & 6 & 5 & 4 & 6 & 4 & 5 & 40 \\
\hline & model 3 & 4 & 3 & 5 & 3 & 5 & 4 & 5 & 3 & 32 \\
\hline & model 4 & 3 & 1 & 2 & 2 & 2 & 2 & 1 & 2 & 15 \\
\hline & model 5 & 1 & 1 & 1 & 2 & 1 & 1 & 1 & 2 & 10 \\
\hline & model 6 & 2 & 2 & 3 & 1 & 3 & 3 & 2 & 1 & 17 \\
\hline \multirow[t]{6}{*}{$18-23$} & model 1 & 1 & 5 & 5 & 5 & 4 & 5 & 6 & 5 & 36 \\
\hline & model 2 & 6 & 6 & 6 & 6 & 6 & 6 & 4 & 6 & 46 \\
\hline & model 3 & 5 & 1 & 4 & 4 & 5 & 4 & 5 & 4 & 32 \\
\hline & model 4 & 4 & 3 & 2 & 3 & 1 & 3 & 2 & 3 & 21 \\
\hline & model 5 & 2 & 2 & 1 & 2 & 3 & 2 & 1 & 2 & 15 \\
\hline & model 6 & 3 & 4 & 3 & 1 & 2 & 1 & 3 & 1 & 18 \\
\hline
\end{tabular}




\subsection{Model Evaluation by Relative Height Classes}

Using average bias, $\mathrm{SEE}$, and $\mathrm{R}^{2}$, overall comparison can show the effectiveness of each model for predicting diameter and volume. However, the model performance in describing the stem for different sections can not be obtained. Therefore, models can be further evaluated by relative height classes $(10 \%, 20 \%, 30 \%, \cdots, 90 \%)$. Since stem analysis was stopped at a 2-inch top diameter and few measurements in the top sections were over 90 percent of total height, the data were split into nine relative height classes. Average bias and SEE were calculated for each model at different sections by relative height ( $10 \%$ interval) along the stem. Bias and SEE were evaluated at nine relative height classes for outside and inside bark taper and volume estimates (Table 3.6).

Table 3.6. Bias and standard error of estimates by relative height $(\mathrm{RH})$ for diameter and volume.

\begin{tabular}{|c|c|c|c|c|c|c|c|c|c|c|}
\hline \multirow{3}{*}{ Models } & \multirow{3}{*}{$\mathrm{RH}$} & \multirow{3}{*}{$\mathrm{n}$} & \multicolumn{4}{|c|}{ Outside bark } & \multicolumn{4}{|c|}{ Inside bark } \\
\hline & & & \multicolumn{2}{|c|}{ Diameter (in.) } & \multicolumn{2}{|c|}{ Volume $\left(\mathrm{ft}^{3}\right)$} & \multicolumn{2}{|c|}{ Diameter (in.) } & \multicolumn{2}{|c|}{ Volume $\left(\mathrm{ft}^{3}\right)$} \\
\hline & & & Bias & SEE & Bias & SEE & Bias & SEE & Bias & SEE \\
\hline \multirow[t]{10}{*}{ model 1} & $0.0-0.1$ & 185 & 0.044 & 1.048 & -0.158 & 0.407 & 0.061 & 0.823 & -0.106 & 0.271 \\
\hline & $0.1-0.2$ & 111 & -0.400 & 0.709 & -0.237 & 0.503 & -0.272 & 0.549 & -0.122 & 0.342 \\
\hline & $0.2-0.3$ & 94 & -0.059 & 0.604 & -0.012 & 0.342 & 0.057 & 0.485 & 0.044 & 0.283 \\
\hline & $0.3-0.4$ & 100 & 0.247 & 0.612 & 0.162 & 0.318 & 0.304 & 0.537 & 0.144 & 0.249 \\
\hline & $0.4-0.5$ & 99 & 0.478 & 0.737 & 0.272 & 0.449 & 0.483 & 0.655 & 0.211 & 0.319 \\
\hline & $0.5-0.6$ & 101 & 0.484 & 0.828 & 0.215 & 0.595 & 0.504 & 0.800 & 0.140 & 0.383 \\
\hline & $0.6-0.7$ & 100 & 0.307 & 1.023 & 0.092 & 0.537 & 0.366 & 0.998 & 0.075 & 0.373 \\
\hline & $0.7-0.8$ & 84 & -0.143 & 0.985 & -0.148 & 0.608 & 0.000 & 0.908 & -0.103 & 0.454 \\
\hline & $0.8-0.9$ & 36 & -0.514 & 1.226 & -0.218 & 0.400 & -0.360 & 1.062 & -0.144 & 0.295 \\
\hline & All & 910 & 0.092 & 0.875 & -0.003 & 0.468 & 0.157 & 0.763 & 0.016 & 0.329 \\
\hline \multirow{10}{*}{ model 2} & $0.0-0.1$ & 185 & 0.544 & 1.439 & 0.278 & 0.656 & 0.529 & 1.290 & 0.270 & 0.534 \\
\hline & $0.1-0.2$ & 111 & -0.141 & 0.925 & 0.241 & 0.805 & -0.064 & 0.793 & 0.269 & 0.658 \\
\hline & $0.2-0.3$ & 94 & -0.022 & 0.898 & 0.223 & 0.866 & 0.038 & 0.811 & 0.225 & 0.745 \\
\hline & $0.3-0.4$ & 100 & 0.132 & 0.837 & 0.243 & 0.642 & 0.116 & 0.735 & 0.184 & 0.529 \\
\hline & $0.4-0.5$ & 99 & 0.235 & 0.838 & 0.208 & 0.610 & 0.156 & 0.752 & 0.125 & 0.481 \\
\hline & $0.5-0.6$ & 101 & 0.160 & 0.910 & 0.039 & 1.017 & 0.076 & 0.833 & -0.043 & 0.802 \\
\hline & $0.6-0.7$ & 100 & -0.008 & 1.154 & -0.088 & 0.742 & -0.069 & 1.078 & -0.114 & 0.573 \\
\hline & $0.7-0.8$ & 84 & -0.477 & 1.269 & -0.429 & 0.976 & -0.459 & 1.174 & -0.379 & 0.806 \\
\hline & $0.8-0.9$ & 36 & -0.791 & 1.562 & -0.491 & 0.715 & -0.753 & 1.434 & -0.404 & 0.584 \\
\hline & All & 910 & 0.078 & 1.112 & 0.093 & 0.775 & 0.067 & 1.005 & 0.076 & 0.630 \\
\hline
\end{tabular}




\begin{tabular}{|c|c|c|c|c|c|c|c|c|c|c|}
\hline \multirow[t]{10}{*}{ model 3} & $0.0-0.1$ & 185 & 0.113 & 0.762 & 0.007 & 0.308 & 0.130 & 0.467 & 0.032 & 0.154 \\
\hline & $0.1-0.2$ & 111 & -0.042 & 0.570 & -0.083 & 0.432 & 0.047 & 0.443 & 0.006 & 0.282 \\
\hline & $0.2-0.3$ & 94 & -0.038 & 0.598 & -0.033 & 0.347 & 0.108 & 0.490 & 0.046 & 0.287 \\
\hline & $0.3-0.4$ & 100 & 0.018 & 0.542 & 0.030 & 0.256 & 0.149 & 0.468 & 0.061 & 0.218 \\
\hline & $0.4-0.5$ & 99 & 0.101 & 0.529 & 0.099 & 0.315 & 0.194 & 0.464 & 0.091 & 0.226 \\
\hline & $0.5-0.6$ & 101 & 0.091 & 0.668 & 0.074 & 0.580 & 0.179 & 0.658 & 0.035 & 0.391 \\
\hline & $0.6-0.7$ & 100 & 0.103 & 0.981 & 0.065 & 0.493 & 0.154 & 0.951 & 0.040 & 0.345 \\
\hline & $0.7-0.8$ & 84 & 0.106 & 0.969 & 0.014 & 0.461 & 0.131 & 0.907 & -0.003 & 0.343 \\
\hline & $0.8-0.9$ & 36 & 0.152 & 1.124 & -0.002 & 0.262 & 0.158 & 1.018 & 0.007 & 0.211 \\
\hline & All & 910 & 0.072 & 0.745 & 0.019 & 0.393 & 0.143 & 0.641 & 0.037 & 0.273 \\
\hline \multirow[t]{10}{*}{ model 4} & $0.0-0.1$ & 185 & -0.069 & 0.726 & -0.035 & 0.294 & -0.014 & 0.410 & -0.004 & 0.096 \\
\hline & $0.1-0.2$ & 111 & 0.074 & 0.215 & -0.033 & 0.333 & 0.047 & 0.139 & 0.012 & 0.057 \\
\hline & $0.2-0.3$ & 94 & -0.039 & 0.211 & -0.042 & 0.176 & -0.010 & 0.187 & -0.005 & 0.102 \\
\hline & $0.3-0.4$ & 100 & -0.023 & 0.228 & 0.008 & 0.144 & -0.016 & 0.213 & 0.002 & 0.097 \\
\hline & $0.4-0.5$ & 99 & 0.013 & 0.263 & 0.046 & 0.206 & 0.027 & 0.242 & 0.029 & 0.114 \\
\hline & $0.5-0.6$ & 101 & -0.014 & 0.530 & 0.036 & 0.530 & 0.007 & 0.453 & -0.010 & 0.299 \\
\hline & $0.6-0.7$ & 100 & -0.035 & 0.906 & 0.027 & 0.460 & 0.027 & 0.782 & 0.020 & 0.280 \\
\hline & $0.7-0.8$ & 84 & 0.090 & 0.875 & 0.052 & 0.408 & 0.162 & 0.777 & 0.037 & 0.266 \\
\hline & $0.8-0.9$ & 36 & 0.347 & 1.101 & 0.072 & 0.245 & 0.359 & 1.011 & 0.064 & 0.204 \\
\hline & All & 910 & 0.016 & 0.624 & 0.006 & 0.332 & 0.045 & 0.506 & 0.011 & 0.178 \\
\hline \multirow[t]{10}{*}{ model 5} & $0.0-0.1$ & 185 & -0.059 & 0.731 & -0.036 & 0.294 & -0.012 & 0.411 & -0.004 & 0.097 \\
\hline & $0.1-0.2$ & 111 & 0.074 & 0.215 & -0.033 & 0.333 & 0.047 & 0.139 & 0.012 & 0.056 \\
\hline & $0.2-0.3$ & 94 & -0.039 & 0.211 & -0.042 & 0.176 & -0.010 & 0.187 & -0.005 & 0.102 \\
\hline & $0.3-0.4$ & 100 & -0.024 & 0.227 & 0.007 & 0.143 & -0.016 & 0.213 & 0.002 & 0.097 \\
\hline & $0.4-0.5$ & 99 & 0.012 & 0.262 & 0.046 & 0.206 & 0.027 & 0.241 & 0.029 & 0.114 \\
\hline & $0.5-0.6$ & 101 & -0.014 & 0.528 & 0.036 & 0.529 & 0.007 & 0.452 & -0.010 & 0.298 \\
\hline & $0.6-0.7$ & 100 & -0.035 & 0.904 & 0.027 & 0.458 & 0.027 & 0.780 & 0.020 & 0.279 \\
\hline & $0.7-0.8$ & 84 & 0.090 & 0.872 & 0.053 & 0.406 & 0.162 & 0.775 & 0.037 & 0.265 \\
\hline & $0.8-0.9$ & 36 & 0.348 & 1.093 & 0.072 & 0.243 & 0.360 & 1.003 & 0.064 & 0.202 \\
\hline & All & 910 & 0.018 & 0.626 & 0.006 & 0.332 & 0.045 & 0.506 & 0.011 & 0.178 \\
\hline \multirow[t]{10}{*}{ model 6} & $0.0-0.1$ & 185 & -0.035 & 0.740 & -0.025 & 0.291 & 0.002 & 0.415 & 0.001 & 0.095 \\
\hline & $0.1-0.2$ & 111 & 0.075 & 0.214 & -0.033 & 0.332 & 0.047 & 0.139 & 0.012 & 0.056 \\
\hline & $0.2-0.3$ & 94 & -0.039 & 0.210 & -0.042 & 0.175 & -0.010 & 0.186 & -0.005 & 0.101 \\
\hline & $0.3-0.4$ & 100 & -0.024 & 0.226 & 0.007 & 0.143 & -0.016 & 0.212 & 0.002 & 0.097 \\
\hline & $0.4-0.5$ & 99 & 0.012 & 0.261 & 0.046 & 0.205 & 0.027 & 0.241 & 0.029 & 0.113 \\
\hline & $0.5-0.6$ & 101 & -0.014 & 0.527 & 0.036 & 0.527 & 0.007 & 0.451 & -0.010 & 0.297 \\
\hline & $0.6-0.7$ & 100 & -0.035 & 0.901 & 0.027 & 0.457 & 0.027 & 0.778 & 0.020 & 0.278 \\
\hline & $0.7-0.8$ & 84 & 0.091 & 0.870 & 0.053 & 0.405 & 0.162 & 0.773 & 0.037 & 0.264 \\
\hline & $0.8-0.9$ & 36 & 0.348 & 1.085 & 0.072 & 0.242 & 0.360 & 0.996 & 0.065 & 0.201 \\
\hline & All & 910 & 0.023 & 0.628 & 0.008 & 0.332 & 0.048 & 0.506 & 0.012 & 0.178 \\
\hline
\end{tabular}

Note: the All for bias and SEE are calculated as overall mean. The relative height (RH) intervals are left-side excluded. For example: $0.3-0.4$ means $0.3<\mathrm{RH} \leq 0.4$. 
To improve visual comparison of model performance for each section, Figure 3.13.4 were developed to display bias and SEE by relative height classes for both diameter and volume (outside and inside bark).

\subsubsection{Comparison of Taper Functions}

Model 4, model 5, and model 6 displayed similar bias trends for all stem sections (Figure 3.1). Bias ranged between -0.07 and 0.09 inch below 80 percent of total height for these three models (Table 3.6). The standard errors of the estimate for the three models were lower than other models tested. Even though the three models did not perform as well for the top sections ( $80-90 \%$ of total height), they performed very well for the sections below 80 percent of total height. Within this range, the three models performed similarly. Model 3 performed better than model 1 or model 2 for most sections. Although model 1 and model 2 had low bias at some sections (0-0.1, 0.2-0.3 and 0.6-0.7), the standard errors of estimates were still higher. A lower bias cannot guarantee good performance of the model because large positive and negative biases may cancel each other. Model 1 and model 2 performed poorly for most sections. For relative heights between $0-10 \%$ and 50-90 \%, all models showed larger standard errors of estimate than at other height intervals. This may be caused by the large variation for butt and upper sections of the yellow-poplar trees tested.

For predicting diameter inside bark, similar results were obtained (Figure 3.2). Model 4, model 5, and model 6 had lower bias and SEE than other models for most sections. The predictive abilities of models 4,5 , and 6 were very similar in terms of predicting diameter inside bark. 


\section{Diameter Outside Bark}
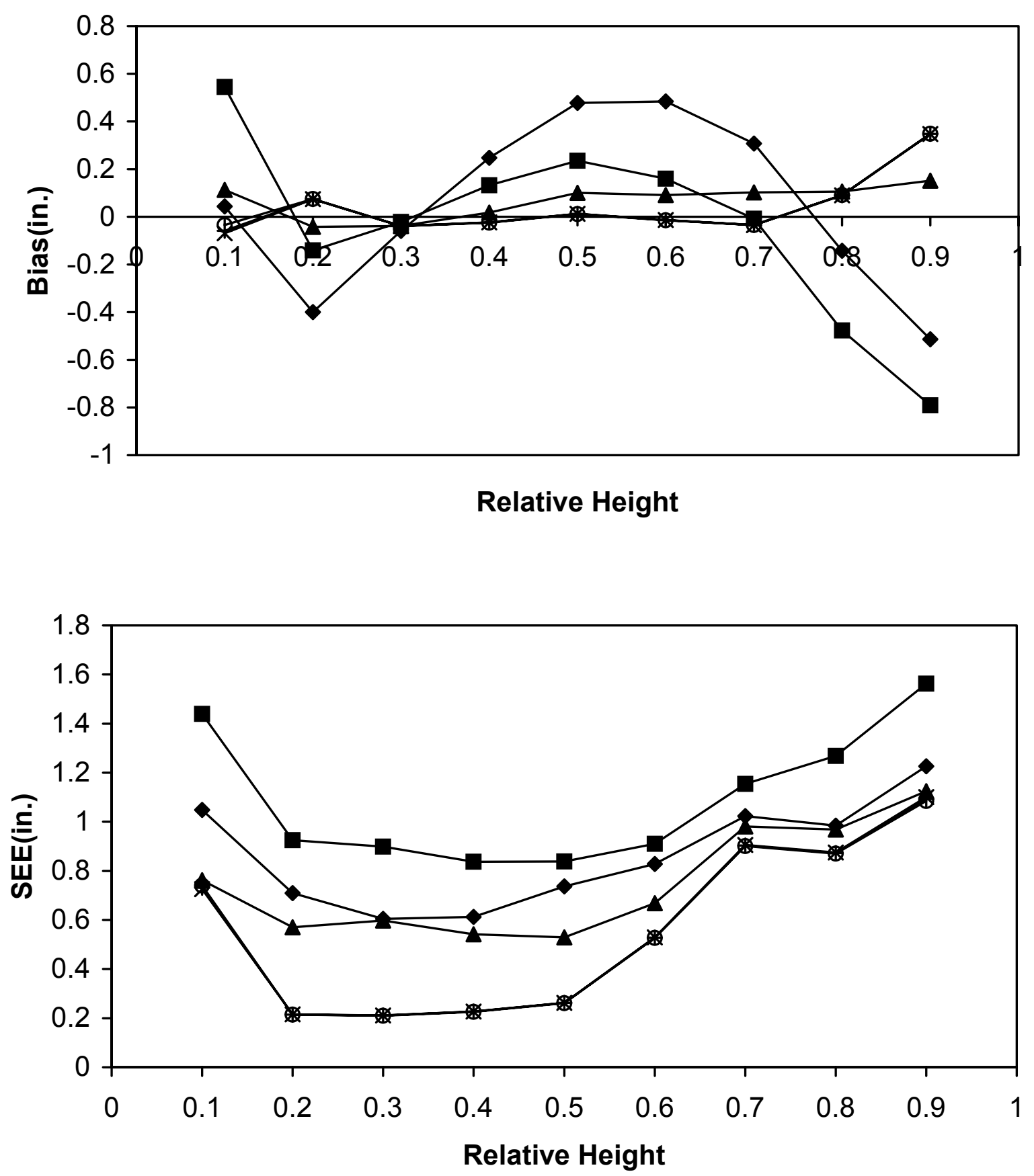

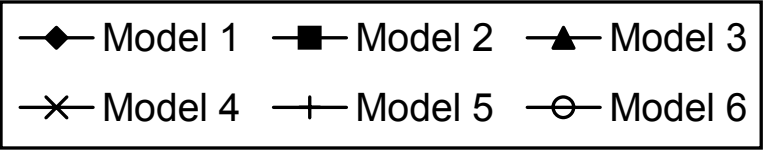

Figure 3.1. Average bias and standard errors of estimate (SEE) for predicting diameter outside bark along the stem by relative height classes. 


\section{Diameter Inside Bark}

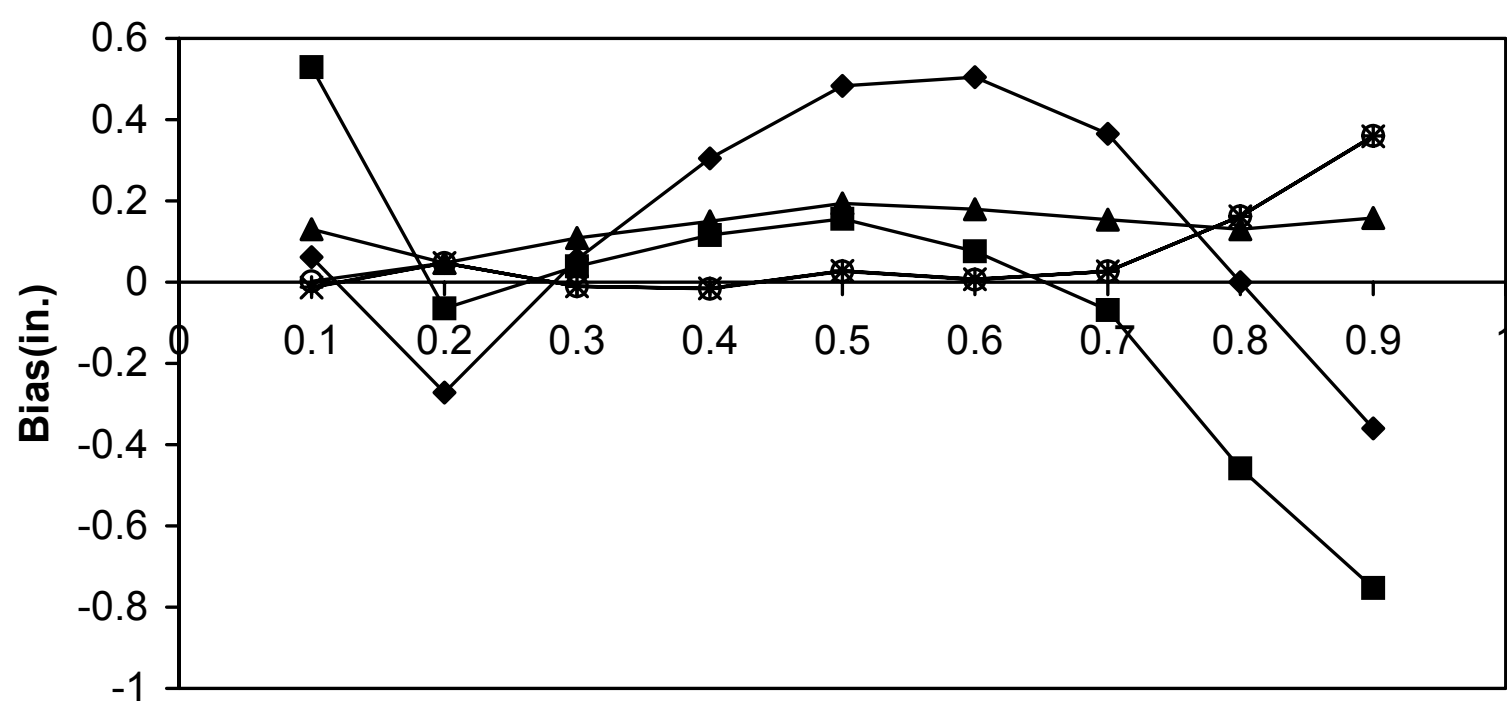

Relative Height

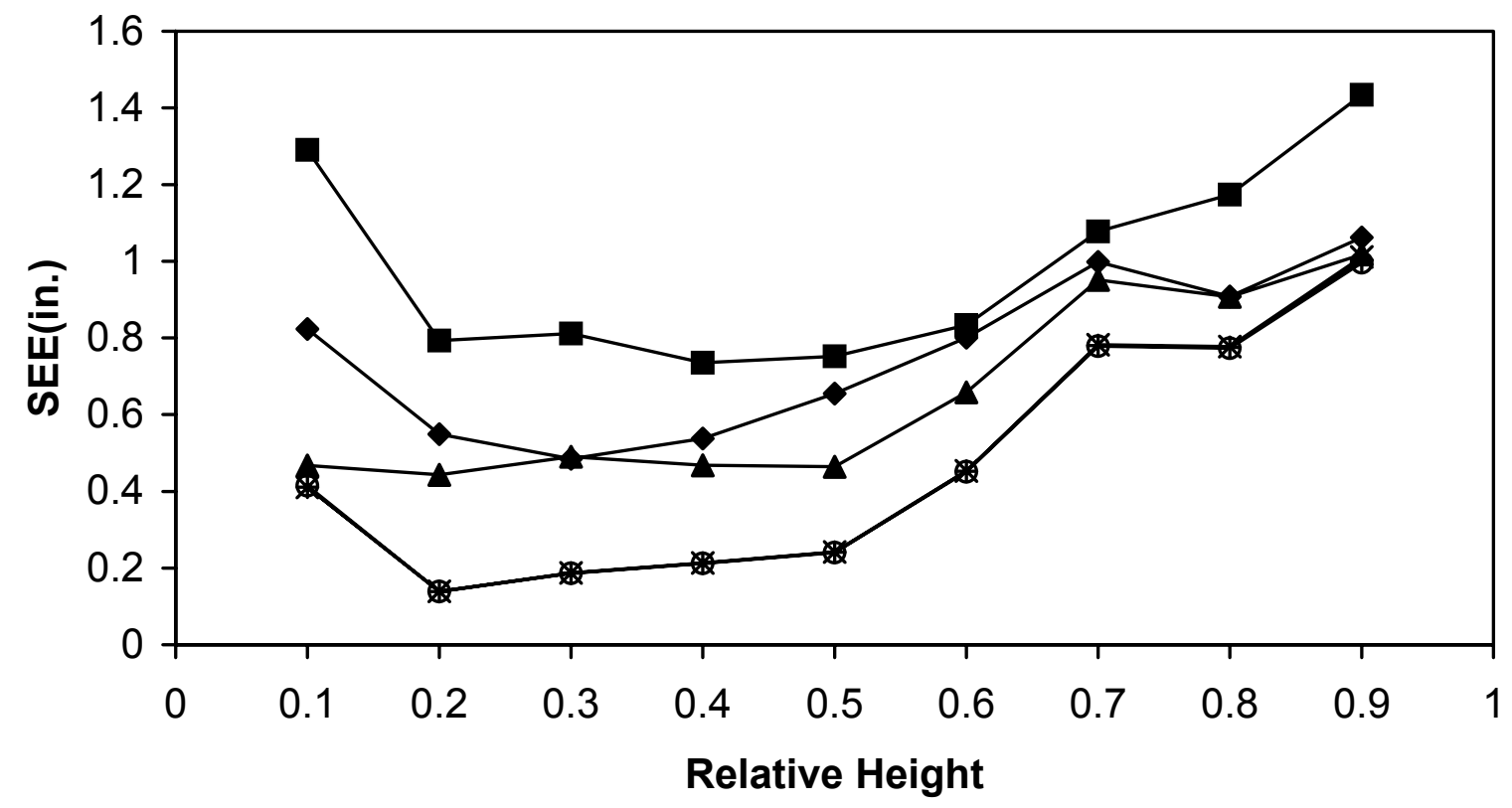

$$
\begin{array}{ccc}
\leftarrow \text { Model } 1 & \rightarrow-\text { Model } 2 & \leftarrow \text { Model } 3 \\
\leftarrow \text { Model } 4 & \rightarrow \text { Model } 5 \rightarrow-\text { Model } 6
\end{array}
$$

Figure 3.2. Average bias and standard errors of estimate (SEE) for predicting diameter inside bark along the stem by relative height classes. 


\subsubsection{Comparison of Volume Prediction}

In the sectional performance test for volume prediction outside bark (Figure 3.3), the best three models (model 4, model 5, and model 6) for estimating diameter outside bark also had similar performance in predicting volumes outside bark. These three models performed well for predicting volume, having lower bias and SEE. The biases were between -0.04 and 0.07 inch below 90 percent of total height (Table 3.6). They tended to overestimate volume below 30 percent of total height and underestimated volume above 30 percent of total height. Model 1 and model 2 generally possessed greater bias for all relative height classes. Model 3 was better than model 1 and model 2 for most sections. Segmented models gave more accurate prediction for outside bark volume. For relative heights between $50-60 \%$, all models showed larger standard errors of the estimate than at other height intervals. This coincides with point associated with the base of the live crown for yellow-poplar trees tested.

For predicting volume inside bark, model 4, model 5, and model 6 also showed good results with lower bias and SEE (Figure 3.4). These three models had an average bias between -0.005 and 0.065 inch below 90 percent of total height, while the bias of model 1 and model 2 ranged from -0.40 to 0.27 inch. Model 4, model 5, and model 6 were better than other models for predicting volume inside bark. Model 3 was better than model 1 and model 2 . 


\section{Volume Outside Bark}
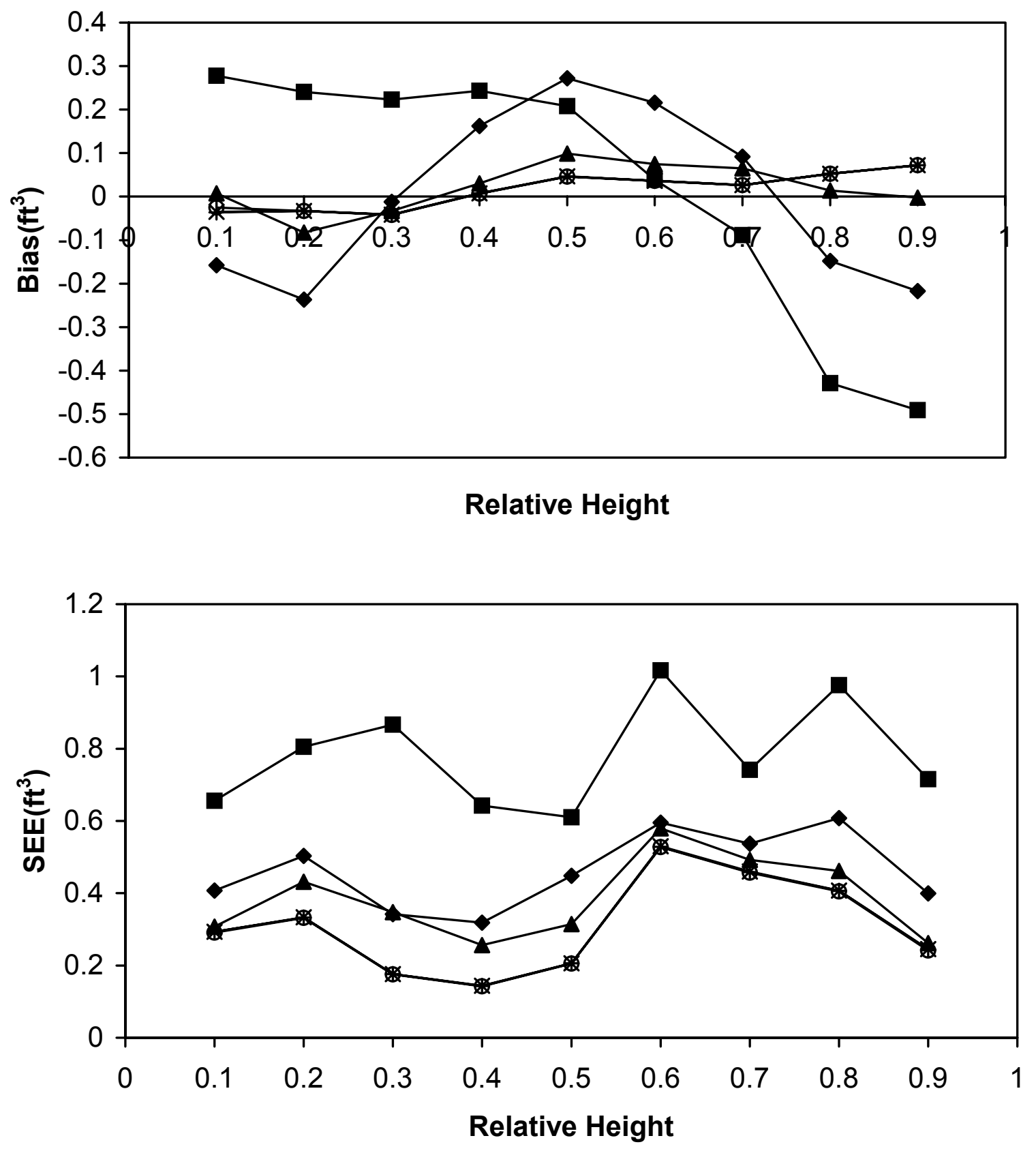

$$
\begin{array}{r}
\multimap \text { Model } 1-\text { Model } 2 \multimap \text { Model } 3 \\
\leftarrow \text { Model } 4 \rightarrow \text { Model } 5 \multimap-\text { Model } 6
\end{array}
$$

Figure 3.3. Average bias and standard errors of the estimate (SEE) for predicting volume outside bark along the stem by relative height classes. 


\section{Volume Inside bark}
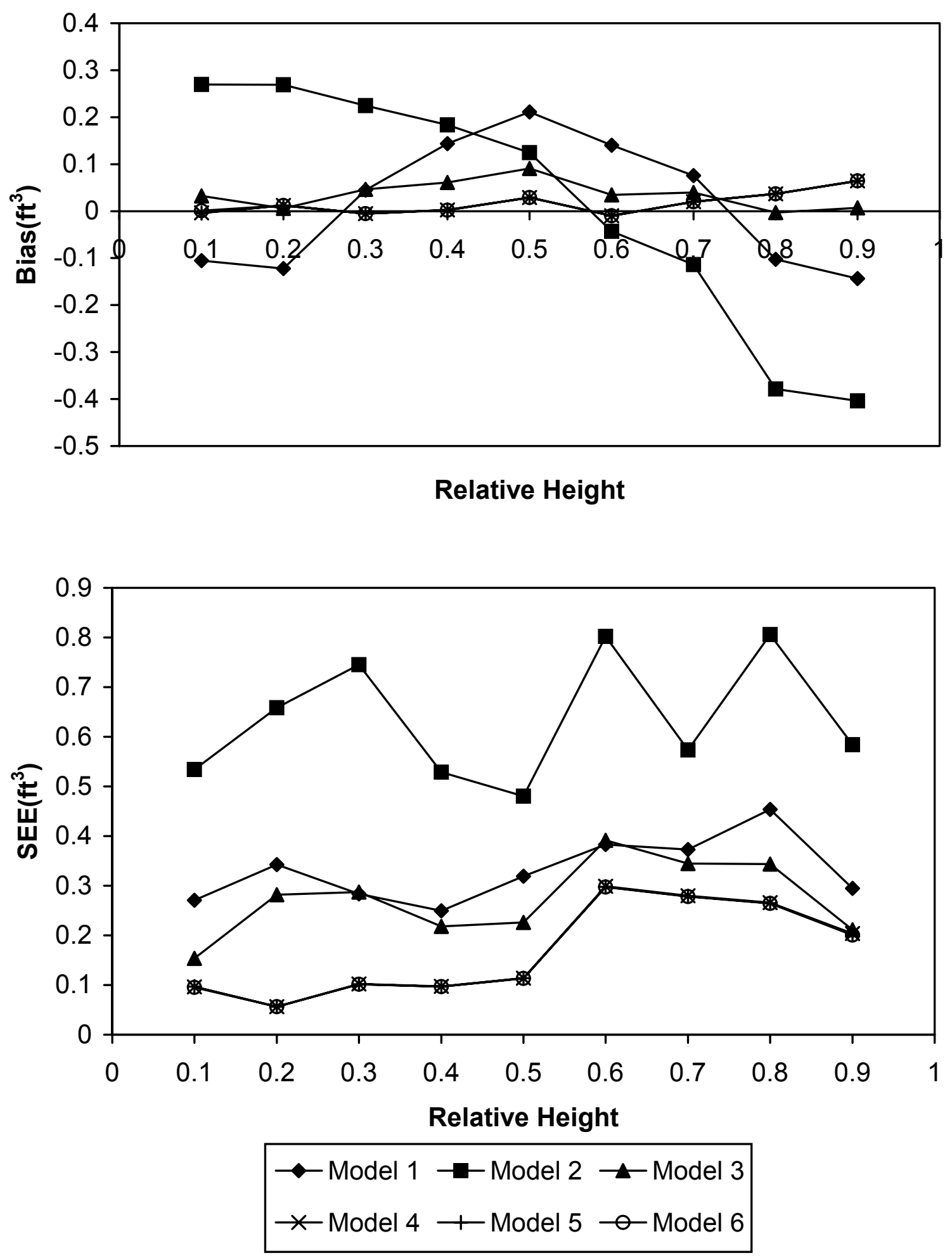

Figure 3.4. Average bias and standard errors of the estimate (SEE) for predicting volume inside bark along the stem by relative height classes. 


\subsection{Diameter Estimates at 4.5 Feet and 17.3 Feet}

Diameter for both outside bark and inside bark at 4.5 feet and 17.3 feet are

required for model 4 , model 5 , and model 6 in order to estimate diameter along stem and stem volume. However, diameter inside bark at 4.5 feet $\left(D_{i}\right)$ is not available in most

cases. This variable can be estimated from $\mathrm{DBH}$. The $D_{i}$ of all sample trees was plotted over DBH (Figure 3.5). As seen in Figure 3.5, $D_{i}$ is closely correlated with DBH. It also indicate that $D_{i}$ could be estimated from DBH using the following simple linear equation:

$$
D_{i}=b_{1}+b_{2}(D)
$$

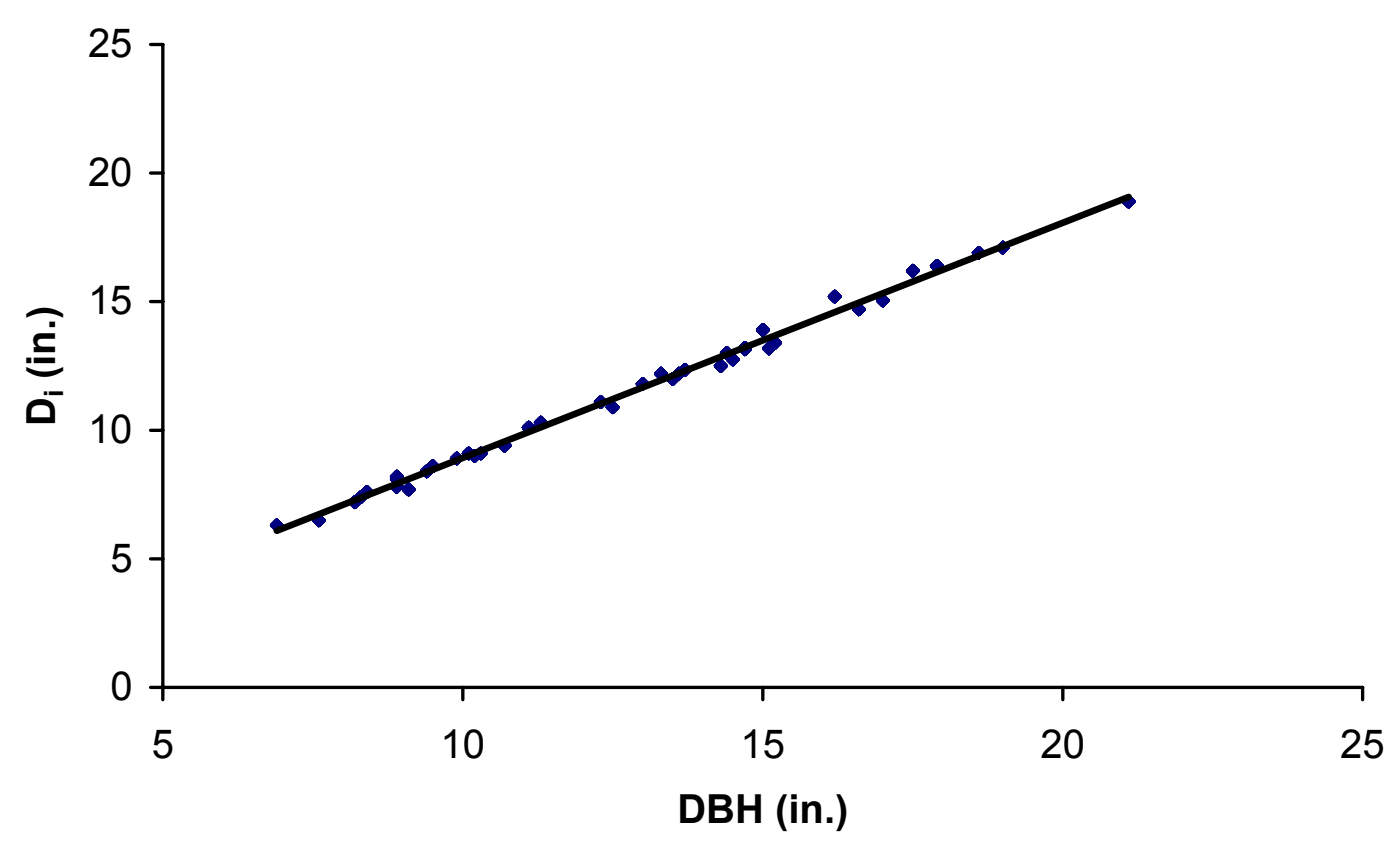

Figure 3.5. The relationship between diameter inside bark and DBH for all sample data 
It is also difficult to measure diameter outside and inside bark at 17.3 feet on standing trees. Clark et al. (1991) proposed the following equations to estimate diameter at 17.3 feet:

$$
\begin{aligned}
& F_{\text {dob17.3 }}=D\left(b_{1}+b_{2}\left(\frac{17.3}{H}\right)^{2}\right) \\
& F_{d i b 17.3}=D\left(b_{1}+b_{2}\left(\frac{17.3}{H}\right)^{2}\right)
\end{aligned}
$$

Where:

$$
\begin{aligned}
& F_{\text {dob17.3 }}=\text { diameter outside bark at } 17.3 \text { feet. } \\
& F_{\text {dib17.3 }}=\text { diameter inside bark at } 17.3 \text { feet. }
\end{aligned}
$$

Other variables as previously defined.

Equation 3.7, 3.8, and 3.9 were fitted to the sample data to obtain parameter estimates. Results of the fitting process are displayed in Table 3.7.

Table 3.7. Estimate of parameters for diameter at 4.5 and 17.3 feet.

\begin{tabular}{ccccccc}
\hline \hline Equations & Parameter & Estimate & Standard Error & $\mathrm{t}$ value & $\mathrm{p}>|\mathrm{t}|$ & $\mathrm{R}^{2}$ \\
\hline$(3.7)$ & $b_{1}$ & -0.5725 & 0.0674 & -8.5 & $<.0001$ & 0.976 \\
& $b_{2}$ & 0.9359 & 0.0049 & 191.13 & $<.0001$ & \\
& & & & & & \\
$(3.8)$ & $b_{1}$ & 0.9354 & 0.0056 & 168.62 & $<.0001$ & 0.973 \\
& $b_{2}$ & -1.2941 & 0.1649 & -7.85 & $<.0001$ & \\
& & & & & & \\
$(3.9)$ & $b_{1}$ & 0.9107 & 0.0048 & 189.49 & $<.0001$ & 0.980 \\
& $b_{2}$ & -0.3112 & 0.1434 & -2.17 & $<.0001$ & \\
\hline \hline
\end{tabular}

The parameters for Equation (3.7 through 3.9) were found to be statistically different by location. Location specific parameter estimates are displayed in Appendix A, Table A.5 and Table A.6. 
Diameter inside bark at 4.5 feet and both diameter outside and inside bark at 17.3 feet can be predicted by equation 3.7, 3.8, and 3.9, respectively. Instead of using the actual measurements, the predicted values can be used in models 4, 5, and 6. Although the predictive accuracy of the three models decreased slightly, the results were still better than model 3 (Table 3.8 and Table 3.9).

Table 3.8. Fit statistics for taper models using diameter predicted at 17.3 feet.

\begin{tabular}{cccccccc}
\hline \hline \multirow{2}{*}{ Model } & \multicolumn{3}{c}{ Outside bark } & & \multicolumn{3}{c}{ Inside bark } \\
\cline { 2 - 4 } \cline { 6 - 8 } \cline { 6 - 8 } & Avg. Bias & SEE & $\mathrm{R}^{2}$ & & Avg. Bias & SEE & $\mathrm{R}^{2}$ \\
\hline Model 3 & 0.072 & 0.745 & 0.966 & & 0.143 & 0.641 & 0.970 \\
Model 4 & 0.029 & 0.741 & 0.967 & & 0.087 & 0.618 & 0.972 \\
Model 5 & 0.031 & 0.742 & 0.966 & & 0.087 & 0.618 & 0.972 \\
Model 6 & 0.037 & 0.744 & 0.966 & & 0.090 & 0.618 & 0.972 \\
\hline \hline
\end{tabular}

Table 3.9. Fit statistics for taper models for volume prediction using diameter predicted at 17.3 feet.

\begin{tabular}{cccccccc}
\hline \hline \multirow{2}{*}{ Model } & \multicolumn{3}{c}{ Outside bark } & & \multicolumn{3}{c}{ Inside bark } \\
\cline { 2 - 4 } \cline { 6 - 8 } \cline { 6 - 8 } Model 3 & Avg. Bias & SEE & $\mathrm{R}^{2}$ & & Avg. Bias & SEE & $\mathrm{R}^{2}$ \\
\hline Model 4 & 0.019 & 0.393 & 0.949 & & 0.037 & 0.273 & 0.963 \\
Model 5 & 0.013 & 0.383 & 0.951 & & 0.027 & 0.253 & 0.968 \\
Model 6 & 0.013 & 0.383 & 0.951 & & 0.027 & 0.253 & 0.968 \\
\hline \hline
\end{tabular}

\subsection{Model Testing}

Model 4, 5, and 6 were validated by using independent dataset. Average bias and standard error of the estimate (SEE) were calculated for model 4, 5, and 6 for outside bark diameter prediction by relative height classes. The results showed that model 6 had 
lower bias and SEE than model 4 and 5 for relative height between 0-10\% (Appendix A, Table A.7). For relative height between $10 \%$ and $70 \%$, model 4, 5, and 6 showed similar results for estimating outside bark diameter.

To further analyze models 4,5 , and 6 , the shape of all sample trees could be considered. All data were plotted by relative diameter over relative height (Figure 3.6). This relationship shows that the relative diameter decreases with an increase in relative height. Relative diameters were much higher when relative height approached the butt section, while the relative diameter decreased rapidly at the top section. It also indicates that yellow-poplar possesses a large butt swell.

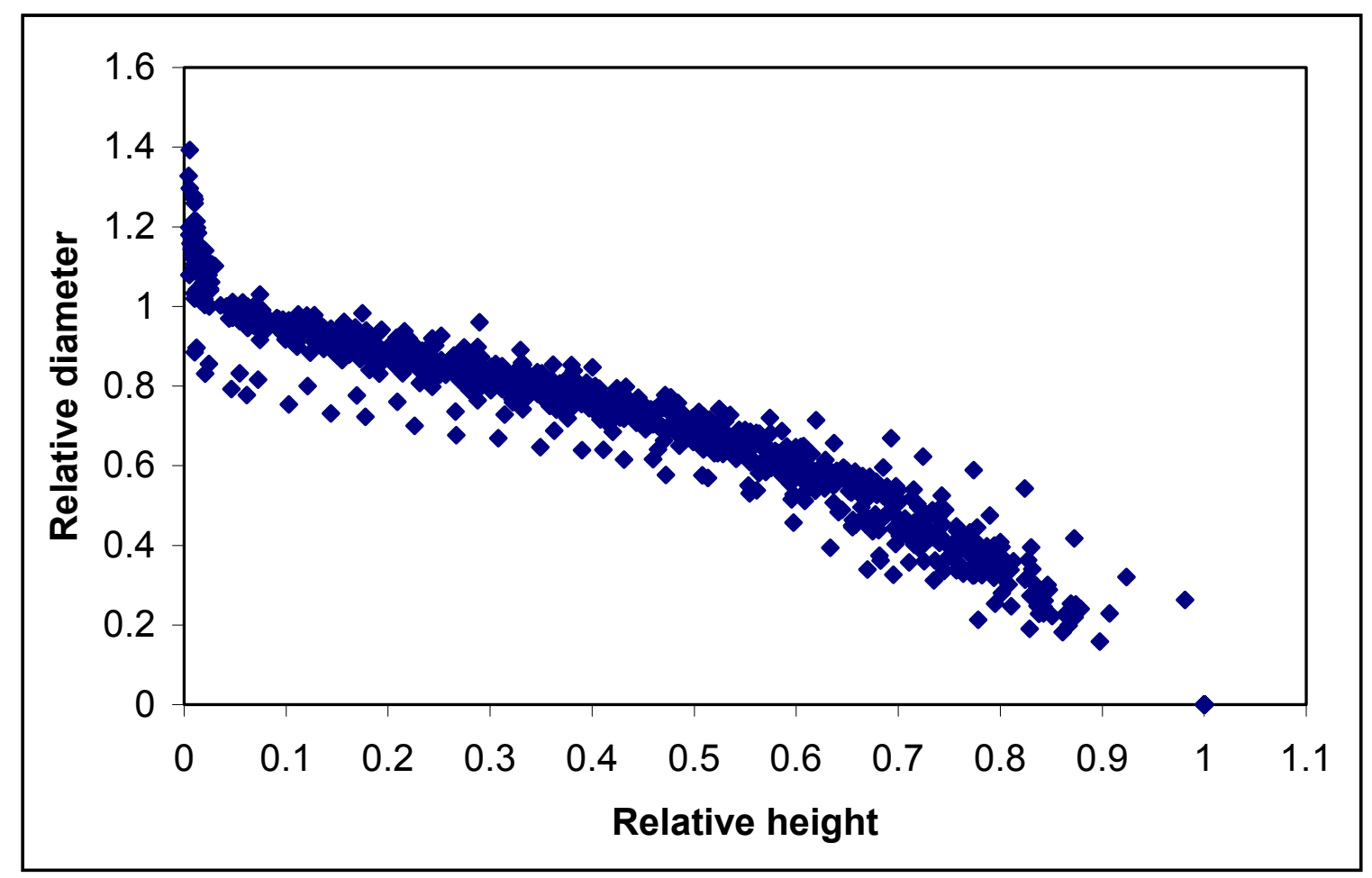

Figure 3.6. Relative diameter over relative height for all yellow-poplar trees.

The DBH of the sample trees ranged from 6.8 to 22.1 inches with a mean of 13.02 inches and a standard deviation of 3.73 inches. Total tree height was between 61.8 and 126.2 
feet with a mean and standard deviation of 92.21 feet and 11.95 feet, respectively. Greater insight can be obtained by plotting diameter and total height relationships. A number of taper curves were generated based on model 4, model 5, and model 6 for trees having different diameters or different total heights.

A series of taper curves were generated for trees having a total height of 90 feet and a DBH of $10,14,18$, and 22 inches based on model 4 , model 5 , and model 6 , respectively (Figure 3.7-Figure 3.9). The simulated curves exhibited the same trend as curves obtained from the sample data. At the same tree height, upper stem diameter decreased with decreasing DBH. It more than doubled at the butt section when DBH changed from 10 to 22 inches, while the difference were less when tree height was increased. The results from the diameter predicted by model 6 were higher than those predicted by model 4 and model 5 at butt sections. The values predicted for model 4 and model 5 were very similar.

Based on models 4, 5, and 6, taper curves were also generated for trees having the same DBH (13 inches) but having different total heights (70, 80, 90, and 100 feet) (Figure 3.10-3.12). Although total tree height varied from 70 to 100 feet, diameter estimates at the butt sections were all similar. These differences increased with increasing total height. Diameter predicted from model 4, model 5, and model 6 were very close above 10 feet, while diameters predicted from model 4 and model 5 were lower than the ones predicted using model 6 below 10 feet.

Figures 3.13-3.15 show the simulation results for model 4, model 5, and model 6 for trees having different total height and dbh. Four total height and dbh groups were used for the simulation: 
Group 1- trees of 10 inches dbh and 70 feet total height.

Group 2- trees of 14 inches dbh and 80 feet total height.

Group 3- trees of 18 inches dbh and 90 feet total height.

Group 4- trees of 22 inches dbh and 100 feet total height.

The simulation results were similar to the trees with same dbh or trees with same total height. The diameters predicted were lower for trees in group 1, and increased when moved to group 2, group 3, and group 4. Model 6 still gave the higher diameter prediction than model 5 and model 6 at butt sections below 10 feet.

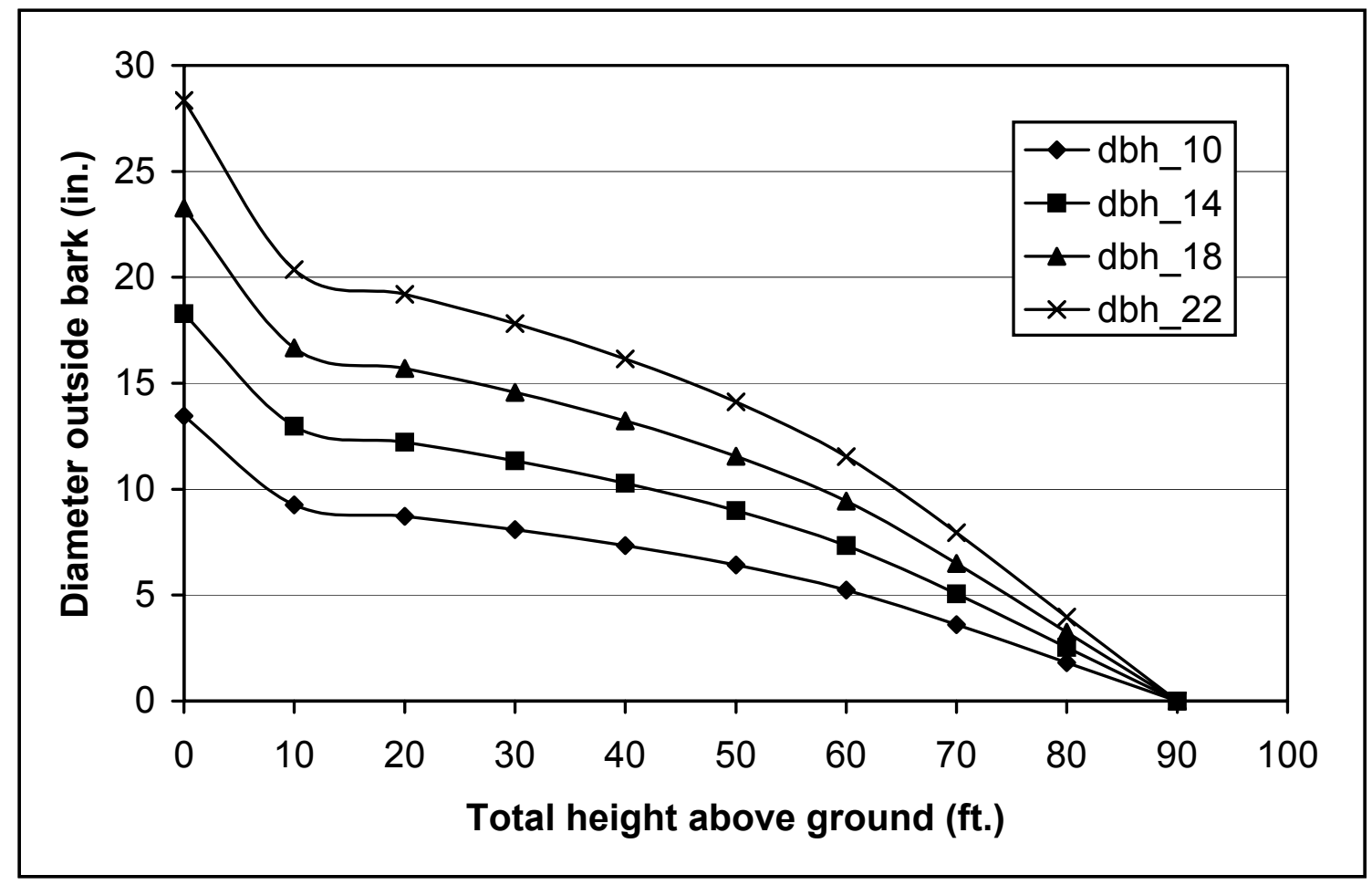

Figure 3.7. A set of taper curves generated from model 4 with the same value of total height (90 feet) and different values of dbh (10, 14, 18, and 22 inches). 


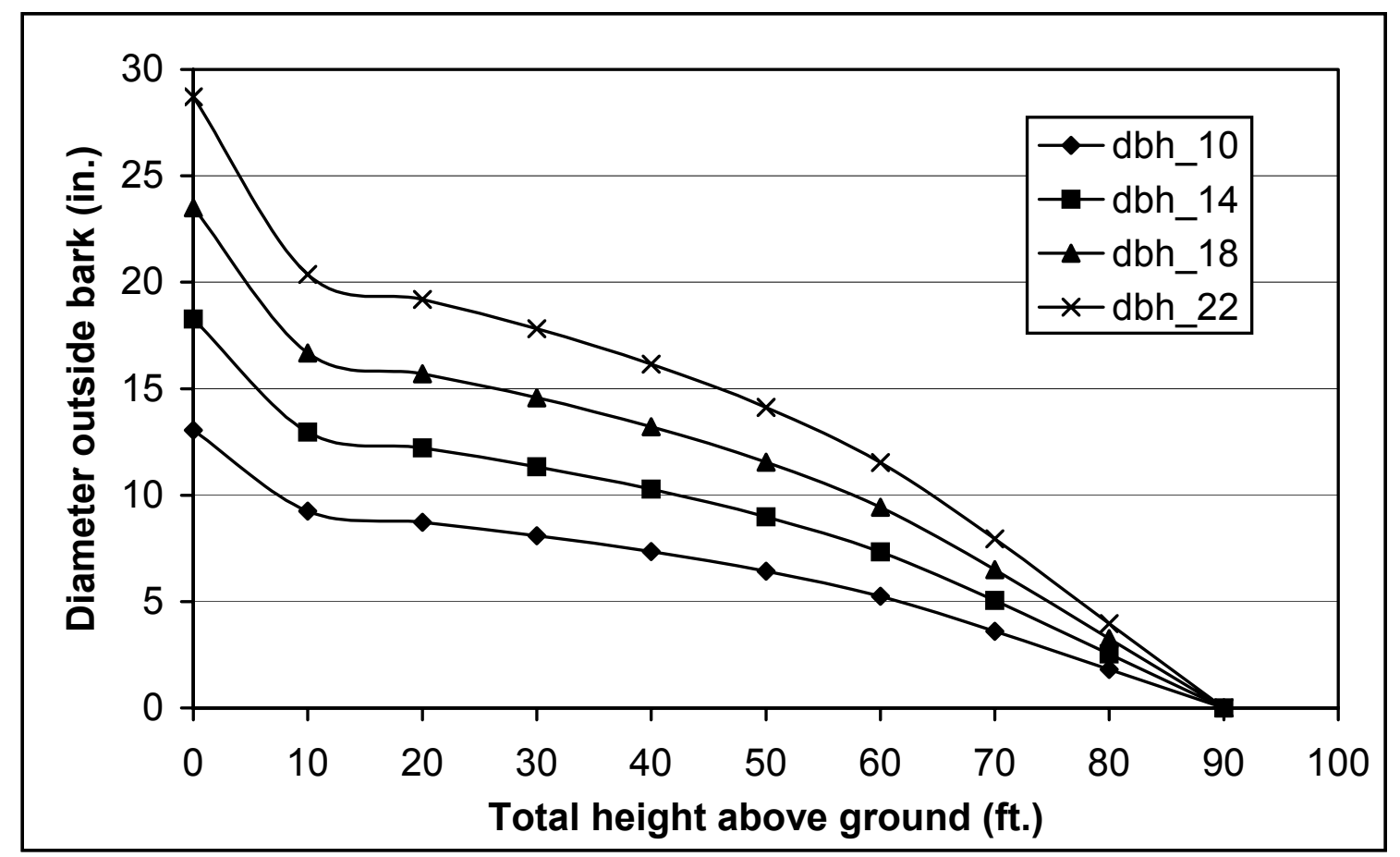

Figure 3.8. A set of taper curves generated from model 5 with the same value of total height (90 feet) and different values of dbh (10,14, 18, and 22 inches).

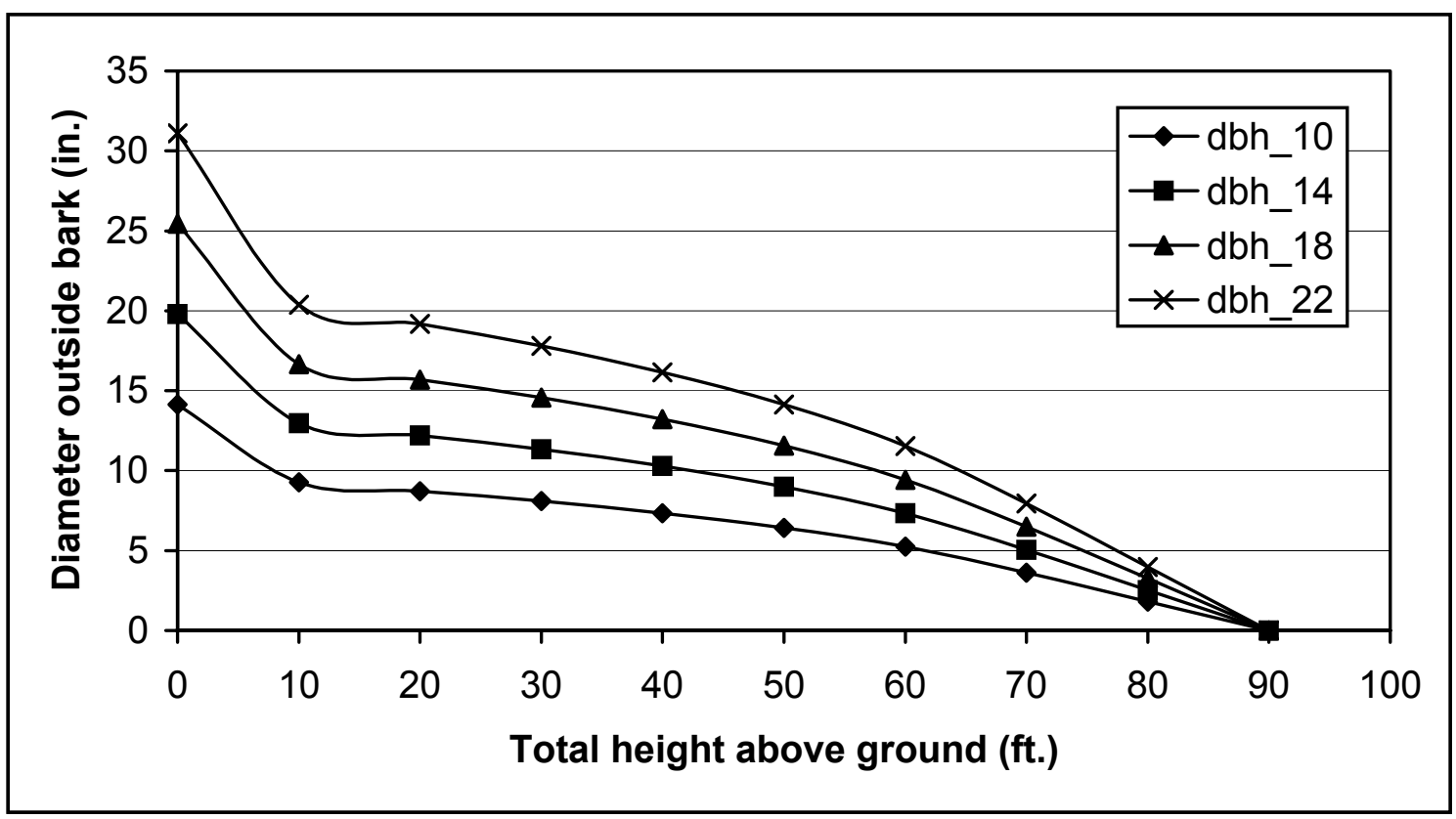

Figure 3.9. A set of taper curves generated from model 6 with the same value of total height (90 feet) and different values of $\mathrm{dbh}(10,14,18$, and 22 inches). 


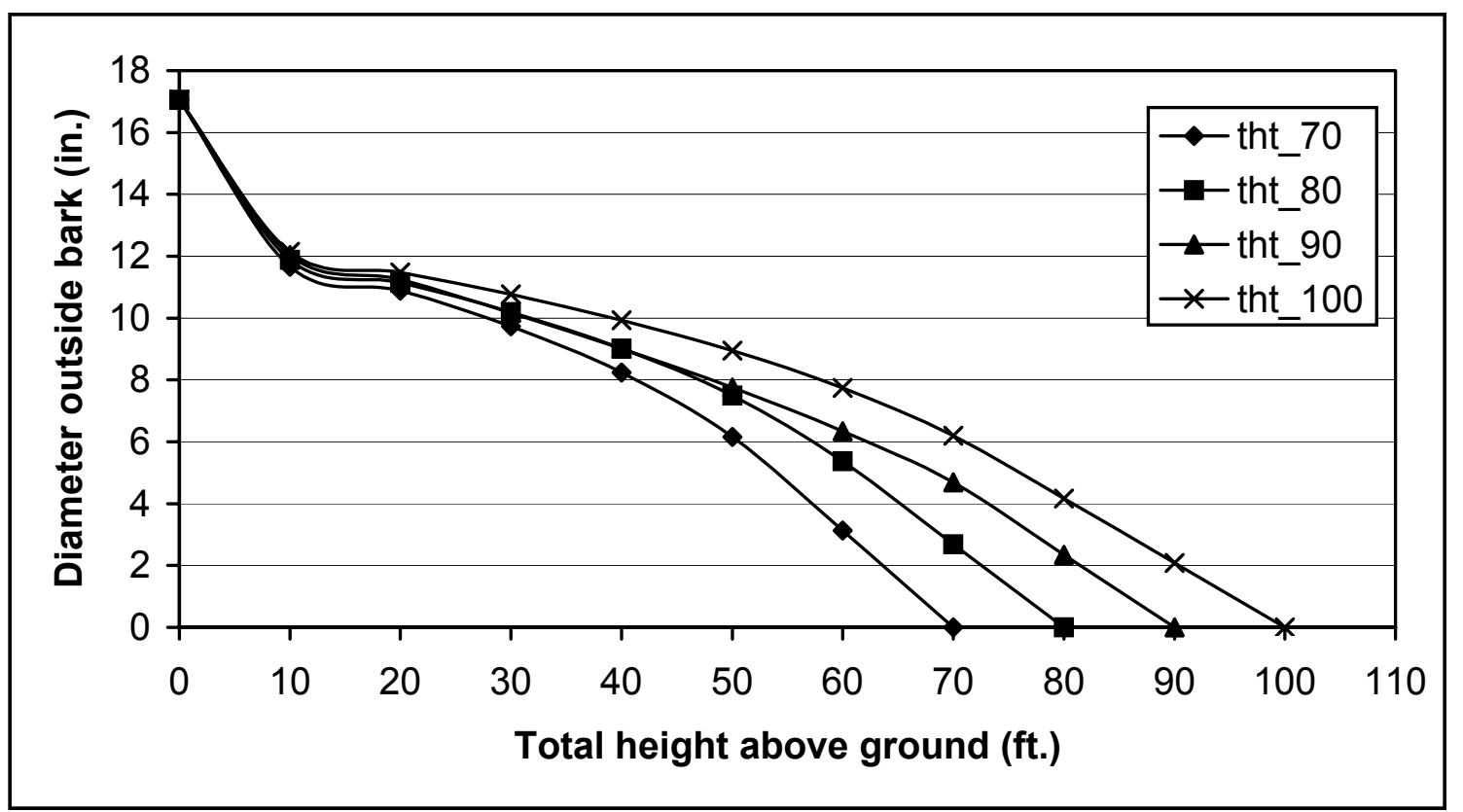

Figure 3.10. A set of taper curves generated from model 4 with the same value of $\mathrm{dbh}$ (13 inches) and different values of total height (70, 80, 90, and 100 feet).

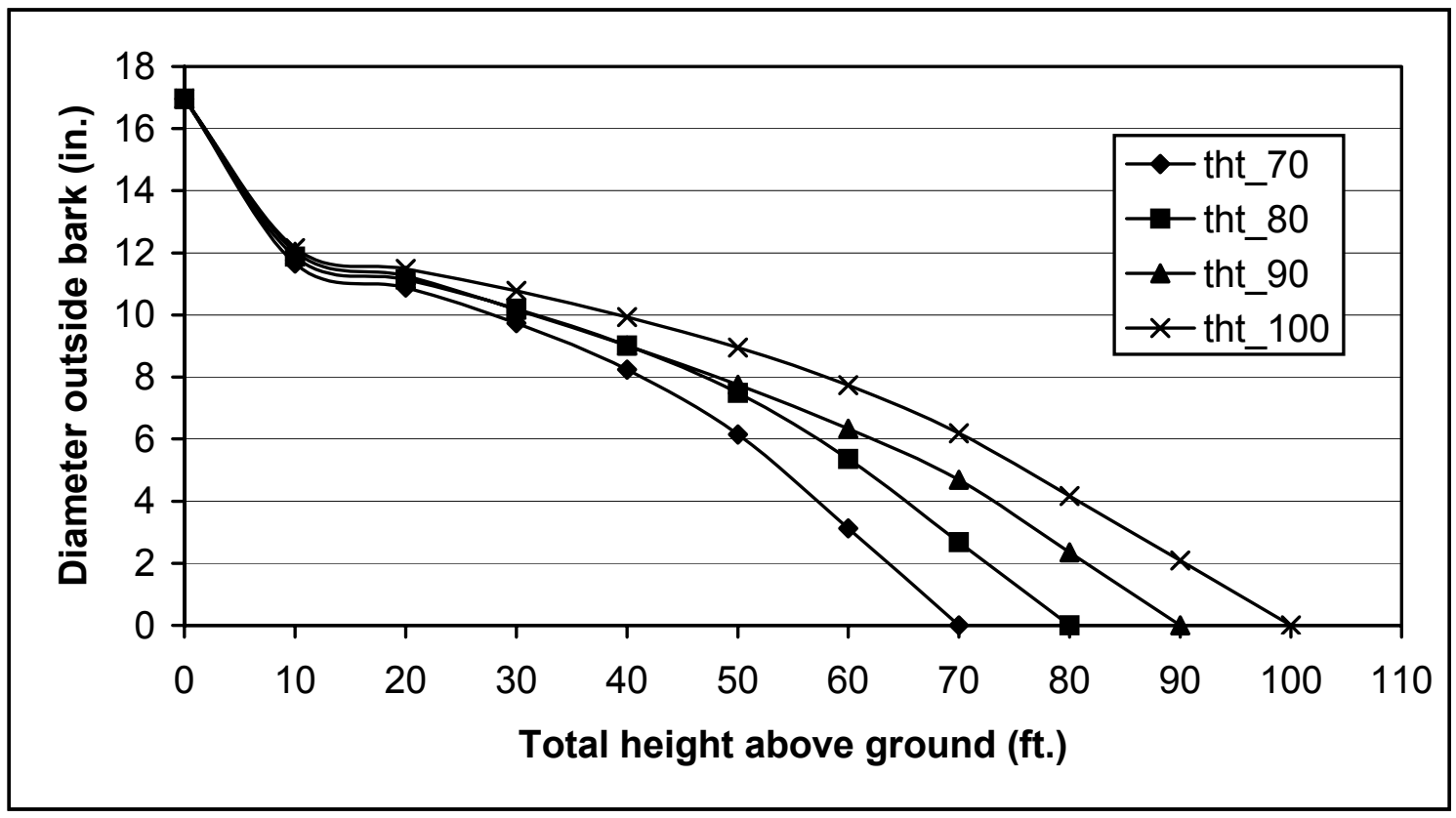

Figure 3.11. A set of taper curves generated from model 5 with the same value of dbh (13 inches) and different values of total height (70, 80, 90, and 100 feet). 


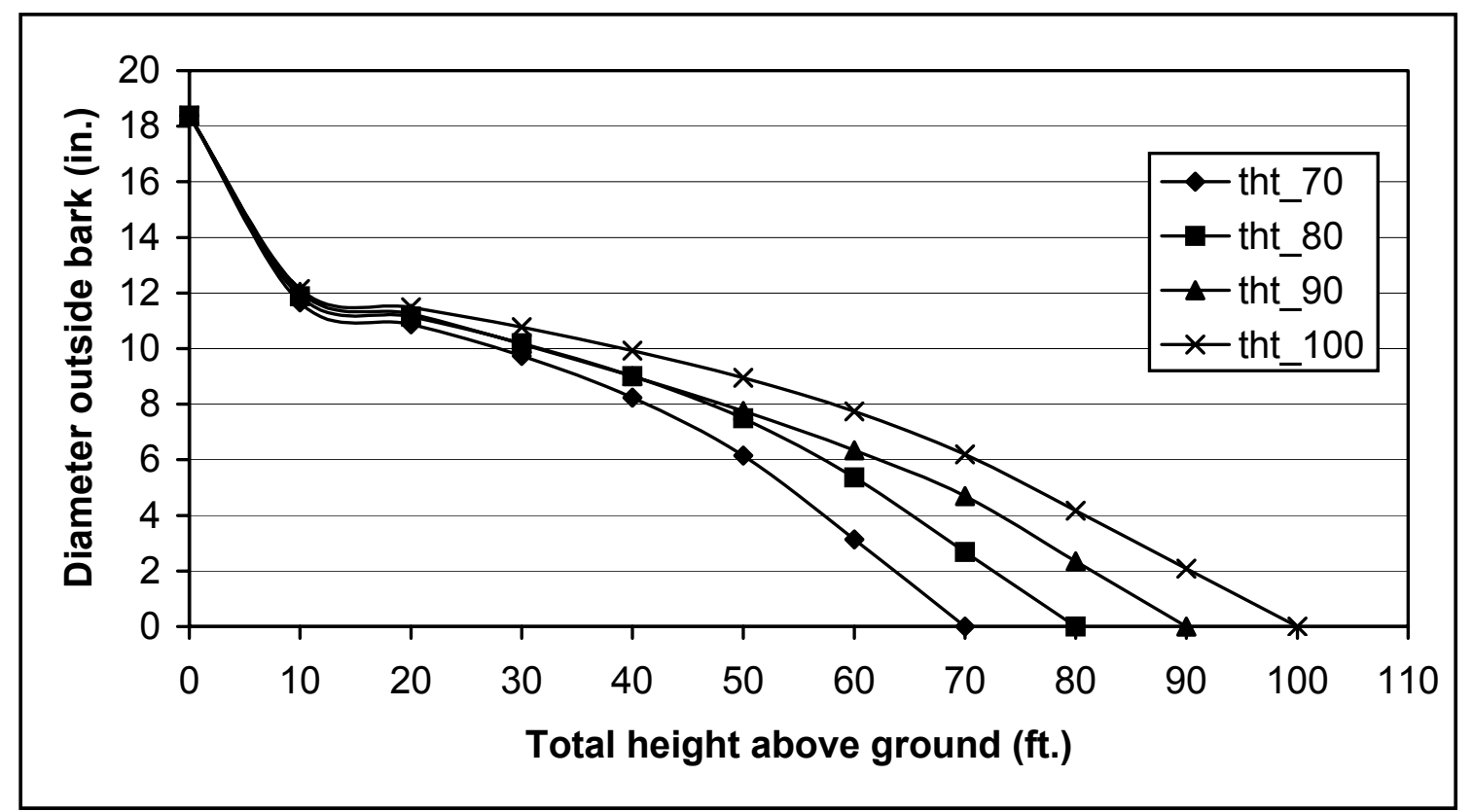

Figure 3.12. A set of taper curves generated from model 6 with the same value of $\mathrm{dbh}$ (13 inches) and different values of total height (70, 80, 90, and 100 feet).

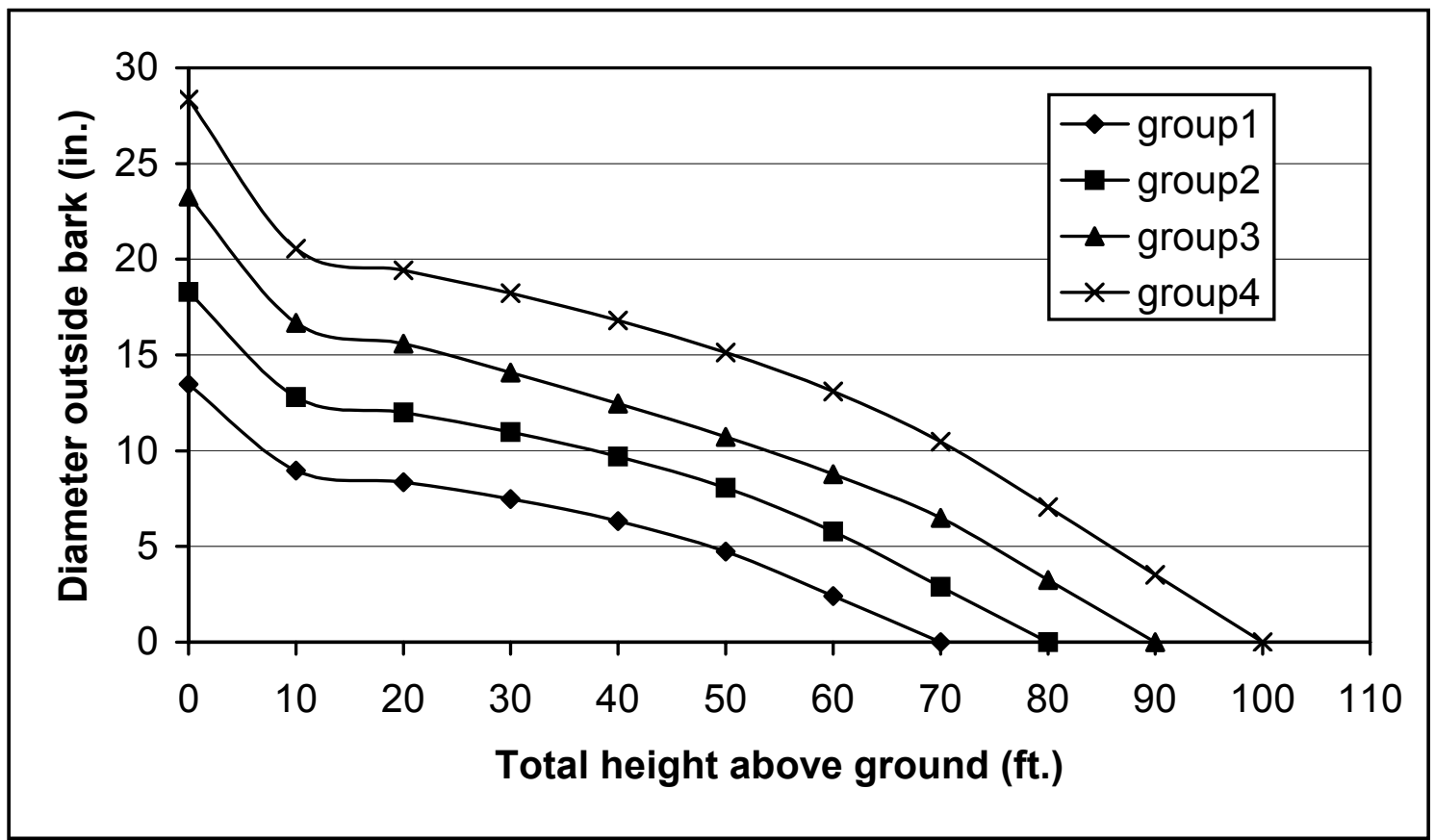

Figure 3.13. A set of taper curves generated from model 4 with the groups by the different values of dbh (10,14, 18, and 22 inches) and different values of total height $(70,80,90$, and 100 feet). 


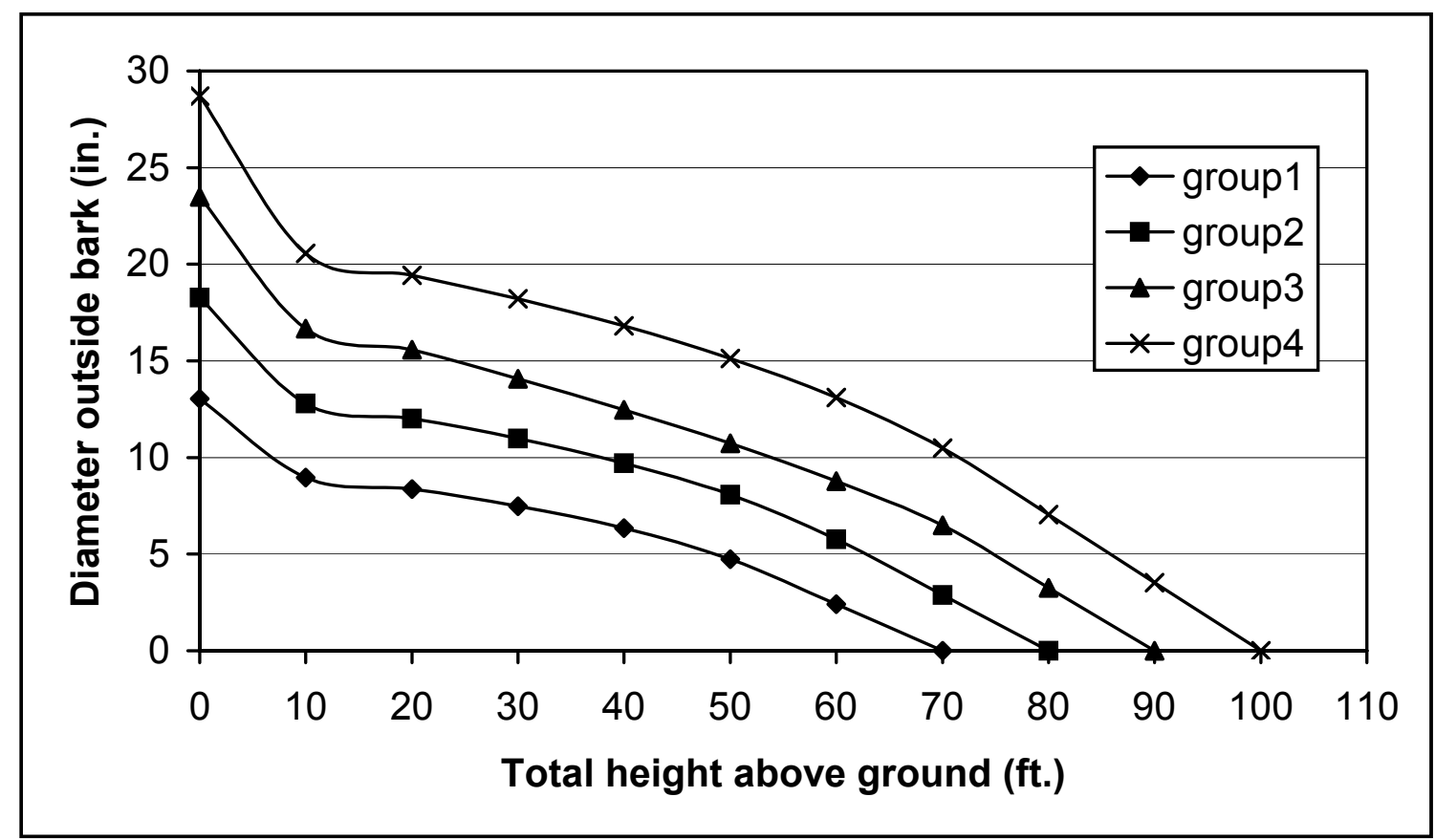

Figure 3.14. A set of taper curves generated from model 5 with the groups by the different values of dbh $(10,14,18$, and 22 inches) and different values of total height $(70,80,90$, and 100 feet).

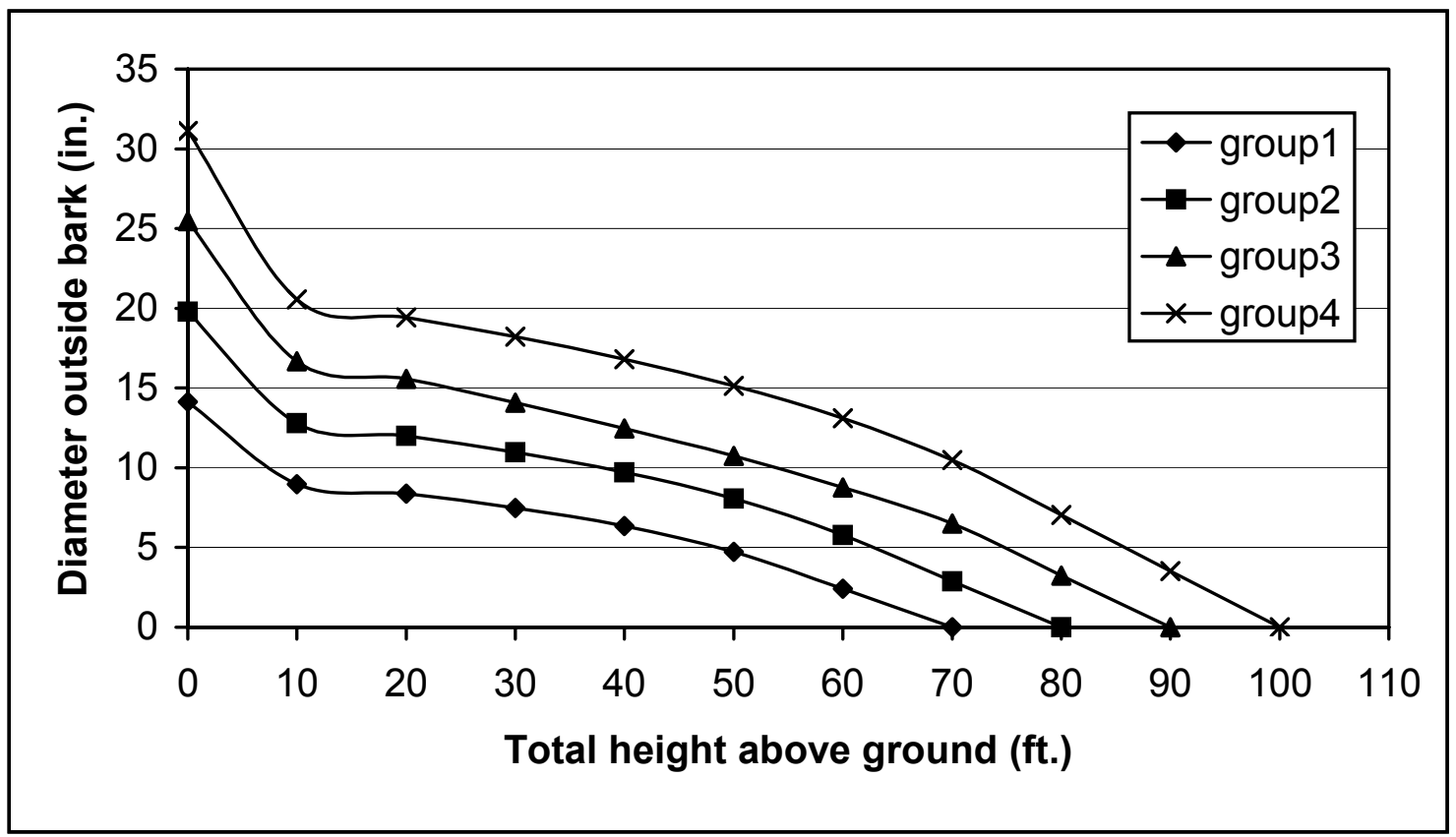

Figure 3.15. A set of taper curves generated from model 6 with the groups by the different values of dbh (10,14, 18, and 22 inches) and different values of total height $(70,80,90$, and 100 feet $)$. 


\section{CHAPTER 4 : CONCLUSIONS AND DISCUSSION}

In this study, comparisons were carried out for four taper equations obtained from previous studies (model 1, model 2, model 3, and model 4) and two additional models (model 5 and model 6) derived from model 4. Model 5 and model 6 were derived from model 4, but with fewer parameters. In addition, six volume equations were derived through integration of these six taper equations. To ensure numeric consistency, a simultaneous fitting procedure was used for each compatible taper and volume equation. All parameters were shared by both the taper and volume functions. Various methods were used for model evaluation. Average bias, SEE, and $\mathrm{R}^{2}$ were used to evaluate models for overall fit. In addition, both average bias and SEE were compared for different sections of the stem using relative height classes and different tree diameter classes. All evaluations were conducted for diameter and volume estimation for both outside and inside bark.

The following results were obtained based on the comparisons for both taper and volume predictions:

(a) Model 4, model 5, and model 6 were superior to other models.

(b) Model 3 was better than model 1 and model 2 .

(c) Model 1 was superior to model 2.

Model 3, model 4, model 5, and model 6 are segmented polynomial taper models. Model 1 and model 2 are simple taper models. The results indicate that segmented taper models are superior to simple taper models. Even though simple taper models provide good predictions for some sections, they exhibited poor performance for most sections due to the complex changes along the tree stem, especially for the butt section, where 
most of the volume and value is concentrated. Segmented models containing several inflection points were more accurate in describing tree taper.

A decision regarding which is the best among the three models (model 4, model 5, and model 6) must be made with some caution. Decisions should not be based on the results of one comparison. Some recommendations can be made:

(1) Model evaluation by overall fit statistics.

Based on the overall fit statistics, when only diameter prediction outside bark was considered, model 4 was found to be superior. However, model 4 and 5 should been chosen as the best models as both had the same average bias, SEE, and $\mathrm{R}^{2}$ for predicting diameter inside bark, volume outside bark and volume inside bark. It should also be noted that model 4 contains a non-significant parameter $\left(b_{3}\right)$.

(2) Model evaluation by dbh classes.

Based on comparisons by dbh classes, model 4, 5, and 6 performed differently for trees of different size classes. When trees with dbh class 6-10 inches were considered, model 4 performed the best for taper and volume. However, model 5 showed the best results for dbh class 14-18 inches and 18-23 inches. Model 6 performed the best for dbh class 10-14 inches. 
(3) Model evaluation by relative height classes.

Graphic analysis was used for model evaluation by relative height classes. The precision and accuracy of these models were determined by the average bias and SEE for taper and volume estimation. The results show that model 4, model 5, and model 6 are more precise and accurate. The three models also displayed very similar trends for average bias and SEE for predicting diameter outside bark, diameter inside bark, volume outside bark and volume inside bark along the tree stem. The three models displayed little difference in predictive ability across the range of relative height classes. However, model 5 and model 6 reduced the number of parameters without decreasing accuracy and precision. Too many regressor variables and coefficients may cause multicollinearity and overparameterization problems when regression analysis is applied (Kozak 1997). Therefore, model 5 and model 6 were preferred to describe the stem profile and predict stem volume outside bark and inside bark by relative height classes. 


\section{LITERATURE CITED}

Avery, T.E. Burkhart, H.E., 2002. Forest Measurements, 5th Edition. McGraw-Hill, New York.

Bailey, R.L. 1994. A compatible volume-taper model based on the Schumacher and Hall generalized constant form factor volume equation. For. Sci. 40:303-313.

Bailey, R.L. 1995. Upper stem volumes from stem analysis data: an overlapping bolts method. Can. J. For. Res. 26:170-173.

Behre, C.E. 1923. Preliminary notes on studies of tree form. J. For. 21:507-511.

Bennett, F.A., F.T. Lloyd, B.F. Swindel, and E.W. Whitehorne. 1978. Yields of veneer and associated products from unthinned, old-field plantations of slash pine in the north Florida and south Georgia flatwoods. USDA For. Ser. Res. Pap. SE-176.

Bruce, D., R.O. Curtis, and C. Vanceoevering. 1968. Development of a system of taper and volume tables for alder. For. Sci. 14:339-350.

Cao, Q.V., H.E. Burkhart, and T.A. Max. 1980. Evaluation of two methods for cubic-volume prediction of loblolly pine to any merchantable limit. For. Sci. 26:71-80.

Clark, A. III, R.A. Souter, and B.E.Schlaegel. 1991. Stem profile equations for southern tree species.USDA For. Serv. Res. Pap. SE-282.

Clutter, J.L. 1980. Development of taper functions from variable-top merchantable volume equations. For. Sci. 26:117-120.

Demaerschalk, J.P., and A. kozak. 1977. The whole-bole system: a conditioned dual- equation system for precise prediction of tree profiles. Can. J. For. Res. 7:488-497.

Demaerschalk, J.P. 1972. Converting volume equations to compatible taper equations. For. Sci. 18:241-245.

Fang, Z., B.E. Borders, and R.L. Bailey. 2000. Compatible volume taper models for loblolly and slash pine based on system with segmented-stem form factors. For. Sci. 46:1-12.

Gray, H.R. 1956. The form and taper of forest-tree stems. Oxford Univ., Imp. For. Inst. Paper $32: 1-74$

Goulding, C.J., and J.C. Murry. 1976. polynomial taper equations that are compatible with tree volume equations. N.Z.J. Forest Sci. 5:313-322. 
Henry, W and R.G. Bailey, 1994. Map Unit Descriptions of Subregions (sections) of the United States. A Table to Supplement the Map of Ecoregions and Subregions of the United States.

Hilt, D.E. 1980. Taper-based system for estimating stem volume of upland oaks. USDA For. Serv. Res.Pap. NE-458.12 p.

Kozak, A., D.O. Munro, and J.H.G. Smith. 1969. Taper functions and their application in forest inventory. For. Chron. 45:278-283.

Kozak, A. 1988. A variable-exponent taper equation. Can. J. For. Res. 18:1363-1368.

Kozak, A. 1997. Effects of multicollinearity and autocorrelation on the variable-exponent taper functions. Can. J. For. Res. 27:619-629.

Larson, P.R. 1963. Stem form development of forest trees. Forest Sci. Monograph 5. 42p.

Matte, L. 1949. The taper of coniferous species with special reference to loblolly pine. For. Chron. 25:21-31.

Martin, A.J. 1981. Taper and volume equations for selected Appalachian hardwood species. USDA For. Serv. Res. Pap. NE-490.

Max, T.A., and H.E. Burkhart. 1976. Segmented polynomial regression applied to taper equations. For Sci. 22:283-289.

McTague, J.P., and R.L. Bailey. 1987. simultaneous total and merchantable volume equations and a compatible taper function for loblolly pine. Can. J. For. Res. 17:87-92.

Muhairwe, C.K. 1994. Tree form and taper variation over time for interior lodgepole pine. Can. J.For. Res. 24: 1904-1913.

Muhairwe, C.K. 1999. Taper equations for Eucalyptus pilularis and Eucalyptus grandis for the north coast in New South Wales, Australia. For. Ecol. Manage. 113:251-269.

Newnham, R.M. 1988. A variable-form taper function. Can. For. Serv. Petawawa Natl. For. Inst. Inf. Rep.PI-X-83.

Newnham, R.M. 1992. Variable-form taper functions for four Alberta tree species. Can. J. For. Res. 22: 210-223. Rep.PI-X-83.

Ormerod, D.W. 1973. A simple bole model. For. Chron. 49:136-138.

Parresol, B.R., Hotvedt, J.E. and Cao, Q.V., 1987. A volume and taper prediction system for bald cypress. Can. J. For. Res. 17:250-259. 
Perez, D.N., H.E. Burkhart, and C.T. Stiff. 1990. A variable-form taper function for pinus oocarpa schiede in central Honduras. For. Sci. 36:186-191.

SAS Institute Inc. 1993. SAS/ETS User's Guide, Version 8.2, Second Edition. SAS Institute Inc., Cary, NC.

Schlaegel, B.E. 1983. Development of a form class taper model for willow oak. University of Georgia. 69 pp. Dissertation.

Schumacher, F.X., and F.S. Hall. 1933. Logarithmic expression of timber-tree volume. J. Agric. Res. 47:719-734. 


\section{APPENDIX A: ADDITIONAL TABLES}

Table A.1. Parameter estimates of location 1 for outside and inside bark taper and volume equations.

\begin{tabular}{|c|c|c|c|c|c|c|}
\hline Model & & Parameter & Estimate & Standard Error & t value & $\mathrm{p}>|\mathrm{t}|$ \\
\hline \multirow[t]{10}{*}{ Model 5} & Outside bark & $b_{1}$ & $79.6501 *$ & 8.5651 & 9.3 & $<.0001$ \\
\hline & & $b_{2}$ & 0.9143 & 0.0779 & 11.73 & $<.0001$ \\
\hline & & $b_{4}$ & $8.5024^{*}$ & 1.6329 & 5.21 & $<.0001$ \\
\hline & & $b_{5}$ & $0.7048 *$ & 0.0076 & 92.33 & $<.0001$ \\
\hline & & $b_{6}$ & $2.3378^{*}$ & 0.0352 & 66.49 & $<.0001$ \\
\hline & Inside bark & $b_{1}$ & 98.7766 & 9.7567 & 10.12 & $<.0001$ \\
\hline & & $b_{2}$ & 0.9977 & 0.0954 & 10.46 & $<.0001$ \\
\hline & & $b_{4}$ & 8.0298 & 1.6548 & 4.85 & $<.0001$ \\
\hline & & $b_{5}$ & $0.7099 *$ & 0.0079 & 89.48 & $<.0001$ \\
\hline & & $b_{6}$ & $2.2799 *$ & 0.0353 & 64.58 & $<.0001$ \\
\hline \multirow[t]{8}{*}{ Model 6} & Outside bark & $b_{1}$ & $88.0063^{*}$ & 3.5743 & 24.62 & $<.0001$ \\
\hline & & $b_{4}$ & $8.5025^{*}$ & 1.6329 & 5.21 & $<.0001$ \\
\hline & & $b_{5}$ & $0.7048 *$ & 0.0076 & 92.33 & $<.0001$ \\
\hline & & $b_{6}$ & $2.3379 *$ & 0.0352 & 66.48 & $<.0001$ \\
\hline & Inside bark & $b_{1}$ & $98.9934^{*}$ & 3.9198 & 25.25 & $<.0001$ \\
\hline & & $b_{4}$ & 8.0296 & 1.6543 & 4.85 & $<.0001$ \\
\hline & & $b_{5}$ & $0.7099 *$ & 0.0079 & 89.51 & $<.0001$ \\
\hline & & $b_{6}$ & $2.2800 *$ & 0.0353 & 64.6 & $<.0001$ \\
\hline
\end{tabular}

Location 1 represents Central Appalachian Broadleaf Forest.

*Diameter estimates are significantly different ( $\alpha=0.05$ ) by location.

Table A.2. Fit statistics of location 1 for outside and inside bark taper and volume equations.

\begin{tabular}{lccccccccc}
\hline \hline \multirow{2}{*}{ Model } & & \multicolumn{3}{c}{ Outside bark } & & \multicolumn{3}{c}{ Inside bark } \\
\cline { 3 - 4 } \cline { 7 - 9 } & & Avg. Bias & SEE & $\mathrm{R}^{2}$ & & Avg. Bias & SEE & $\mathrm{R}^{2}$ \\
\hline Model 5 & Taper & 0.0049 & 0.5040 & 0.9834 & & 0.0051 & 0.4540 & 0.9837 \\
& Volume & -0.0013 & 0.1570 & 0.9890 & & -0.0003 & 0.1300 & 0.9890 \\
& & & & & & & & & \\
Model 6 & Taper & 0.0060 & 0.5040 & 0.9834 & & 0.0051 & 0.4538 & 0.9837 \\
& Volume & -0.0006 & 0.1570 & 0.9890 & & -0.0003 & 0.1300 & 0.9891 \\
\hline \hline
\end{tabular}


Table A.3. Parameter estimates of location 2 for outside and inside bark taper and volume equations.

\begin{tabular}{|c|c|c|c|c|c|c|}
\hline Model & & Parameter & Estimate & Standard Error & t value & $\mathrm{p}>|\mathrm{t}|$ \\
\hline \multirow[t]{10}{*}{ Model 5} & Outside bark & $b_{1}$ & $137.0064 *$ & 27.8488 & 4.92 & $<.0001$ \\
\hline & & $b_{2}$ & 0.7649 & 0.1788 & 4.28 & $<.0001$ \\
\hline & & $b_{4}$ & $18.6375^{*}$ & 4.0476 & 4.6 & $<.0001$ \\
\hline & & $b_{5}$ & $0.5873 *$ & 0.0196 & 29.97 & $<.0001$ \\
\hline & & $b_{6}$ & $1.8684 *$ & 0.0440 & 42.43 & $<.0001$ \\
\hline & Inside bark & $b_{1}$ & 99.6955 & 12.2969 & 8.11 & $<.0001$ \\
\hline & & $b_{2}$ & 0.7871 & 0.0831 & 9.47 & $<.0001$ \\
\hline & & $b_{4}$ & 9.5857 & 2.0014 & 4.79 & $<.0001$ \\
\hline & & $b_{5}$ & $0.5367 *$ & 0.0139 & 38.68 & $<.0001$ \\
\hline & & $b_{6}$ & $1.6778 *$ & 0.0236 & 71.09 & $<.0001$ \\
\hline \multirow[t]{8}{*}{ Model 6} & Outside bark & $b_{1}$ & $169.1315^{*}$ & 10.9693 & 15.42 & $<.0001$ \\
\hline & & $b_{4}$ & $18.7348^{*}$ & 4.0570 & 4.62 & $<.0001$ \\
\hline & & $b_{5}$ & $0.5875^{*}$ & 0.0196 & 30 & $<.0001$ \\
\hline & & $b_{6}$ & $1.8688 *$ & 0.0440 & 42.43 & $<.0001$ \\
\hline & Inside bark & $b_{1}$ & $126.6427 *$ & 5.2058 & 24.3 & $<.0001$ \\
\hline & & $b_{4}$ & 9.6052 & 2.0027 & 4.8 & $<.0001$ \\
\hline & & $b_{5}$ & $0.5363 *$ & 0.0139 & 38.57 & $<.0001$ \\
\hline & & $b_{6}$ & $1.6771 *$ & 0.0236 & 70.98 & $<.0001$ \\
\hline
\end{tabular}

Location 2 represents Eastern Broadleaf Forest Province.

*Diameter estimates are significantly different ( $\alpha=0.05$ ) by location.

Table A.4. Fit statistics of location 2 for outside and inside bark taper and volume equations.

\begin{tabular}{llcccccccc}
\hline \hline \multirow{2}{*}{ Model } & & \multicolumn{3}{c}{ Outside bark } & & \multicolumn{3}{c}{ Inside bark } \\
\cline { 3 - 5 } \cline { 7 - 9 } & & Avg. Bias & SEE & $\mathrm{R}^{2}$ & & Avg. Bias & SEE & $\mathrm{R}^{2}$ \\
\hline \multirow{2}{*}{ Model 5 } & Taper & 0.0232 & 0.8024 & 0.9715 & & 0.0720 & 0.5343 & 0.9804 \\
& Volume & 0.0109 & 0.4736 & 0.9435 & & 0.0163 & 0.2042 & 0.9840 \\
& & & & & & & & \\
\multirow{2}{*}{ Model 6 } & Taper & 0.0281 & 0.7019 & 0.9715 & & 0.0778 & 0.5356 & 0.9803 \\
& Volume & 0.0123 & 0.4730 & 0.9436 & & 0.0180 & 0.2040 & 0.9840 \\
\hline \hline
\end{tabular}


Table A.5. Parameter estimates of location 1 for diameter at 4.5 and 17.3 feet.

\begin{tabular}{ccccccc}
\hline \hline Equations & Parameter & Estimate & Standard Error & $\mathrm{t}$ value & $\mathrm{p}>|\mathrm{t}|$ & $\mathrm{R}^{2}$ \\
\hline$(3.7)$ & $b_{1}$ & -0.3678 & 0.0405 & -9.08 & $<.0001$ & 0.9939 \\
& $b_{2}$ & 0.9279 & 0.0031 & 297.18 & $<.0001$ & \\
& & & & & & \\
$(3.8)$ & $b_{1}$ & 0.9465 & 0.0047 & 202.11 & $<.0001$ & 0.9887 \\
& $b_{2}$ & -1.2533 & 0.1367 & -9.17 & $<.0001$ & \\
$(3.9)$ & & & & & & \\
& $b_{1}$ & 0.9526 & 0.0059 & 160.31 & $<.0001$ & 0.9831 \\
\hline \hline
\end{tabular}

Table A.6. Parameter estimates of location 2 for diameter at 4.5 and 17.3 feet.

\begin{tabular}{ccccccc}
\hline \hline Equations & Parameter & Estimate & Standard Error & $\mathrm{t}$ value & $\mathrm{p}>|\mathrm{t}|$ & $\mathrm{R}^{2}$ \\
\hline$(3.7)$ & $b_{1}$ & -1.1994 & 0.1610 & -7.45 & $<.0001$ & 0.9564 \\
& $b_{2}$ & 0.9685 & 0.0108 & 89.36 & $<.0001$ & \\
$(3.8)$ & $b_{1}$ & 0.9321 & 0.0107 & 87.47 & $<.0001$ & 0.9558 \\
& $b_{2}$ & -1.6272 & 0.3235 & -5.03 & $<.0001$ & \\
$(3.9)$ & & & & & \\
& $b_{1}$ & 0.8689 & 0.0068 & 127.8 & $<.0001$ & 0.9817 \\
& $b_{2}$ & 0.6314 & 0.2081 & 3.03 & 0.0026 & \\
\hline \hline
\end{tabular}

Table A.7. Bias and standard error of estimates for outside bark diameter for the validation data.

\begin{tabular}{cccccccccc}
\hline & & \multicolumn{2}{c}{ Model 4} & & \multicolumn{2}{c}{ Model 5} & & \multicolumn{2}{c}{ Model 6 } \\
RH & $\mathrm{n}$ & Bias & SEE & & Bias & SEE & & Bias & SEE \\
\hline $0.0-0.1$ & 1582 & 0.539 & 1.578 & & 0.562 & 1.569 & & 0.441 & 1.296 \\
$0.1-0.2$ & 347 & 0.333 & 0.720 & & 0.333 & 0.720 & & 0.334 & 0.719 \\
$0.2-0.3$ & 351 & 0.078 & 0.763 & & 0.078 & 0.762 & & 0.078 & 0.761 \\
$0.3-0.4$ & 350 & -0.003 & 0.855 & & -0.003 & 0.854 & & -0.004 & 0.854 \\
$0.4-0.5$ & 332 & -0.200 & 1.032 & & -0.200 & 1.031 & & -0.201 & 1.031 \\
$0.5-0.6$ & 198 & -0.146 & 1.021 & & -0.146 & 1.019 & & -0.147 & 1.018 \\
$0.6-0.7$ & 39 & 0.495 & 1.054 & & 0.494 & 1.047 & & 0.494 & 1.039 \\
\hline \hline
\end{tabular}

